\title{
DOE/PC/91008--23Pt, 2 \\ Predicting the Natural State of Fractured Carbonate Reservoirs: An Andector Field, West Texas Test of a 3-D RTM Simulator
}

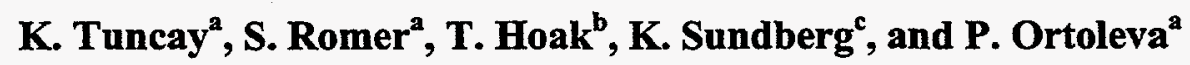

a Laboratory for Computational Geodynamics

Department of Chemistry

Indiana University

Bloomington, Indiana 47405

b Kestrel Geoscience, LLC

9683 West Chatfield Avenue, Unit D

Littleton, Colorado 80128

c Phillips Petroleum Company

252 Geoscience Building

Bartlesville, Oklahoma 74004

MASTEO 


\section{DISCLAIMER}

Portions of this document may be illegible in electronic image products. Images are produced from the best available original document. 


\section{CONTENTS}

I Introduction $\quad 1$

II Basin RTM Modeling 5

A. Comprehensive, Process-Based Modeling ......................................................5

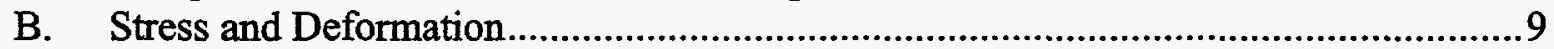

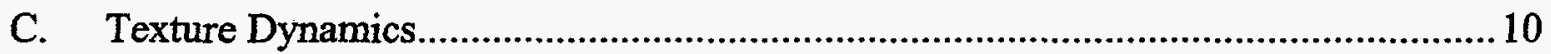

D. Multi-Phase Fluid Reaction-Transport Dynamics........................................ 11

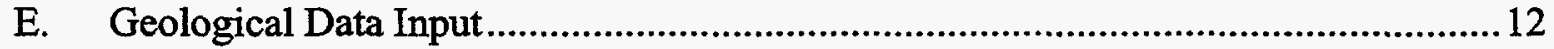

III Study Area and Input Data $\quad 15$

A. Study Area Overview................................................................................... 15

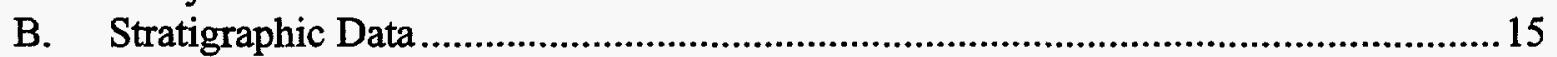

1. Generalized Stratigraphy and Sedimentology of the Permian Basin................. 15

2. Precambrian Rocks ................................................................................. 16

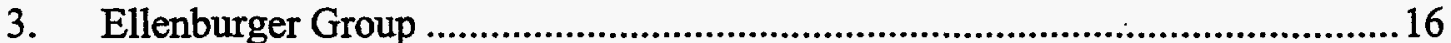

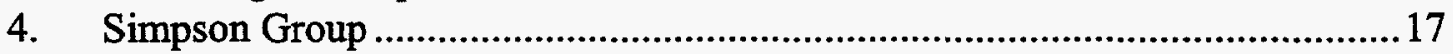

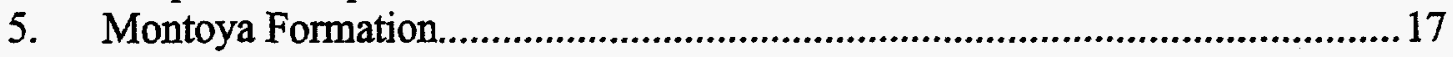

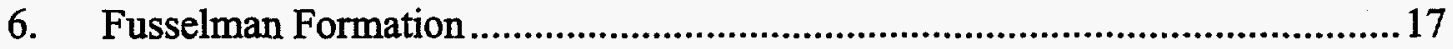

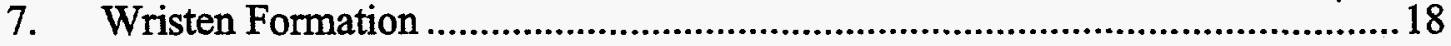

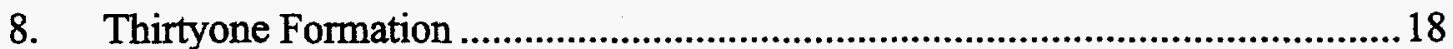

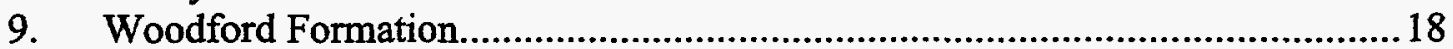

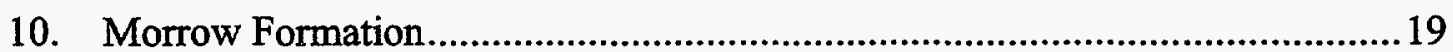

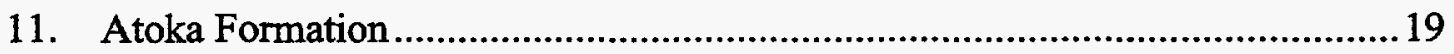

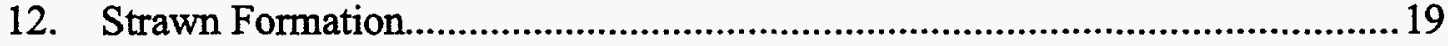

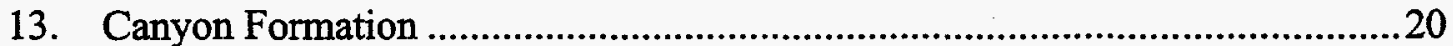

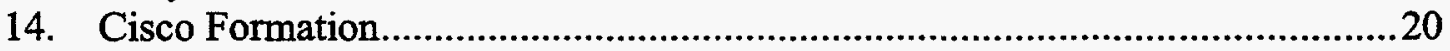

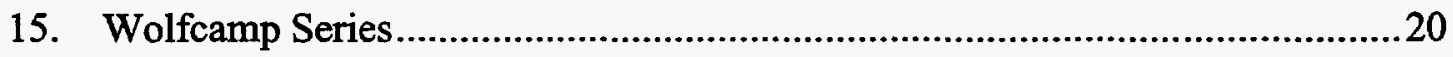

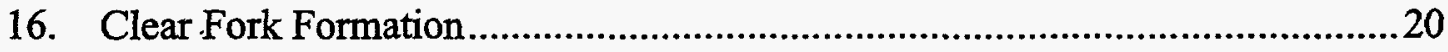

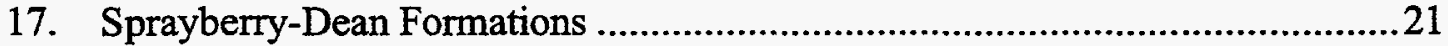

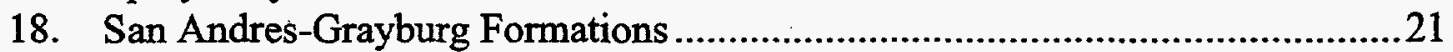

19. Queen Formation .............................................................................. 21

20. Capitan Reef, Seven Rivers, Tansill and Yates Formations............................22

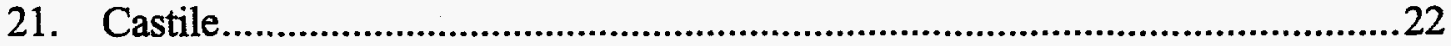

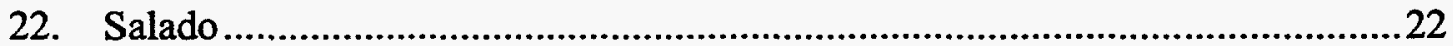

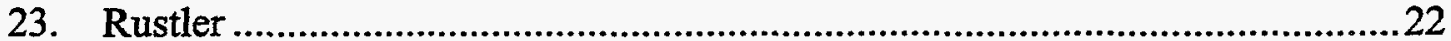

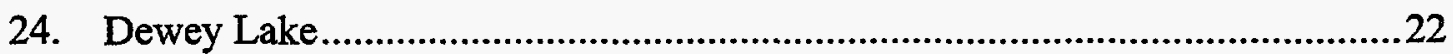

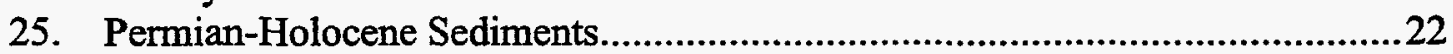

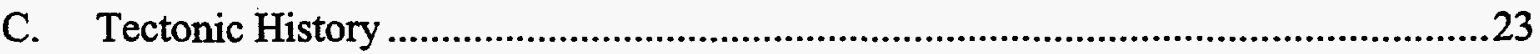

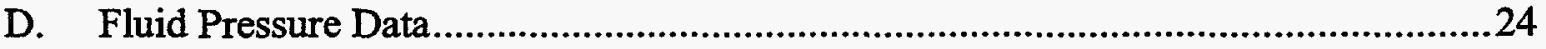

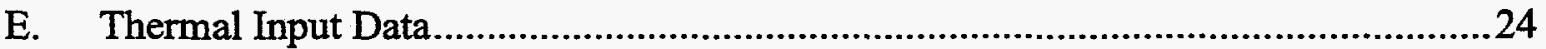


IV Organic Kinetics and Transport

A. The Oil Generation/Expulsion/Trapping Problem ...............................................41

B. Simpson and Ellenburger Source Rocks .............................................................4

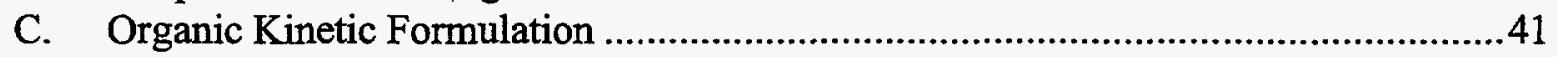

V 1-D Simulations $\quad \mathbf{4 5}$

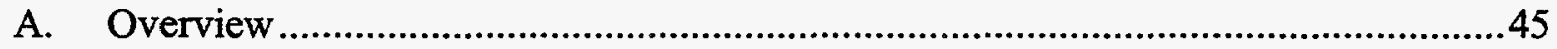

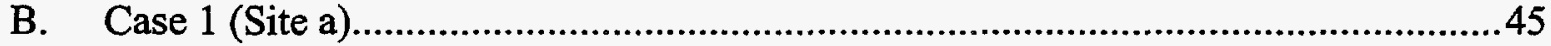

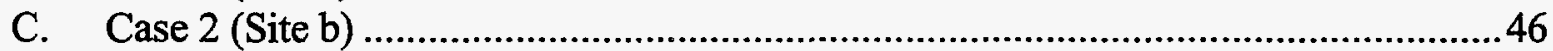

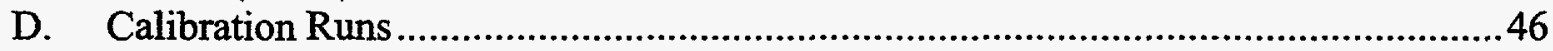

E. Pulsatile Petroleum Expulsion ..................................................................................46

$\begin{array}{ll}\text { VI 3-D Simulations } & \mathbf{7 7}\end{array}$

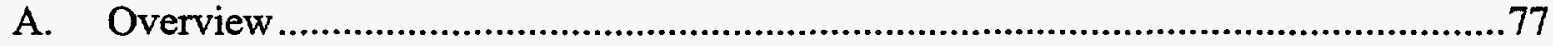

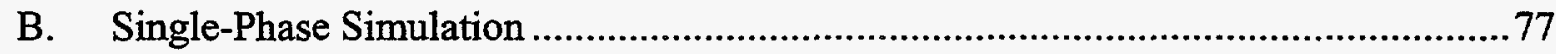

$\begin{array}{ll}\text { VII Conclusions } & 91\end{array}$

$\begin{array}{ll}\text { References } & 95\end{array}$

\section{DISCLAIMER}

This report was prepared as an account of work sponsored by an agency of the United States Government. Neither the United States Government nor any agency thereof, nor any of their empleyees, makes any warranty, express or implied, or assumes any legal liability or responsibility for the accuracy, completeness, or usefulness of any information, apparatus, product, or process disclosed, or represents that its use would not infringe privately owned rights. Reference herein to any specific commercial product, process, or service by trade name, trademark, manufacturer, or otherwise does not necessarily constitute or imply its endorsement, recommendation, or favoring by the United States Government or any agency thereof. The views and opinions of authors expressed herein do not necessarily state or reflect those of the United States Government or any agency thereof. 


\section{ABSTRACT}

A key challenge for the petroleum industry is to improve the accuracy of predictions of the location, characteristics and history (on the geological and production time scale) of naturally fractured reservoirs. Present day fractures affect producibility while the history of fractures affects petroleum expulsion, migration paths and trapping. The power of our reaction, transport, mechanical (RTM) modeling approach is that it directly uses the laws of geochemistry and geophysics to extrapolate fracture and other characteristics from the borehole or surface to the reservoir interior. Unlike simplistic approaches like curvature analysis, our approach accounts for time-dependent deformation, i.e., fast or slow flexure of beds can give dramatically different fracture/continuous deformation scenarios for the same present day flexure. Also, remote fracture sensing leaves a great deal of ambiguity. We provide the dynamical element of deformation by using bed age and other historical data to predict fractures, also accounting for predicted fluid geochemical, rock rheological and thermal processes.

The objectives of this facet of the project were to refine and test the viability of our basin/reservoir forward modeling approach to address fractured reservoir in E\&P problems.

Our study attempts to resolve the following issues:

- role of fracturing and timing on present day location and characteristics;

- clarifying the roles and interplay of flexure dynamics, changing rock rheological properties, fluid pressuring and tectonic/thermal histories on present day reservoir location and characteristics; and

- test our integrated RTM modeling/geological data approach on a carbonate reservoir.

Sedimentary, thermal and tectonic data from Andector Field, West Texas, were used as input to our RTM basin/reservoir simulator to predict its preproduction state. The results were compared with data from producing reservoirs to test our RTM modeling approach. The effects of production on the state of the field are discussed in a companion report.

We draw the following conclusions.

a) RTM modeling is an important new tool in fractured reservoir E\&P analysis.

b) The strong coupling of RTM processes and the geometric and tensorial complexity of fluid flow and stresses require the type of fully coupled, 3-D RTM model for fracture analysis as pioneered in this project.

c) Flexure analysis cannot predict key aspects of fractured reservoir location and characteristics.

d) Fracture history over the lifetime of a basin is required to understand the timing of petroleum expulsion and migration and the retention properties of putative reservoirs. 


\section{INTRODUCTION}

Naturally fractured carbonate reservoirs present E\&P challenges due to the many factors that come together to create their preproduction state. These factors include:

- tectonics and sedimentary environment;

- changing rock rheologic properties over geologic history of the basin;

- overpressuring mechanisms including compaction, fluid thermal expansion and petroleum generation;

- processes creating and destroying macroporosity (vugs and karst terrains) and associated reservoir capacity and stress sensitivity;

- diagenesis may enhance or inhibit producibility by dissolution or dolomitization-induced increases in porosity or by fracture filling cementation, respectively.

Due to these and other reaction, transport and mechanical (RTM) processes, carbonate reservoir preproduction states are difficult to predict by simplistic approaches such as flexure analysis or interbasinal correlations that miss the detailed and individual history of the target area. The goal of this report is to present a new RTM modeling approach that incorporates these factors in making predictions of the preproduction state of fractured carbonate reservoirs.

Fractures may play often conflicting roles in production. Local zones of large permeability may lead to bypassed reserves. On the other hand, such fractured zones may constitute zones within which wells have a large drainage area so that production may be fast and efficient. However, such zones may also be extremely sensitive to fluid pressure as draw-down during production may close the fractures (depending on ambient stress). Voids may be connected by fractures so as to enhance permeability. However, fractures may also lead to vug collapse and hence loss of reservoir capacity and producibility. To predict the response of a reservoir under production and to optimize exploration for ideal reservoirs, this report describes and evaluates a basin/reservoir modeling approach for predicting the preproduction state of a fractured carbonate reservoir.

To meet the need for E\&P optimization in these reservoirs, advanced modeling tools are needed that can integrate commonly available seismic, well log, geochemical, surface geologic and other data. We believe this can most effectively be done using the laws of geochemistry, rock deformation and hydrology to predict the location, stress environment and lithologic characteristics of these reservoirs. In this report, we present our model and evaluate its potential for extrapolating key data away from the wellbore or down from the outcrop.

We have developed basin/reservoir simulation tools to optimize E\&P strategies for naturally fractured reservoir systems. Our modeling tools are based on our basin/reservoir RTM simulator and a predictor of vug mechanical stability. The latter is described in another report (Ozkan and Ortoleva 1998) included below in the final report to this project.

The challenges of fractured reservoir prediction are great, defying simple analysis. Fig. I-1 indicates the cross-coupled nature of the many operating processes that affect fractured reservoir location and characteristics. Rates of change of any one variable (fracture length and orientation, fluid pressure, grain size, etc.) are affected by the values of all the other variables. The approach taken in this project is unique it its inclusion of a comprehensive list of processes and its accounting for all the cross-coupling relations among them. Clearly, models limited to a few 


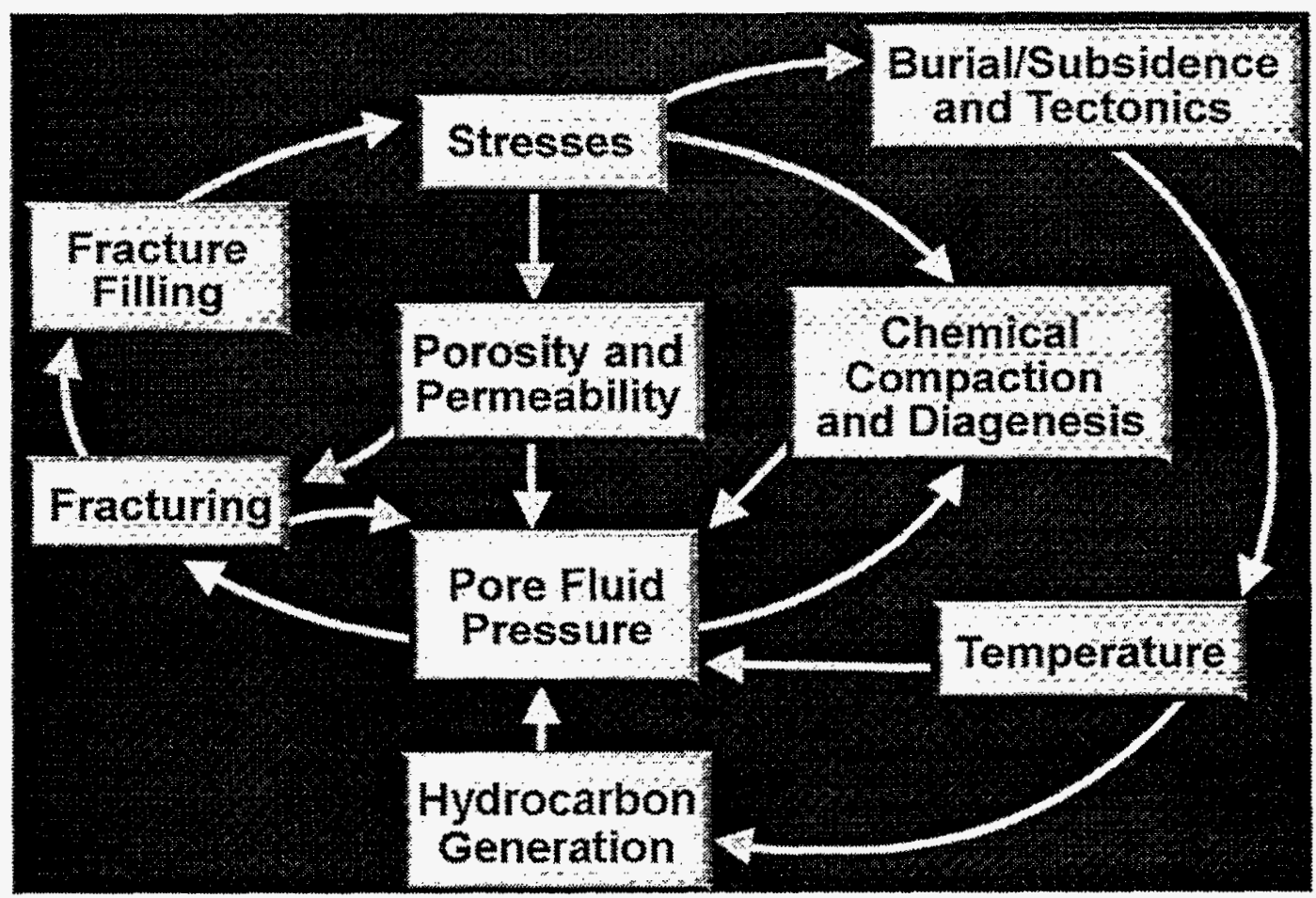

Fig. I-1 Complex network of coupled processes underlying the dynamics of a sedimentary basin or evolving reservoir.

variables, not coupled to the entire network of other variables, are likely to have serious limitations.

An example of a popular oversimplified approach is curvature analysis. It attempts to relate fracture location to the curvature of sedimentary layers. However, it is the rate of curvature development that determines fracture. Whether a given total flexure developed rapidly or slowly determines whether fracturing occurs. Thus, very slow bending of a bed will allow ductile deformation to take up the induced local extensional strain so that fractures do not occur. Furthermore, in an evolving geomechanical medium, rheology is continuously changing. Thus, it is not only curvature and flexure rate but also the interval in time in the geological past that determine whether fracturing can occur. Finally, even if the inclusions form, they may have healed or infilled with cements. It is the inclusion of all these factors that gives our modeling its unique power.

To achieve the required predictability, we have invented new modeling tools including:

- a mathematical and numerical simulator that can predict the geometry and directional characteristics of a multi-generation fracture network;

- equations and graphical techniques linking the aforementioned fracture model predictions to fracture intensity maps and rose diagrams;

- improved calibration of our multiple mechanism deformation model (rheology) for carbonate systems;

- new organic kinetic model based on molecular structure for predicting oil generation kinetics; and 
- the new processes and models were integrated into our 3-D, finite element code in such a way as to preserve all coupling relations between them and those in pre-existing modules. The latter coupling is central to our RTM modeling approach. As noted in the next section, decoupled basin models miss the effects such as the episodic release of petroleum from source rock. Indeed, many of the processes in a basin are so strongly coupled that they can only be understood through a model that preserves the dependence of the rate of change of any of the key variables on the value of all the others.

In this report we present results on the application of our 3-D RTM basin/reservoir simulator to fractured reservoir analysis. Predictions for Andector Field on the Central Platform, Permian Basin, West Texas are presented in Sections V and VI. We evaluate the potential of our modeling approach for predicting petroleum location, reserves and reservoir characteristics. The preproduction state of fracturing and stress, and matrix porosity/permeability are predicted for Ellenburger and Simpson reservoirs.

Our basin/reservoir simulator is described in Section II. The Andector study area and geological data used in our simulations are reviewed in Section III. The oil generation kinetic model used in our simulations is presented in Section IV. Simulation results for the Andector study area are presented in Sections V and VI as are brief comparisons with observations. Conclusions on the viability of our RTM modeling approach as a part of an integrated E\&P strategy are drawn in Section VII. 



\section{BASIN RTM MODELING}

\section{A. COMPREHENSIVE, PROCESS-BASED MODELING}

Fractured reservoirs present one of the greatest challenge for quantitative predictive modeling. A complex network of coupled reaction, transport, and mechanical (RTM) processes underlies the genesis, dynamics, and characteristics of such petroleum reservoirs. Prediction of reservoir location and characteristic is, therefore, outside the realm of simple correlation approaches. As the present day state of fracturing is a consequence of the individual history of the reservoir, this history must be simulated or otherwise deduced from available observations.

As the goal of applied basin research is to gain a predictive capability, a unique quantitative basin model, capable of integrating all the relevant geological factors and RTM processes, was developed. As petroleum reservoirs are fundamentally 3-D in nature, the starting point of our reservoir and field analysis is, therefore, a fully coupled, 3-D RTM model.

In this section, our unique model (CIRF.B) is presented. Results on naturally fractured reservoirs and sealing phenomena using this model are presented in later sections.

CIRF.B (chemical interaction of rock and fluid simulator for basin/reservoir analysis) accounts for the full suite of RTM processes commonly believed to be important in the formation of petroleum reservoirs, faults, and other basin phenomena.

The set of processes and geological factors accounted for in CIRF.B is suggested in Fig. II-1. External influences such as sediment input rate and character, sea level, and thermal and tectonic effects are indicated. Within the basin the RTM processes modify the sediment chemically and mechanically to arrive at petroleum, mineral, and potable water reserves, petroleum reservoirs, and other basin features.

The CIRF.B approach for predicting the location and characteristics of petroleum reservoirs is through a novel basin model and computer simulation algorithms. CIRF.B provides a platform for integrating all available geological data into an exploration/resource development strategy through the laws of physics and chemistry.

Available information can be divided into geological data and the physico-chemical laws and associated parameters. The former provide the information that makes a simulation capture the personality of a specific basin. The physico-chemical information is universal and thereby gives CIRF.B the power to predict resource location and characteristics. It can also be used to carry out a sensitivity analysis or to identify basin data that are most critical for making accurate predictions.

CIRF.B simulations can be used to show the windows of time during which formations along a putative migration pathway were open and not closed due to compaction, formation collapse, or cementation. Similarly, CIRF.B predicts whether formations bounding likely reservoirs form in time (before the reservoir became charged with petroleum) or whether the sealing rock was breached due to natural fracturing or permeability-enhancing diagenetic reactions. It also can be used to predict reservoir producibility by estimating fracture network characteristics and effects on permeability due to diagenetic reactions. These considerations can be made in a self-consistent way through the inclusion of a multi-phase, organic and inorganic, reaction-transport module. 


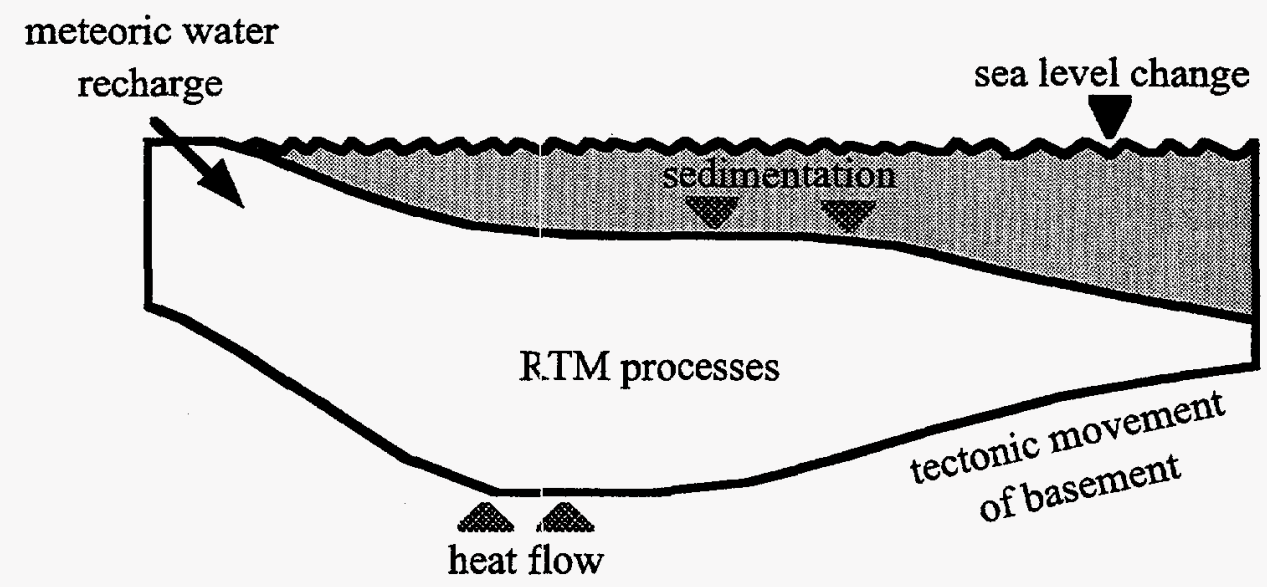

Fig. II-1 Schematic basin cross-section indicating the processes and geological constraints accounted for in the CIRF.B basin simulator.

Calculations of all effects are done self-consistently because all cross-coupling between processes is accounted for.

The cross-coupling relationships in CIRF.B and in nature allow for feedback processes that are completely missed in simpler, decoupled approaches. For example, fracturing $\rightarrow$ permeability $\rightarrow$ fluid pressure $\rightarrow$ fracturing. There are many other such feedback processes. For example, determination of temperature is affected by transport which is in turn affected by the changes of porosity that arise due to temperature-dependent reaction. The rate of kerogen decomposition depends on temperature which, in turn, depends on thermal transport that is affected through fluid buoyancy, thermal conductivity, capillarity, and relative permeability on the content of organic material. All such coupling relations between the full set of RTM processes are accounted for.

Predictive power is diminished for approaches that use statistical correlations. For example, porosity history is often based on a formula relating it to mineralogy and depth. However, porosity evolves due to the detailed stress, fluid composition, and pressure and thermal histories. These histories are different for every basin. Thus, a simple correlation of porosity with depth and lithologic type does not exist in principle. CIRF.B avoids such problems by solving the fully-coupled rock deformation, fluid and nnineral reactions, fluid transport, and temperature problems. While there are thousands of sedimentary basins that the statistical correlations must account for, the calibration required for the physico-chemical approach involves less factors and, unlike for the statistical approach, there is no fundamental contradiction in its formulation. In short, the laws of physics and chemistry hold in all basins and, furthermore, capture the individual personality of every basin when the history of the influence of the basin's surroundings is specified. Statistical approaches can only hope to capture the average personality, i.e., they can only predict a stereotypical basin's evolution.

The interplay of geological and physico-chemical information in CIRF.B is suggested in Fig. II-2. Consider one time step in CIRF.B modeling. The purpose of the incremental evolution step is to advance the state of the basin from a time $t$ to a later time $t+\delta t$. Two distinct operations take place simultaneously during this time interval $\delta t$. The geological information is used to (1) fix the input/output of energy and mass at the basin boundaries and (2) impose the tectonic history 


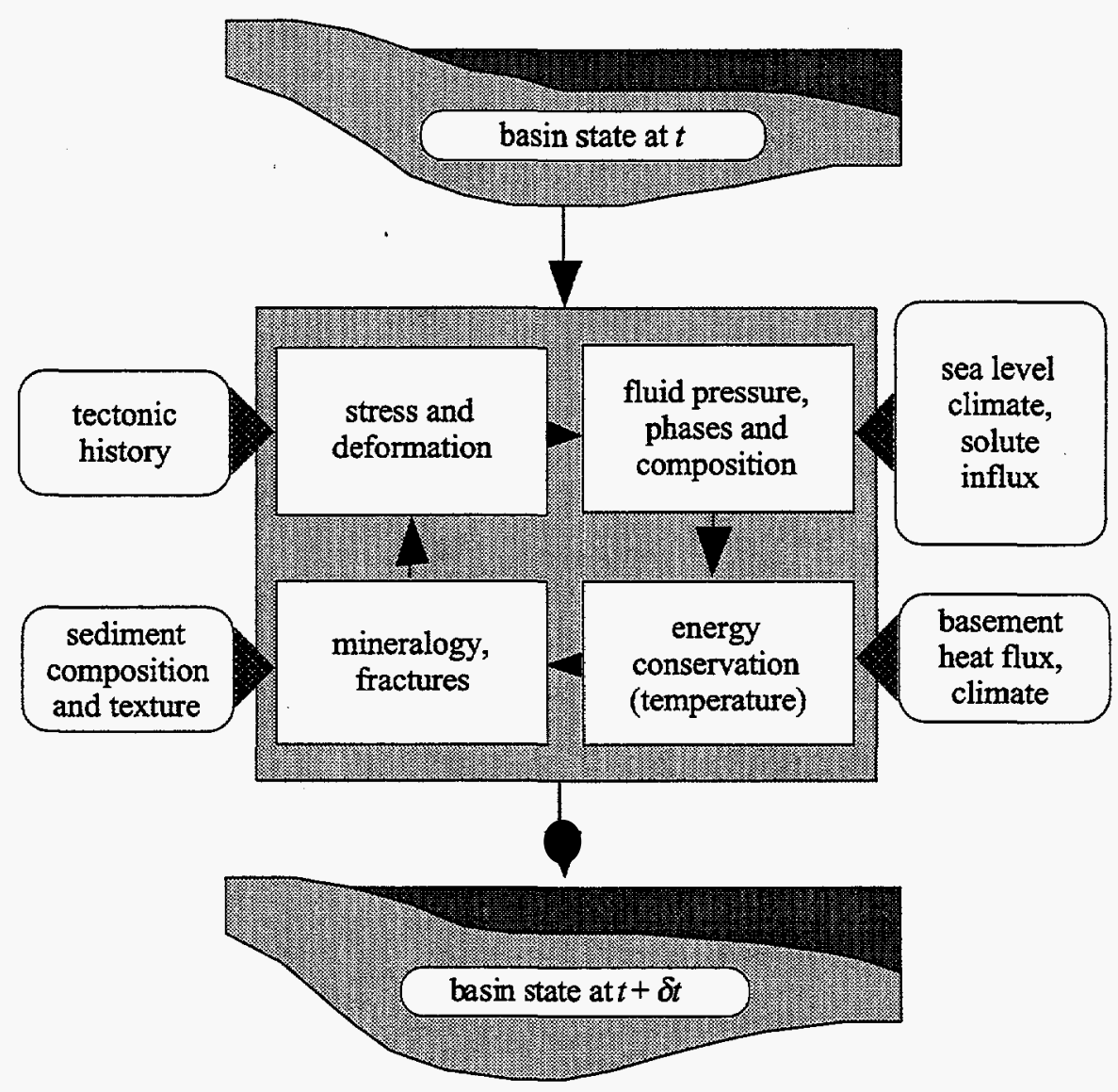

Fig. II-2 Flow chart showing how the interplay of geologic data and physico-chemical (i.e., reaction-transportmechanical) process modules evolve the basin over a computational time interval $\delta t$.

(i.e., the overall basin deformation) at the basin boundary. On the other hand, the physicochemical processes are used to determine the evolution in $\delta t$ of the spatial distribution of the local state. The latter describes stress, fluid properties, mineral content, rock texture, permeability, fracture characteristics, and temperature.

The CIRF.B geological input data is divided into four categories as shown in Fig. II-2. The tectonic data gives the change in the lateral extent and the shape of the basement-sediment inter face during $\delta$. As suggested in Fig. II-2, this data provides the conditions at the basin boundary needed to calculate the changes in the spatial distribution of stress and rock deformation within the basin. This latter physico-chemical calculation is carried out by a stress module that solves equations of incremental stress rock rheology and force balance.

The next type of geological data is that affecting fluid transport, pressure, and composition. This fluid data includes sea level changes, recharge conditions and the composition of fluids injected from the ocean, and meteoric and basement sources. This history of boundary input data is then used by the hydrologic and chemical modules to calculate the evolution of the spatial distribution of fluid pressure, composition, and phase within the basin. These physico-chemical calculations are based on single- or multi-phase flow in a porous medium and of fluid phase molecular species conservation of mass (i.e., the reaction-transport equations). The physico-chemical equations draw on internal data banks for permeability-rock texture relations, relative permeability formulae, chemical reaction rate laws, and reaction and phase-equilibrium 
thermodynamics.

The spatial distribution of heat flux imposed at the bottom of the basin is another geological input/control. This data as well as the temperature imposed at the top of the sediment pile (i.e., climate and ocean-bottom temperature) is used to evolve the spatial distribution of temperature within the basin during the time interval $\delta t$. This evolution is computed using the equations of energy conservation, and formulae and data for mineral and rock thermal properties (conductivities and specific heats).

The sedimentation data provides the textural characteristics such as grain size, shape, mineralogy, mode, and organic texture of the sediment being deposited during $\delta t$. The physicochemical laws and data are used to calculate the change of the spatial distribution of mineral and organic texture within the basin during $\delta t$. These physico-chemical calculations involve the rate laws and data for free face grain chemical kinetics, pressure solution, grain rotation or breakage, grain nucleation, and the laws of kerogen chemical kinetic transformation. Also used are the laws of fracture nucleation, extension, aperture dynamics, and the kinetics of cement infilling.

All this geological input data and the physico-chemical calculations are integrated in a CIRF.B basin simulation to arrive at a unique predictive power for the evolutionary history and the present-day internal state of a basin. The physico-chemical laws translate the boundary constraints (geological data) into a prediction of the changes of internal basin state that take place during $\delta t$. The incremental time advancement is repeated until the evolution of the basin internal state is computed from the inception of the basin (or other chosen initial state) to the present.

The above modeling approach can only be considered practical if the required geological data is as complete as or less than that presently used in petroleum exploration, resource development, and other applications. In fact, all the geological data noted above is in common usage. It is derived from well $\log$ analysis, seismic data, general basin tectonic history reconstruction studies, vitrinite reflectance and other temperature history measurements, stress and strain indicators, core analysis, and production data. In work in progress, methods are being developed for the input of geological data into CIRF.B in the form of well logs, seismic data, core analysis, and other "raw" data. Most of the physico-chemical data is available in data compilations and the literature.

The physico-chemical computations provide a new way of integrating the presently-used geological data. These calculations put constraints on the interpretation of the geological data. For example, an interpretation of the geological data without the benefit of CIRF.B is subject to assumptions on the relative timing of events; estimating the times of these events could be made more reliably when they are predicted based on the known rates of the underlying physicochemical processes.

Like any analysis of the geological data (including those presently used in other approaches), data integration and predictions using CIRF.B are subject to uncertainties. These are of three types:

- variations among the interpretations of the geological data;

- incomplete physico-chemical phenomenologies or required data; and

- errors arising from the numerical simulation algorithms.

All these discrepancies must be addressed in evaluating any predictions. CIRF.B itself serves as a tool for error analysis. By carrying out sensitivity studies, one can determine the contributions of uncertainties in the various factors. This is accomplished by varying the less well-constrained geological and physico-chemical data and the parameters controlling the numerical accuracy (time and space step, convergence criteria for iterative algorithms, etc.).

The enormity of the physico-chemical problem may at first sight make the computations 
seem unfeasible. However, the rapid improvements in computer hardware surmount this difficulty. These improvements are in calculational speed, large memory, and parallelism. Advances in modeling approaches also are reducing the computations. These include homogenization techniques whereby small-scale spatial features can be embedded into large (basin) scale simulations. The latter is done in such a way that the particularities of the small-scale features are not lost in a crude averaging. Advances in numerical techniques (notably adaptive gridding, higher order discretization schemes, and iterative, sparse linear solvers) also make the computations fast, accurate, and robust.

\section{B. STRESS AND DEFORMATION}

Key processes affecting fractured reservoir location and characteristics are compaction, fracturing ductile deformation, and compartment motility. These processes depend strongly on basin stress history. Thus, good estimates of the evolution of stress distribution are required to predict compartment location and characteristics. As fracturing occurs when fluid pressure exceeds least compressive stress by rock strength, estimates of the time of fracture creation, growth, healing or closure, and orientation rely on estimates of the stress tensor distribution and its history. Simple estimates of vertical stress from overburden and less well controlled lateral stress conjectures are not sufficient for accurate predictions.

The stress evolution is tightly coupled to other effects. For example, fracture permeability can affect fluid pressure through escape of fluids from overpressured zones; in turn, fluid pressure strongly affects stress in porous media. For these and other reasons, the ability to estimate the history of the distribution of stress must be carried out within a basin model that accounts for the coupling among all processes. Such a coupled model is required for key applications of compartment theory such as naturally fractured reservoirs, OFEC cyclic fluid release form overpressured zones, and earthquake hazard reduction.

A rock rheological model has been developed in CIRF.B based on incremental stress theory (Zienkiewicz and Cormeau 1974; Rice 1975). The incremental stress formalism has been extended to include fracturing and pressure solution into a unified theory with elastic and viscous/plastic mechanical rock response. This rheology combined with the force balance conditions yields the evolution of the basin deformation over time. The stress solver employs a moving, second order, finite element discretization. An efficient iterative solution approach is used to solve the resulting discretized equations.

The incremental stress rheology used in CIRF.B to integrate all the strain mechanisms has the form (Tuncay and Ortoleva 1998a,b)

$$
\dot{\underline{\varepsilon}}=\underline{\underline{\varepsilon}}^{e l}+\underline{\dot{\varepsilon}}^{i n}+\underline{\dot{\varepsilon}}^{p s}+\underline{\underline{\varepsilon}}^{f r}
$$

Here $\underline{\underline{\varepsilon}}$ is the net rate of strain while the terms on the right hand side give the specific dependence of the contributions to $\underline{\underline{\varepsilon}}$ from four processes. These are poroelasticity $(e l)$, continuous inelastic mechanical (in), pressure solution ( $p s$ ), and fracturing ( $f r)$. Specific expressions for each term have been taken from the literature or newly developed for CIRF.B.

The boundary conditions implemented in the CIRF.B stress module are indicated in Fig. II-3.

They allow for a prescribed tectonic history at the bottom and sides of the basin. This data is input as a history of rock velocity at these boundaries. This type of geological input data is obtained through the sedimentary history input data by CIRF.B and directly input by the user from 


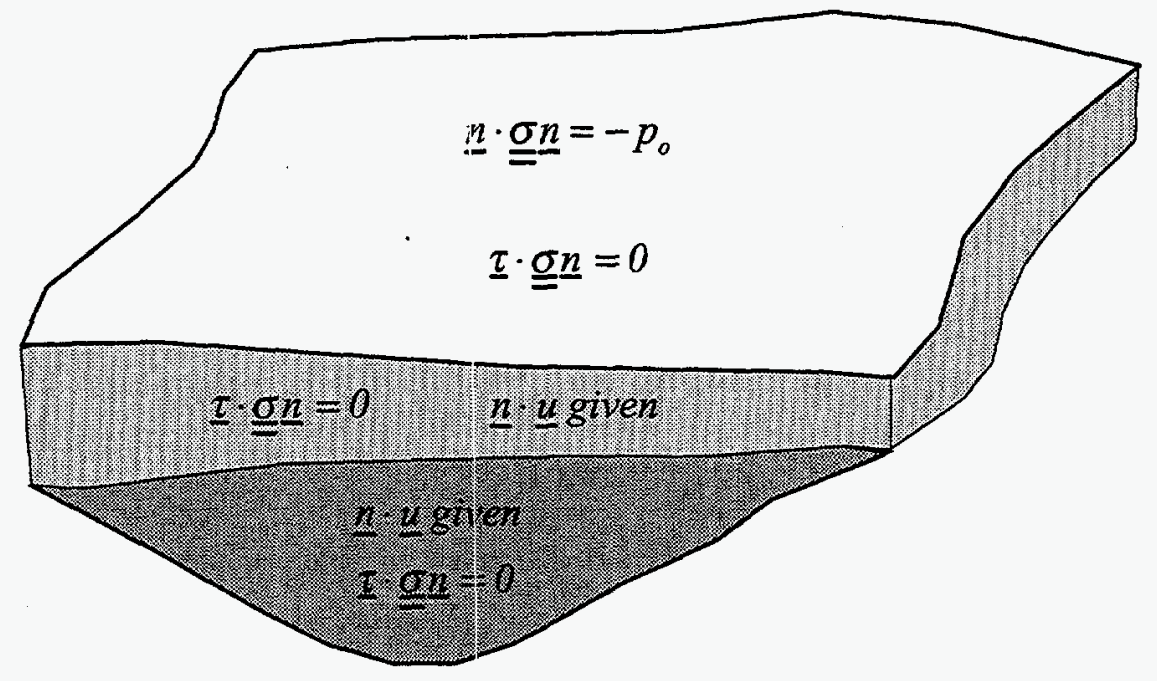

Fig. II-3 Conditions at boundary of basin simulation domain allow for imposition of ocean bottom or atmosphere pressure $p_{o}$ and no tangential shear at the top ( $\underline{\tau}$ being a unit tangent vector and $\underline{n}$ being an outward pointing unit normal vector with respect to the basin boundary). At the bottom the tectonic history fixes the evolution of the normal component of the deformation velocity $\underline{u}$ with a slip condition (and similarly for the sides-lightly shaded).

an analysis of the overall tectonics of the basin. At the simulation domain sides and bottom the tangential components of shear are set to zero. This avoids artificial interference with the natural dynamics of the strain mechanisms there. Normal stress at the top of the basin is set to ocean bottom or atmospheric pressure. Tangential shear on the top is also set under the assumption that the shears imposed by ocean currents may be neglected.

The boundary conditions in the CIRF.Es stress module allow for the full range of tectonic scenarios to which a basin is subjected. These include complex histories of subsidence and uplift, compression or extension, and the variation of these effects with map-view position along the basin periphery and basement-sediment interface. These features make the CIRF.B 3-D stress and deformation module a powerful tool uniquely able to capture the interplay between rock deformation, hydrology, and diagenesis.

\section{TEXTURE DYNAMICS}

A compartment is defined by the spatial distribution of porosity and permeability. These factors are dictated by matrix texture (grain size, shape, and packing) and fracture density, geometry, and connectivity. In CIRF.B these properties are evolved within a texture module.

The texture description and kinetics model used in CIRF.B is the mean contact model (Park and Ortoleva 1998). In that model the grains of a given mineral are all assumed to be of the same size and shape, i.e., they are represented by the average (mean) grain of that mineral. The mean grain of mineral $i(=1,2, \cdots M)$ of the $M$ mineral system is described by a set of four lengths $L_{i \gamma}(\gamma=1,2,3,4)$. The length $L_{i \gamma}$ is used to keep track of growth/dissolution of facets of type $\gamma$ for mineral $i ; \gamma=1,2,3$ represents contacts allong a set of three Cartesian axes while $\gamma=4$ represents free faces, i.e., those facets of a grain bounding a fluid-filled pore. The situation is suggested in Fig. II-4. The $\gamma=1,2,3$ variable:s account for pressure solution while $L_{i 4}$ keeps track of mineral $i$ overgrowth/dissolution. 


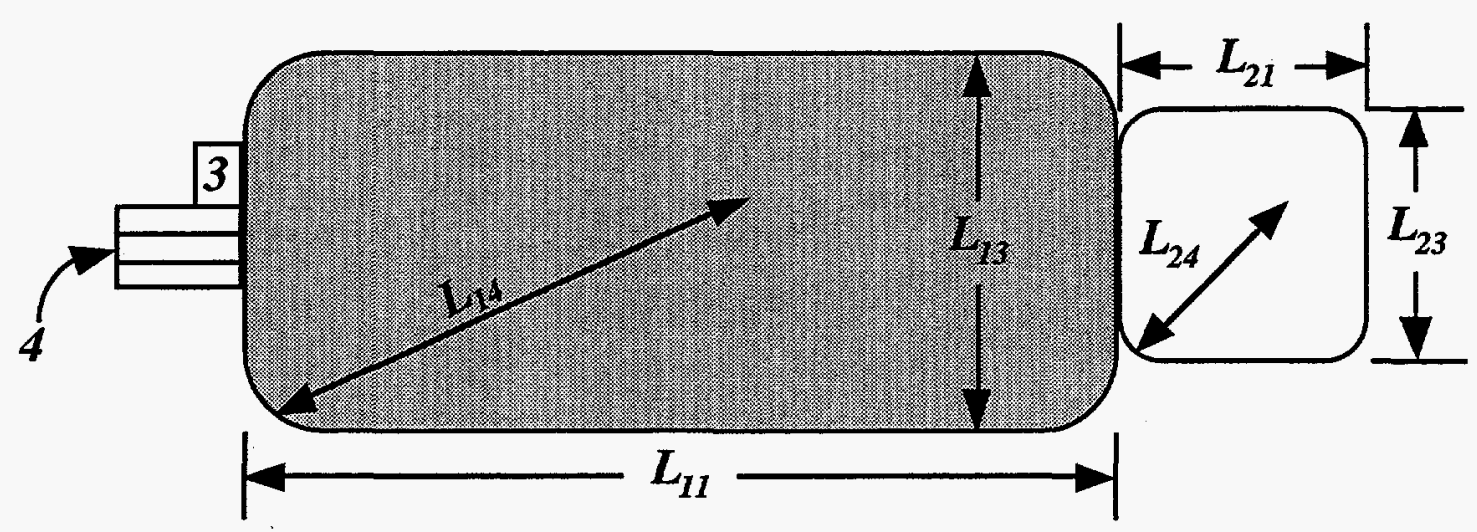

Fig. II-4 Schematic view of texture model showing a relatively large, flatter grain of mineral $l$ and a more equant grain represent mineral 2 . The 2-direction is assumed normal to the page. At the left, a mineral 3 grain and a mineral 4 grain are also suggested.

To complete the geometric description of texture, a number of formulae for grain geometry are also introduced. Let $V_{i}$ be the volume of a mineral $i$ grain; then a formula $V_{i}=V_{i}\left(\underline{L}_{i}\right)$ is set forth $\left(\underline{L}_{i}=\left\{L_{i l}, L_{i 2}, L_{i 3}, L_{i 4}\right\}\right)$.If $n_{i}$ is the number of $i$-grains per rock volume then the porosity $\phi$ (volume fraction of rock that is pore space) is given by

$$
\phi=1-\sum_{i=1}^{M} n_{i} V_{i}\left(\underline{L}_{i}\right)
$$

Finally, the $\gamma$ type grain surface areas $A_{i \gamma}$ are set forth as function of $\underline{L}_{i}$ and $\phi$. The $\phi$-dependence of $A_{i \gamma}$ serves to insure that as porosity vanishes so do the free face $(\gamma=4)$ surface areas $\left(A_{i 4} \rightarrow 0\right.$ as $\left.\phi \rightarrow 0\right)$.

Kinetics of the texture is contained in the growth/dissolution laws

$$
\frac{D L_{i \gamma}}{D t}=G_{i \gamma} .
$$

Here, $G_{i \gamma}$ is the rate of growth $\left(G_{i \gamma}>0\right)$ or dissolution $\left(G_{i \gamma}<0\right)$ at facet type $\gamma$ for a mineral $i$ grain. Allowance is made for the nucleation of new mineral grains within the pore space. These join the population of stress-bearing grains when they reach a pore diameter-dependent size.

The growth laws $G_{i \gamma}$ depend on fluid composition and pressure as well as temperature. For stress-bearing contacts $(\gamma=1,2,3)$, pressure solution formulae relating contact-normal stress to texture and macrostress (as calculated by the stress module) are also incorporated in CIRF.B.

The specific formulae used in CIRF.B for the volumes, contact areas, and growth laws are presented in Park and Ortoleva (1998).

\section{MULTI-PHASE FLUID REACTION-TRANSPORT DYNAMICS}

The theory underlying multi-phase dynamics implemented in CIRF.B is discussed in detail in Tuncay, Zhan, and Ortoleva (1998) and Ortoleva (1996). Briefly, the approach used is as follows.

Transport is via a newly modified version of the black oil model. Formulae and data for relative permeabilities, capillary pressure, and equations of state are taken from the literature and released industry reports. The formulation implemented allows for the transport and spontaneous 
creation or disappearance of phases (gas, aqueous, oil, and $\mathrm{CO}_{2}$-dominated) under the assumption that all processes transferring molecules between phases are at equilibrium. Both rapid (equilibrated) intra-phase reactions and finite rate (kinetic law determined) intra-phase and fluidsolid reactions are accounted for. A model of the kinetics of kerogen thermal decomposition into organic fluid species is also implemented. The formulation involves a new kinetic reaction network calibrated using published experimental data (see Payne and Ortoleva 1998; Tuncay and Ortoleva 1998c).

\section{E. GEOLOGICAL DATA INPUT}

To analyze a specific basin, the detailed sedimentary, tectonic, and other histories must be entered into the simulator. Such data specifies the interaction between the basin and its surroundings.

Any practical approach must be limited to readily available data. This includes seismic, well $\log$, core analysis, surface geology, and various isotopic and geochemical data. A practical basin simulator must be able to use this data in forms which are as close as possible to that in which it is taken. Furthermore, the spatial resolution of features (lithologic units, basement faults, etc.) must be automatically (not manually) generated. The data must also be readjusted for erosion. Finally, a number of parameters (climate, sea level, basement heat flux) are sensitive to interpretation.

In this section, some of the CIRF.B data input is reviewed as are issues such as computational grid adaptation and built-in graphical modules. The accuracy of a prediction depends strongly on the spatial resolution of the grid on which the solutions of the equations are obtained. More precisely, accuracy depends on the degree to which the grid is sufficiently fine in regions where rock properties (permeability, elasticities, or failure parameters) change dramatically (e.g., at lithologic contacts).

Much of the required grid adaptation to regions of rapid change is carried out in the CIRF.B sediment history reconstruction module. As sediment is added, layers of calculational grid are added when required to capture lithologic contacts. The gridding used has cubic logic and is hexahedral. Space is divided into an array of distorted bricks that conform to lithologic units. One layer of grid has the form of a set of quadrilaterals inscribed on a nonplanar surface. In order to capture a set of lenticular sandstone or other bodies, for example, the quadrilaterals of an added new grid layer are automatically concentrated at the periphery of a sedimentary feature. Finally, grid layers are dynamically reorganized when erosion removes material.

In CIRF.B this entire process of construction of the sediment history and computational gridding is completely automated. The data input strategy implemented is tailored to the nature and format of available well data as follows.

A data file must be created describing the present-day mineralogy, texture, and age for all available lithologies at each of a set of well locations in the basin. A key factor of the approach used is that well locations can be arbitrary (not on a regular grid) and data in any well need not be complete. At any time, the CIRF.B sediment history reconstruction module examines all the wells and identifies the observed grain size, mode, and other data for each mineral. The rate of deposition and the original porosity and permeability are computed via a decompaction algorithm that is sensitive to average grain size and sorting. Then an interpolation subroutine determines these factors at all grid points in map view on a contact-adopted grid in a way that captures sharp transitions between distinct units and gradational changes within a given unit. Deposition 


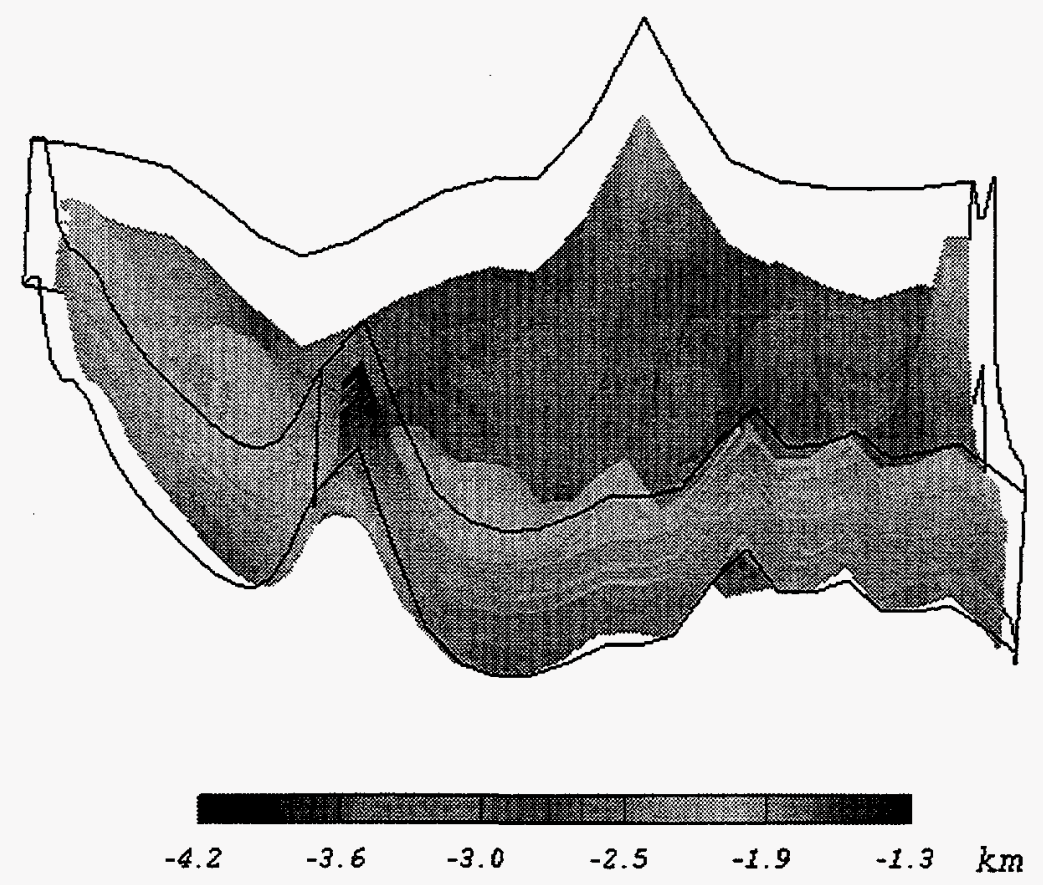

Fig. II-5 3-D, depth-shaded view of the Mancos shale.

and erosion rates are similarly interpreted using data on unit thickness and age.

In order to make the sedimentation module most flexible, data at any well may be incomplete. Thus, some time intervals may be missing at a subset of wells. CIRF.B automatically fills in the missing data by an interpolation algorithm based on the data present and interpolated from the wells wherein the data is available at a time of interest. Authigenic minerals must be discounted by the user as they were not present at deposition. Hence, some user interpretation is required (unlike for the decompaction into CIRF.B). As the CIRF.B sediment history reconstruction module has direct access to the present-day well data, it also may be used to make comparisons between CIRF.B predictions and observations.

An important element in creating the data input files and of examining the final predictions of CIRF.B is 3-D graphics. A number of such tools have been implemented in CIRF.B. Two examples are seen in Figs. II-5 and 6. Fig. II-5 is a 3-D view of the Mancos shale of the Piceance Basin. The shading indicates the distance from the surface of the sediment down to the boundary of the Mancos shale. Fig. II- 6 shows a view of the units of the Iles Formation. These depictions of one, several, or all units are essential in evaluating input data quality, the need for improved spatial resolution, and the 3-D architecture of the lithologic units. These graphical features, along with isosurface, flow vector, and other graphical techniques, facilitate the interpretations of CIRF.B predictions and input quality analysis. The data input module also allows one to add certain qualitative information about sedimentological processes to augment the data set in regions of poor well coverage. 


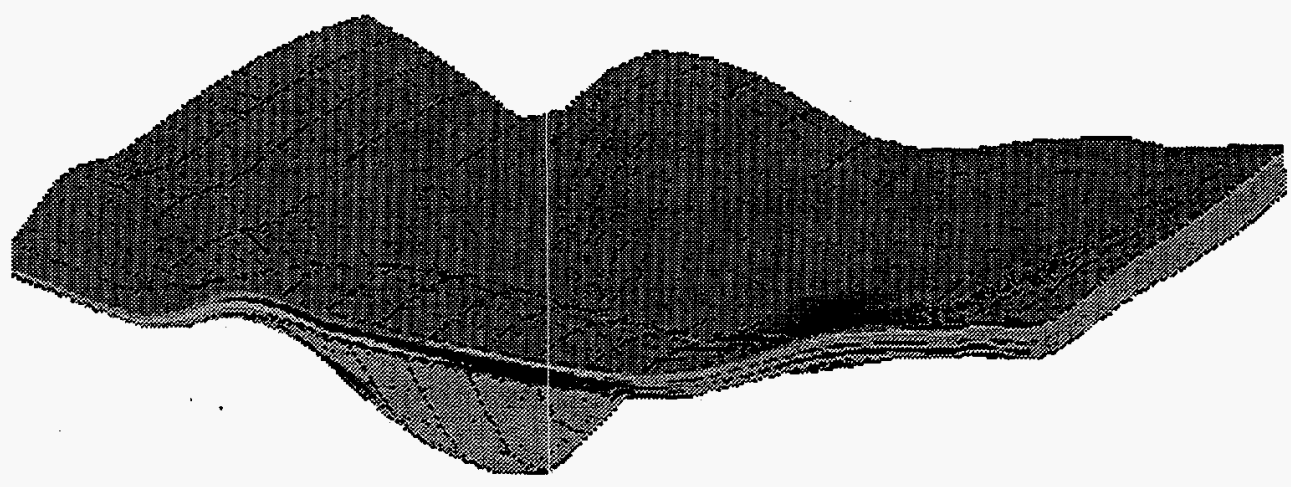

Fig. II-6 3-D map of the lles Formation in the Piceance Basin, between 72 and $75 \mathrm{My}$, showing shoreline sand units interbedded with marine shale. The overlying unit represents the lowermost part of the Williams Fork Formation. 


\section{STUDY AREA AND INPUT DATA}

\section{A. STUDY AREA OVERVIEW}

Andector Field is an oil producing area in Ector County, Texas (see Fig. III-1) on the Central Platform of the Permain Basin, West Texas. This particular field was chosen for our study because of its:

- data availability;

- intensive fracturing;

- vuggy and karst reservoirs; and

- because it is the largest Ellenburger oil producing field.

Andector field has produced $154 \mathrm{MMBL}$ of oil, as of 1982 (Galloway et al. 1983). It is considered one of the best analogs for approximately 50 fields of the same type (see Fig. III-2). A map of the study area is shown in Fig. III-3.

The stratigraphy input data is comprised of 15 structural tops (see Figs. MI-4, 5 and 6), starting with the deepest unit, Ellenburger (Hoak et al. 1998). The stratigraphy in this field is comprised of mostly brittle, fractured carbonate rocks (Kerans 1988). The initial composition . and grain size information for the 15 units was derived from present day compositions (Hoak et al. 1998) and average porosity and grain size values (Williams, Turner, and Gilbert 1982; Pettijohn 1975; Roberts 1974; Lane 1947). Some of the initial grain size and porosity values were altered to meet the data input criterion for the RTM model.

Diagenetic, hydrologic and mechanical processes are strongly dependent on temperature and fluid pressure. Because of its strong influence, we have gathered fluid pressure data for Ector County, Texas (see Fig. III-7). This pressure data represents a unified data set for pressure measurements recorded in Ector County, Texas. The wide range of values is influenced by production procedures such as draw-down pressure and injection pressure. The gradient probably suggests a hydrostatic normal based on gradient measurements performed by Powley.

Since the field is on the Central Platform, most of the stratigraphic units lie flat along the structural uplift (see Figs. III-5, 6 and 7). However, Fig. III-8 and, on a smaller scale Fig. III-9, show the Ellenburger Formation with structural highs in the north fault block, along the saddle between the north and south fault block, and on the south fault block. The structural highs are typically were the oil is being extracted (Katz et al. 1994). Oil-water contacts are shown to be near the structural lows on the Ellenburger Formation (Galloway et al. 1983). Because of this information, we have chosen two sites (see Fig. III-3) on the north and south fault block for 1-D single- and multi-phase CIRF.B simulations.

\section{B. STRATIGRAPHIC DATA}

\section{Generalized Stratigraphy and Sedimentology of the Permian Basin}

The Permian Basin occupies an extensive area encompassing nearly $300,000 \mathrm{~km}^{2}$ in southeast New Mexico and west Texas. Major structural elements within this region include the Delaware Basin, the Central Basin Platform, and the Midland Basin (Fig. III-10). During the Paleozoic, the basin was the site of the Tobosa Basin (Galley 1958), a shallow marine basin with boundaries 
corresponding to the later Permian Basin. The region has experienced nearly equal amounts of clastic and carbonate sedimentation whose areal extent reflects the complex interplay between sea level, sediment supply, basin accommodation space (subsidence) and regional tectonics.

The region has experienced one primary period of tectonism during the late Mississippianlate Middle Pennsylvanian. Final deformation occurred during the early Permian. This deformation coincided with continental collision and the formation of the Marathon-Ouachita thrust belt. Following this deformation, the region has experienced little tectonism except related to Laramide (Cretaceous-Tertiary-age) and Basin-and-Range (Paleocene-Recent) extensional deformation along the western margin of the Delaware Basin. This later deformation has not affected the majority of the Permian Basin. The stratigraphy will be discussed in order from oldest to youngest. The Ellenburger and Clear Fork formations will be discussed in greater detail because understanding their evolution currently represents one of the primary objectives of the CIRF.B modeling effort.

A stratigraphic column for the region is shown in Fig. III-11. The majority of the following discussion is modified and synthesized frorn the regional summary provided by Frenzel et al. (1988) and Hanson et al. (1991). Where additional sources are used, they are explicitly referenced.

\section{Precambrian Rocks (Crystalline Basement)}

Little is known about the internal variation found in the Precambrian-age basement of the Permian Basin. Precambrian-age outcrops are found in the Trans-Pecos area and in central New Mexico. In the basin proper, the majority of information comes from subsurface regions of uplift such as the Central Basin Platform where complex structure and relatively shallow drilling depths to basement have allowed several wells to penetrate into crystalline basement (Hills 1984; Shumaker 1992). Unfortunately, cuttings and core samples of these wells are rarely preserved and there are few reliable records of basement samples. Even fewer wells have had isotopic age measurements for the basement samples. As a result, a great deal of our information is indirect, coming from interpretations of gravity, aeromagnetics and seismic data. From these data, we know that the Precambrian is cut by numerous NW- and NNW-trending fault systems, thought to be wrench faults (Hills 1984; Shumaker 1992). The age of initial deformation of much of this crust was thought to be Proterozoic in age. The interpreted composition of the basement is apparently quite variable ranging from granophyres through mafic intrusives. In Andector Field, core studied as part of the current project found basement rocks that we characterized as a muscovite schist. This rock showed a penetrative cleavage fabric and a strong lineation on this surface. Small porphyroblasts of unknown mafic mineral (chlorite?) were also present in these cored samples. This occurrence will be discussed in detail in future reports.

In several localities, a Cambrian-age deposit designated the "Granite Wash" is found lying unconformably on top of the crystalline basement. The nature of this lithofacies apparently reflects the composition of the underlying eroded source. Due to limited well penetrations, the regional extent and occurrence of this facies is poorly understood. It has been penetrated in a very limited number of wells on the Central Basin Platform.

\section{Ellenburger Group (Lower Ordovicisı)}

The Ellenburger Group represents the deepest, large hydrocarbon reservoir in the Permian Basin. The Ellenburger was deposited on a broad, open cratonic basin (Fig. III-12). This Paleozoic basin has been called the Tobosa Basin. Its depocenter now corresponds to the approximate center of 
the Delaware Basin. It is important to realize that the present geometry of the Permian Basin, composed of the Central Basin Platform and the adjacent Delaware and Midland basins, only achieved its present configuration in the early Permian. As a result, the majority of pre-Permian lithologies show similar lithologic characteristics and correlate across the Permian Basin. Ellenburger reservoirs are structural traps composed of thick dolomites deposited on a restricted circulation carbonate ramp environment. The Ellenburger attains a thickness of more than $550 \mathrm{~m}$ south of the Llano Uplift, and a maximum thickness of 490-520 meters in the southern Delaware Basin.

The Ellenburger is considered a classic fractured reservoir. In nearly all fields it is described as pervasively fractured. The significance and genesis of this brecciation will be discussed in greater detail in a section that follows this general overview of all regional stratigraphy. In addition, this later section will discuss models of Ellenburger deposition and diagenesis in greater detail.

\section{Simpson Group (Middle Ordovician)}

The carbonates of the Ellenburger Group are unconformably overlain by the Simpson Group. The Simpson Group is composed of up to 700 meters of green to gray shales interbedded with limestone and occasional sandstone. The Simpson Group is readily divided into formations (e.g. Bromide and Tulip Creek formations) whose distinct log characteristics permit their identification of that formation throughout the area. The basal sands are apparently the best reservoirs in the group. The Delaware Basin represents the western extent of deposition and the sands thin to the west and south.

\section{Montoya Formation (Upper Ordovician)}

The Montoya (Upper Ordovician) lies unconformably on top of the Simpson Group. It represents a transgressive system that ranges in thickness up to 180 meters. To the east, in the Midland Basin, the Montoya is redesignated the Sylvan Shale. There its thickness ranges from 030 meters with an average of 7-10 meters. The shale is greenish-gray in color. The greatest thickness of the Montoya Formation is between 150 and $180 \mathrm{~m}$ at the southeastern part of the Delaware Basin. Thickening of the Montoya Formation is abrupt along the east edge of the depositional basin, suggesting that the rate of subsidence was faster in the Delaware Basin than in the area of the Central Basin Uplift (Frenzel et al. 1988). In most areas, the Montoya is not considered a drilling target primarily because it generally lacks an adequate reservoir seal. Although the Montoya does contain abundant zones of fracture-enhanced porosity that allows communication with overlying and underlying reservoirs, the absence of a top seal precludes the preservation of large hydrocarbon reserves. If the top seal is not present, economic production requires continuity with overlying Siluro-Devonian reservoirs.

\section{Fusselman Formation (Silurian)}

The Fusselman Formation represents the oldest Silurian age formation in the Permian Basin subsurface. It is a shallow-water carbonate unit that lies conformably on the Montoya Formation and facies-equivalent Sylvan Shale (to the east in the Midland Basin). There are two dominant lithologies. In the basin, the Fusselman is a biogenic limestone ranging between 15-60 meters thick. To the north and west, the Fusselman thickens to over 250 meters. Fusselman traps are: 1) structural closures; 2) truncation by Pennsylvanian-Permian erosion on uplifted blocks of the Central Basin Platform; and 3) truncation by Woodford Shale along the eastern eroded margin of the formation. The overlying Wristen Formation is thought to represent the source beds of most 
of the Fusselman hydrocarbons and also rejresents the reservoir seal. Although the Fusselman dolomite facies are really extensive, hydrocarbons are only found near the limestone facies where it is overlain and sealed by the Wristen Formation or the Woodford Shale.

\section{Wristen Formation (Late Silurian)}

The Fusselman is overlain by the Wristen Formation. Its stratigraphic thickness ranges from a minimal $30 \mathrm{~cm}$ to more than 90 meters thick. The formation is present across the southern Central Basin Platform and the southern Midland Basin. To the north and west, the Upper Silurian thickens markedly to over 460 meters and changes facies to a shallow-water carbonate lithology that includes limestone and dolomite with coral and stromatoporoid reefs.

\section{Thirtyone Formation (lower Devonian)}

The lower Devonian Thirtyone Formation is dominated by chert in the western area of the basin and changes to a chert and limestone to the east. Thickness ranges from 0-300 meters and the formation is found in the same areas as the underlying Wristen Formation. The Thirtyone Formation produces from tectonically brecciated structures (Delaware Basin chert reservoirs), chert and limestone reservoirs (central and northern Central Basin Platform), and an unusual reservoir called tripolite. Tripolite contains calcite and dolomite within a siliceous framework. These rocks ranges from siliceous dolomites to slightly calcareous, dolomitic chert. The key attribute to these reservoirs are their very high porosity (average 16\%), low permeability and very small pore throats due to microfracturing.

\section{Woodford Formation (Late Devonian-Early Mississippian)}

The Devonian formations were deposited into a subsiding, deepening basin following an erosional event that is observed at Middle Devonian time. Woodford thickness reaches a maximum of 185 meters. Commencing in the late Devonian, the Woodford Formation shales transgressed the underlying formations. The transgression persisted through the Mississippian. These shales form important reservoir seals capping the Paleozoic-age reservoirs. Because of their organic richness, they are also considered the primary source beds for most of the hydrocarbons in the underlying reservoirs. In addition, the Woodford shales represent one of the best regional markers for stratigraphic correlations due to their marked contrast with underlying and overlying formations on geophysical logs.

In northern parts of the Permian Basin the entire Mississippian System is less than $30 \mathrm{~m}$ thick. The Mississippian Period was transitional between two very different tectonic styles in the evolution of the Permian Basin. From the Cambrian time until the Mississippian the Permian Basin region was a relatively stable part of the midcontinent craton, as indicated by the abundance of shallow-water carbonate deposition. In Late Mississippian time, local structures, formed by earlier epeirogenic few and relatively mild tectonism, began to develop and assert themselves. Increasingly more violent tectonism became the style and the geologic environment of the Permian Basin until Middle Permian time. Deposition characteristics in the Permian Basin changed from predominantly carbonates to dominantly shales, and later to coarse-grained and thicker clastics (Frenzel et al. 1988). The greatest of all the tectonic episodes that affected the evolution of the Permian Basin was the Marathon-Ouachita Orogeny, whose initial phase occurred during Late Mississippian times. 


\section{Morrow Formation (Pennsylvanian)}

The Pennsylvanian rocks of the Midland Basin, Central Basin Platform, and Delaware Basin are extremely variable in distribution, thickness, and lithology. The Pennsylvanian strata which consist of shales, carbonates and sandstones, were deposited in various environments such as shallow-marine carbonate shelves, fluvial coastal plans, and deltas. In the Delaware Basin, the Pennsylvanian-Mississippian contact in the deep part of the Delaware Basin is typically below $4,250 \mathrm{~m}$.

In the Midland Basin, Pennsylvanian rocks are generally less than $300 \mathrm{~m}$ thick near the eastern and western margins, and less than $150 \mathrm{~m}$ in its center. The typical depth to the Pennsylvanian-Mississippian contact is approximately 3,000 to 3,500 m near the basin axis. The beginning of Pennsylvanian time also saw the deposition of the Morrow Formation whose deposition was restricted to what is now the Delaware Basin. The Midland Basin and Central Basin Platform areas were topographically elevated and shed sediments into the deeper Delaware Basin depositional environments. All of these uplifted areas around the Delaware Basin represent the source for the Morrow terrigenous clastics.

\section{Atoka Formation (Pennsylvanian)}

The dramatic onset of regional tectonic deformation in the late Pennsylvanian (Atoka-time) produced marked changes in the paleogeography of the Permian Basin. As flysch and related clastic sedimentation occurred in the foredeep in front of the advancing Ouachita-Marathon foldand-thrust belt, significant deformation to the north significantly modified the geometry of the Paleozoic-age Tobosa Basin. The presence of these foredeep-related sediments in the Permian Basin proper, however, did not occur until Virgilian time. Most notably, this deformation resulted in the basin configuration we see today composed of the Delaware and Midland basins with the Central Basin Platform separating the two basins. From its inception, the Delaware Basin has been deeper and more asymmetric than the Midland Basin.

The maximum thickness observed in the Delaware Basin is 110 meters. On the Northwest Shelf, the Atokan section consists of a series of time-transgressive carbonate shelves that prograded southward into the Delaware Basin. In the northern part of the Eastern Shelf, a variable thickness of the Bend Conglomerate is present. This facies was deposited in terrestrial to near-shore marine depositional systems.

\section{Strawn Formation (Pennsylvanian)}

The Desmoinesian-age Strawn Formation in the Permian Basin has been subdivided into two stratigraphic units based on fusulinid fossil zonations. The lower or early section is dominated by shallow marine and terrestrial sediments deposited over much of the Midland Basin and Northwest Shelf of the Delaware Basin. The thickness of the Strawn sediments range from 0-70 meters. Because of uplift and related erosion along the southern part of the Central Basin Platform, many of the uplifted blocks remained topographically high well into the Permian.

During upper or late Desmoinesian time, fluctuations in eustatic sea level profoundly affected the nature and distribution of sediments. This time marked the beginning of the rapid subsidence of the Midland and Delaware basins. Due to this subsidence, many nonmarine facies were flooded and the two basins became deep water, sediment-starved systems. Pennsylvanian oil is trapped stratigraphically in clastic rocks near shelf margins or hinge lines and also in reef-like carbonate buildups within the Midland Basin. The most significant Pennsylvanian oil 
accumulations are in the carbonates of the Horseshoe Atoll, which is as much as $915 \mathrm{~m}$ thick. The atoll is composed of biohermal and biostonnal carbonate buildups and their respective talus deposits.

\section{Canyon Formation (Pennsylvanian-Missourian)}

Due to continuing deepening of the basins and concurrent sea level highstands, the Canyon section is composed almost entirely of shelf limestones. The deep basin areas received only thin sections of shale. Maximum thickness of the Magadalena Shale facies of the Canyon-Cisco system is 280 meters. The shelf limestones show thicknesses of up to 50 meters.

\section{Cisco Formation (Pennsylvanian-Virgilian)}

The Cisco facies represent a continuation of those Canyon deposits over most of the Permian Basin. Only along the eastern margin of the Midland Basin did a change in depositional system occur. In this area, the basin was relatively shallow and rapidly filled. As a result, the shelf edge prograded out into the basin. Although these sediments appear laterally continuous with the Canyon-age parts of the reef, these Cisco sands were mistakenly attributed to the older depositional system.

During Virgilian time and extending into middle Wolfcampian time, the Marathon-Ouachita system developed along the south side of the Permian Basin and shed muds and sands into the adjacent basins.

\section{Wolfcamp Series (Permian-Wolfcampian)}

Continued growth of the carbonate shelves and margins continued into the Permian. As the carbonate systems grew along the basin margins, the Delaware and Midland basins became starved because no sediments were able to bypass the shelf margin carbonate systems and reach the deep basin. The Wolfcampian Series consists of a thick (over 670 meters) sequence of carbonates and siliciclastics. There are two primary depositional styles. Although the geometry of many Wolfcamp deposits suggest reef environment, most of them are composed of grainstones and small mud-prone buildups. In the Delaware and Midland basins, debris flow carbonates dominate Wolfcampian time. These debris flows were sourced from adjacent platform areas. The thickest. Wolfcampian deposits are located adjacent to the Central Basin Platform. it reaches 4,300 $\mathrm{m}$ thickness and thins northward to approximately $1,585 \mathrm{~m}$ in Ward County and to less than $610 \mathrm{~m}$ in the western Delaware Basin (Wilde 1976). In the Midland Basin the Wolfcampian is represented by mostly gray shales with interbedded limestones and some sandstones near the basin margin. These rocks attain a thickness of about $600 \mathrm{~m}$ in the deep parts of the basin (Wilde 1976).

\section{Clear Fork Formation (Permian-Leonardian)}

In the Permian Basin, the Leonardian strata are represented by the Glorieta, Clear Fork, Tubb, Abo, Ouachita, Ouachita-Albany, Sprayberry/Dean, and Bone Spring formations. Clear Fork carbonates were deposited as upward-shoaling sequences of shallow-marine to supratidal platform carbonate sediments. Thicknesses of the Clear Fork range up to 825 meters thick. The Clear Fork is areally restricted to the northeast Central Basin Platform and the adjacent Northwest Shelf. Clear Fork sediments were partly to completely dolomitized and contain abundant sulfate minerals as nodules and cements. Rapid lateral migration of shoreline facies has 
resulted in extreme lateral discontinuity (Tyler et al. 1991) that impedes reservoir continuity between wells.

\section{Sprayberry-Dean Formations (Permian-Leonardian)}

These deposits are restricted to the Midland Basin depocenter. These are typically deep water submarine fan, very fine-grained sandstones and siltstones that were deposited basinward of the southward-prograding Northwest Shelf. In the Midland Basin, the lower Leonardian strata attain up to $350 \mathrm{~m}$ in thickness that were deposited in deep (more than $200 \mathrm{~m}$ ) waters. The Sprayberry Formation is about 300 meters thick and the Dean is about 65 meters thick. In the Delaware Basin, the lower Leonardian strata reaches a maximum of $915 \mathrm{~m}$ thickness (Hardy 1976). Because of complex internal architecture of the submarine fans, recovery efficiency of these reservoirs is quite poor $(\sim 10 \%$ of oil-in-place). These reservoirs contain fractures and have low matrix permeability. To date, there has been little attempt to characterize the fractures in these formations.

\section{San Andres-Grayburg Formations (Permian-Guadalupian)}

The San Andres and overlying Grayburg are frequently lumped together because of their close association on the Central Basin Platform, their similar depositional environments and because together they represent the largest hydrocarbon reservoir in West Texas. Both the San Andres and Grayburg formations were deposited in the open marine shelf environment that surrounded the Midland Basin. Depositional environments range from bar and bank complexes along the shelf edge to restricted subtidal lagoons and tidal flats shoreward of the shelf margin. Over time, the San Andres shelf edge prograded eastward into the basin so that the Grayburg shelf edge lies basinward of the San Andres shelf. It reaches 250 to $425 \mathrm{~m}$ thickness and consists of cyclic limestone, dolomite, and evaporites of a shallow shelf depositional environments ranging from open marine to sabkha and tidal flat.

San Andres-Grayburg reservoirs consist of upward-shallowing cycles approximately 100 meters thick. The lower two-thirds of each cycle is composed of subtidal facies such as dolomitized skeletal wackestone to pellet grainstone. Local bioherms and skeletal grainstones are also present. Overlying this assemblage is a thin zone of subtidal to intertidal pellet, skeletal and grainstones. These grainstones are well-sorted, often laminated and crossbedded and interpreted to indicate high-energy deposition. The top of each cycle is capped by a supratidal sequence consisting of interbedded mudstone, siliciclastic siltstone and pisolite facies. These mud-rich flooding surfaces are easily recognizable on most $\log$ suites. The dominant production associated with these formations are found on the eastern margin of the Central Basin Platform. On the Ozona Arch, there are also reservoirs found in the high-energy facies of the Grayburg Formation. These units range in thickness from 170 to $365 \mathrm{~m}$.

\section{Queen Formation (Permian-Guadalupian-Ochean)}

The Queen Formation represents a tidal flat sandstone that is found along the northern edge of the Delaware Basin, the margins of the Central Basin Platform and the southeast edge of the Midland Basin. The Queen Formation thickens to the southeast in the Midland Basin and thins onto the Central Basin Platform and Northern Shelf. Thicknesses of the Queen range from 5 meters to more than 100 meters in the Midland Basin. Queen reservoir sands consist of a diverse suite of eolian, tidal flat and shoreface-tidal flat depositional environments. The sands are overlain by sabkha dolomitic mudstones and massive anyhydrite. The massive anhydrite is commonly 
overlain by eolian sheet sands. The anhydrite generally represents the seal for individual reservoir sands.

\section{Capitan Reef, Seven Rivers, Tansill and Yates Formations (Permian-Guadalupian)}

The Capitan Reef and related facies from a continuous trend along the western margin of the Central Basin Platform. The Capitan Formation represents the true reef facies. The Seven Rivers, Yates and Tansill formations represent the restricted platform equivalents of the middle and lower Capitan Reef. On the west side of the Central Basin Platform, the Yates Formation is a sequence of siliciclastics associated with sabkha carbonates and evaporites. These sediments were deposited in a prograding tidal flat, lagunal setting upslope of the shelf-margin reef. Sediments were sourced from the Northwest Shelf, Eastern Shelf, and Southern Shelf. Yates reservoirs consists of siltstone to fine-grained sandstone with varying amounts of cement and clay content. Lithologically, the Yates and Seven Rivers are very similar. The average thickness of the Seven Rivers, Yates, and Tansill sequence ranges from 300 to $490 \mathrm{~m}$. The Delaware Mountain Group ranges in thickness from 285 to about $1,070 \mathrm{~m}$. The overall thickness of the Guadalupian sequence in the Midland Basin is up to $820 \mathrm{~m}$.

\section{Castile (Permian-Guadalupian)}

In late Permian time, continued restriction of the Permian Basin resulted in deposition of the Castile Formation evaporites. These evaporites form a thick ( 600 meter) blanket that effectively precludes vertical migration of fluids. This formation is characterized by centimeter-scale laminations of brown calcite and white anhydrite (varves). Any hydrocarbons generated from the darker varves were apparently expelled laterally into the carbonate reefs. There are no remaining hydrocarbons thought to be present in the Castile.

\section{Salado (Permian-Guadalupian)}

The Guadalupian-Ochean sediments in the Permian Basin consist of the Saludo, Rustler, and Dewey Lake formations. In the Delaware Basin, the Guadalupian-Ochean sediments reach up to $1,375 \mathrm{~m}$ in thickness. They also suggest a maximum water depth of deposition that is more than $200 \mathrm{~m}$ (Frenzel et al. 1988). The Salado evaporites added to the thickness deposited earlier but were deposited in shallow water lacking significant organic material. The Salado Formation reaches a maximum thickness of 670 meters.

\section{Rustler (Permian-Ochoan)}

Deposition of the Rustler involved continued deposition of evaporite and dolomite. Prior to deposition of the Rustler, subaerial exposure is thought to have removed approximately 100 meters of overburden. The Rustler Formation achieves a maximum thickness of 160 meters.

\section{Dewey Lake (Permian-Ochoan)}

These sediments are continental red beds that reach a maximum thickness of 60-70 meters.

\section{Permian-Holocene Sediments}

The Permian section is capped by an unconformity. This unconformity separates the Permian from the overlying Triassic-age Santa Rosa Sandstone that reaches a maximum thickness of 80 meters. Another unconformity is present that separates the Lower Cretaceous-age Trinity Sandstone from the underlying Triassic section. The Trinity ranges in thickness from 0-10 meters. Separated from the underlying Trinity by another unconformity, the Lower Cretaceous- 
age Edwards Limestone reaches a thickness of 30 meters. Finally, overlying these rocks are the sediments of the Tertiary-age Ogallala Group (up to 30 meters thick) and additional Pleistocene and Holocene alluvial deposits.

\section{TECTONIC HISTORY}

The tectonic and structural information in this section is from Hoak et al. (1998). The Central Basin Platform is a NW-trending uplifted basement block that separates the Midland Basin (to the east) from the Delaware Basin (to the west). The Central Basin Platform (or CBP) was uplifted in mid-late Pennsylvanian time. Until that time, the two basins and the CBP were relatively low relief features within a shallow Paleozoic-age basin that has been called the Tobosa Basin. Following the development of the two individual basins by uplift of the CBP, the Tobosa Basin ceased to exist. The Central Basin Platform represents an uplifted zone of basement rock. As a result, drilling depths to deeper reservoir horizons (e.g. Ellenburger Formation) is much shallower. This shallow drilling greatly improves the economics of wells and fields along this structure.

In Wolfcampian time, the uplift of the CBP ceased, and a regional erosional unconformity developed that beveled off the top of the underlying structures. Above this unconformity, the carbonate reef and related proximal facies were deposited on the relatively flat erosional surface. A consequence of this erosional event and subsequent deposition is that deeper fold and thrust structures are capped by flat-lying carbonate reservoirs at shallower depths. These stratigraphic trap reservoirs, together with the deeper structural traps, represent a complex system of multiple pay zones that greatly increase the economic potential of drilling activity in this area.

The northern termination of the CBP is the Northwest Shelf. The Northwest Shelf represents a broad shelf extending northward to the Palo Duro Basin. This shelf, though only slightly faulted, extends from the Midland Basin to the broad depositional shelf that extends northward to the Matador Arch. The San Simon Syncline represents a narrow sag that separates the CBP from the shelf region. The southern termination of the CBP is the Val Verde Basin. The Val Verde Basin represents a foredeep basin of the Pennsylvanian and early Permian-age Marathon Foldand-Thrust Belt. The Val Verde Basin is filled with over 15,000 feet $(>5,000 \mathrm{~m})$ of flysch and related clastic rocks derived from the advancing thrust sheets.

The Midland Basin represents the primary focus of this study. In cross-section perpendicular to the basin axis, its shape is slightly asymmetric and deepens to the west. The western boundary is delineated by the complex folds and faults that have formed along the eastern margin of the Central Basin Platform (including the Gandu Unit). The eastern basin boundary is somewhat indistinct and is designated the Eastern Shelf. The Eastern Shelf represents a gradual rise from the western, deepest part of the basin. As a result, the eastern boundary of the Midland Basin is somewhat arbitrary.

The Delaware Basin contrasts strongly with the Midland Basin. The Delaware Basin is significantly deeper, is more asymmetric and deepens to the east. Because of its greater burial depth and sediment influx, organic sediments in the Delaware Basin have experienced greater thermal maturity and much of the deeper hydrocarbon reserves have been converted to natural gas. The western margin of the Delaware Basin is bounded by the Salt Flat Graben, a Tertiary-age system related to the Basin-and-Range extensional tectonics. Finally, further to the west, lies the Diablo Platform, a paleogeographic high that has persisted since the Paleozoic. 


\section{FLUTD PRESSURE DATA}

An attempt was made to gather fluid pressure data for comparison with predictions. The wide range of Ector County data in Fig. III-7 does not apparently support a clean pattern of overpressure or underpressure. Apparently, production-related changes in fluid pressure have made a study of the preproduction state of pressure in the Andector Field readily available. However, it appears that the field was norrnally pressured.

\section{E. THERMAL INPUT DATA}

The Permian Basin area of Texas is a Paleozoic basin that has been in a stable configuration for a long time. Fig. III-13 (Katz et al. 1994) shows a burial history of a Central Basin Platform well. In this history,

1) a slowly subsiding basin is filled by secliment for about $250 \mathrm{My}$;

2) a rapid subsidence and basin filling takes place from about 280 to $250 \mathrm{Mybp}$;

3) the area becomes quasi stable for the last $250 \mathrm{My}$; and

4) during this last interval, petroleum generation and migration takes place.

Heat flow in the area has been relatively constant over the Permian basin. Katz et al. (1994) argue that the depth to the oil window across the Central Basin Platform is at a relatively constant depth (Fig. III-14). This uniformity indicates that the temperature profiles have been more or less constant for a long time. In particular, the temperature profiles have been stable during the extended period of stability following the rapid subsidence and deposition at the close of the Paleozoic.

Mineralogically, the entire basin is dominated by carbonates. As a result, the gross physical properties like matrix density and thermal conductivity will be relatively constant with depth. Consequently, the relatively uniform temperature will imply a relatively isotropic heat flow. These observations are consistent with other geochemistry and with observations of current temperature.

Vitrinite reflectance, which behaves to a first approximation as a maximum reading paleothermometer, is linearly related to depth over large parts of the Basin. Because vitrinite reflectance is an effective maximum temperature paleothermometer, we can conclude the paleotemperature history has been linear with depth, at least during the time of oil and gas generation.

Stahl and Carey (1975) published vitrinite reflectance data for a collection of wells in the Delaware Basin segment of the Permian basin. Their data for the Ellenburger Formation are summarized in Table III-1 and presented graphically in Figs. III-15 and 16. We see that the reflectance is a linear function of depth over the basin. The Ellenburger depths considered range from 5,000 to $20,000 \mathrm{ft}$, so this linearity is not just an artifact of considering a small portion of one formation in one area. The relation holds over a large party of the Permian Basin. Fig. III-17 shows an index map locating these wells.

Bostick (1971) published a modification of a graph by Karwell (1956) and Teichmuller and Teichmuller (1968) relating vitrinite reflectance, maturation time, and temperature. Reference to this graph, using a maturation time of time since the close of the Permian (elapsed time since the rapid subsidence), provide estimates of the source rock temperature relationship seen in Fig. III15. That relation would indicate a paleogeothermal gradient of $1.1^{\circ} \mathrm{F} / 100 \mathrm{ft}$. 


\begin{tabular}{|l|r|r|r|r|r|r|}
\hline Field & Form & \multicolumn{1}{|c|}{ Depth } & \multicolumn{1}{|c|}{$R_{0}$} & \multicolumn{1}{|c|}{$R_{0}$ fit } & Age & D-Age \\
\hline Grey Ranch, Blackstone & Elbg & 14350 & 1.9 & 1.75 & 480 & 230 \\
\hline Mi Vida & Elbg & 18250 & 2.25 & 2.26 & 480 & 230 \\
\hline Worsham Bayer & Elbg & 16850 & 1.98 & 2.07 & 480 & 230 \\
\hline Wyatt & Elbg & 7000 & 0.95 & 0.79 & 480 & 230 \\
\hline Pecos Valley - South & Elbg & 7450 & 0.65 & 0.85 & 480 & 230 \\
\hline
\end{tabular}

Table III-1 Vitrinite reflectance values for wells from selected Delaware Basin fields.

Subsurface temperature measurements are generally consistent with this value. Fig. III-16 shows an edited collection of bottom hole temperature observations for the eastern Delaware Basin, Central Basin Platform, and western Midland Basin. Plotting these temperatures as functions of depth, one obtains the geothermal gradient of $0.96^{\circ} \mathrm{F} / 100 \mathrm{ft}$. Given the well-known tendency for bottom hole temperatures to underestimate true formation temperatures, these geothermal gradients can be taken as functionally equal. The editing performed simply eliminated a few wells with bottom hole temperatures that were clearly below those one would expect. The source of the errors could have been errors in measurement, cold drilling mud, etc.

The geothermal gradient estimated here can be used to estimate heat flow in the area. This is a Fick's law problem, and it will allow us to make an estimate of the effective thermal conductivity of the Permian Basin section.

The gradient we estimate is somewhat larger than that of Nichols (1947). See the contours on Fig. III-17. We expect related thermal effects in this area to be more important than one might expect based on classic values from the literature. 
33.00

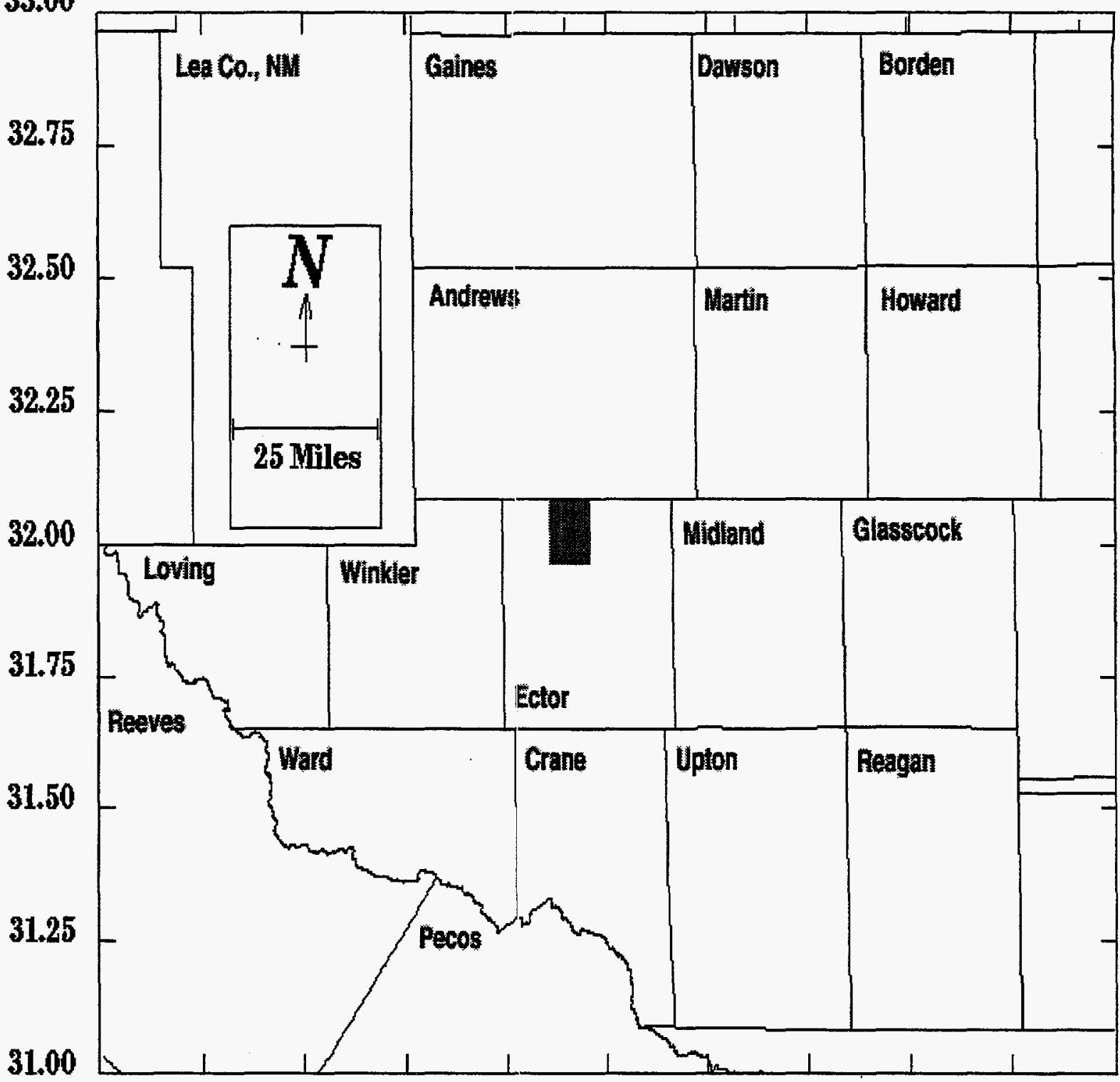

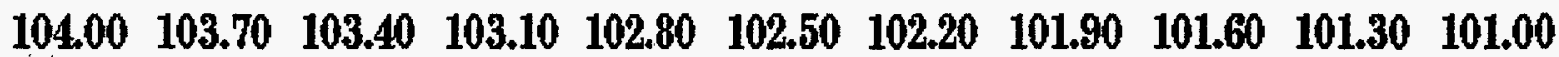

Fig. III-1 Regional map of the West Texas Permian Basin showing the location of our study area, Andector Field (gray box). 


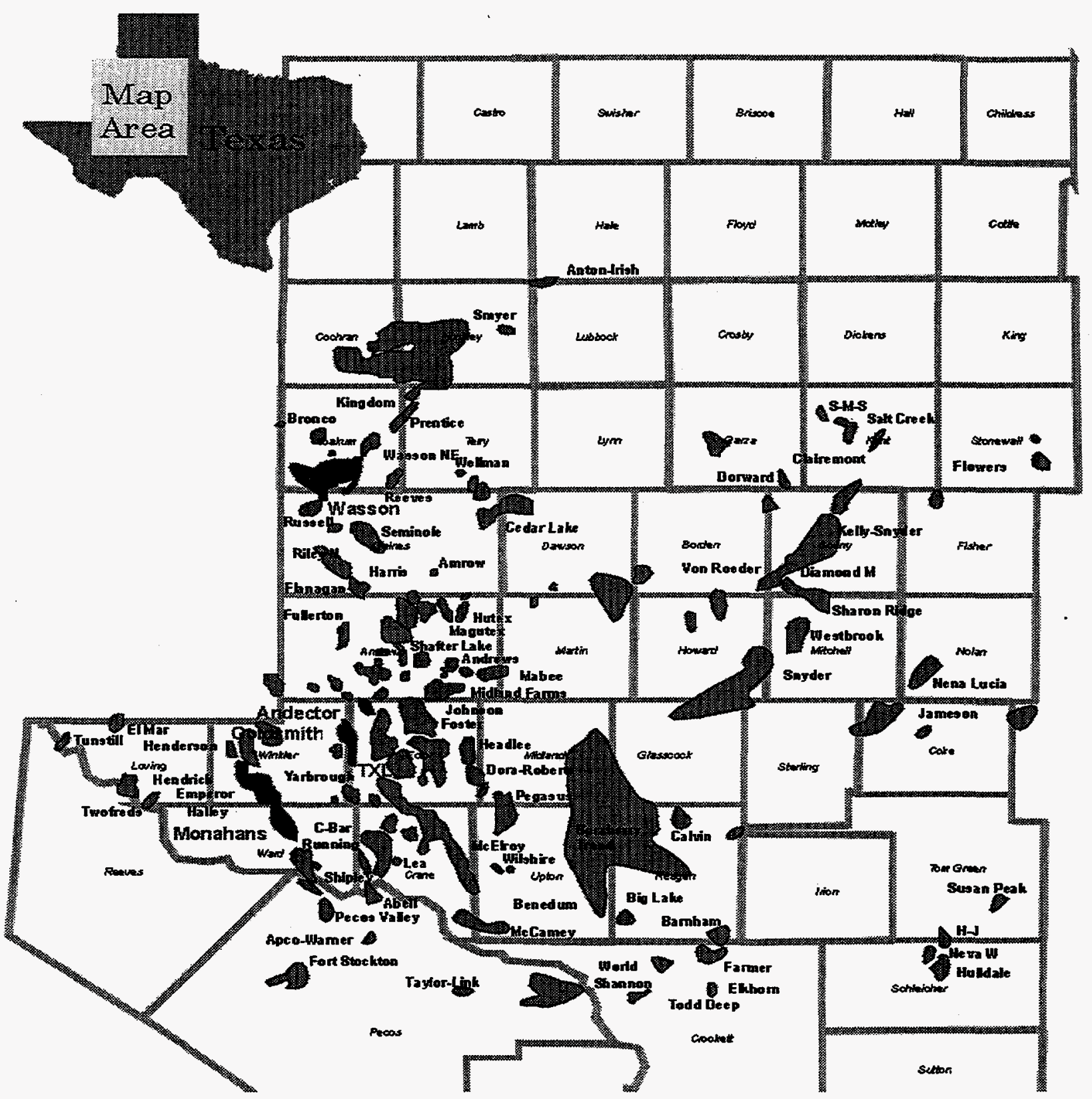

Fig. III-2 Regional map of West Texas Permian Basin showing the location of prominent oil fields, including Andector Field in black in the northeastern comer of Ector County, Texas (Galloway et al. 1983). 

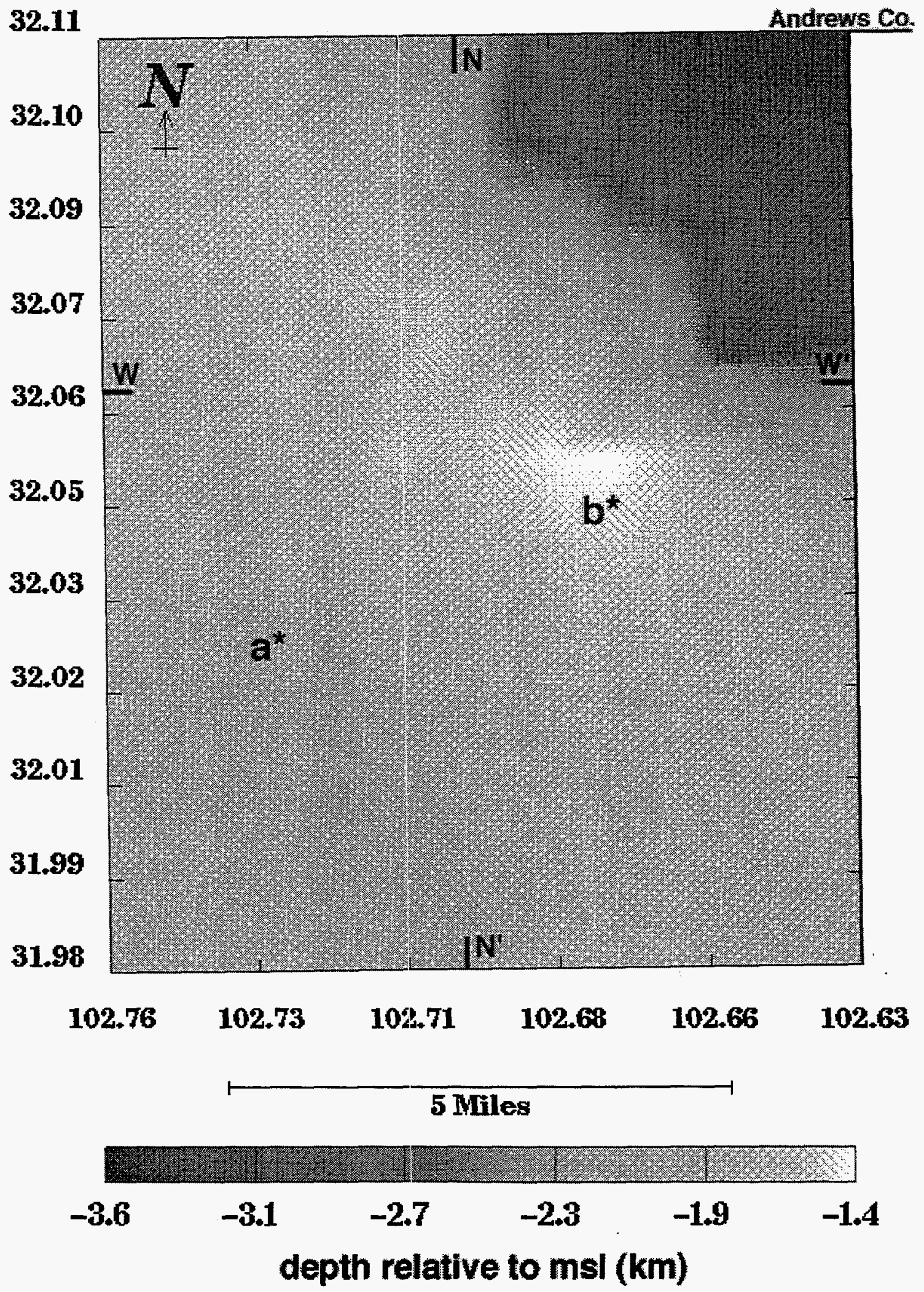

Fig. III-3 Map of Andector Field showing the locations of cross-sections NN' and WW' and the shading is the depth from MSL to the top of the Ellenburger structure (see Fig. III-9 for a detailed Ellenburger structure map). The map also shows the locations of $1-D$ simulations $a$ and $b$. 


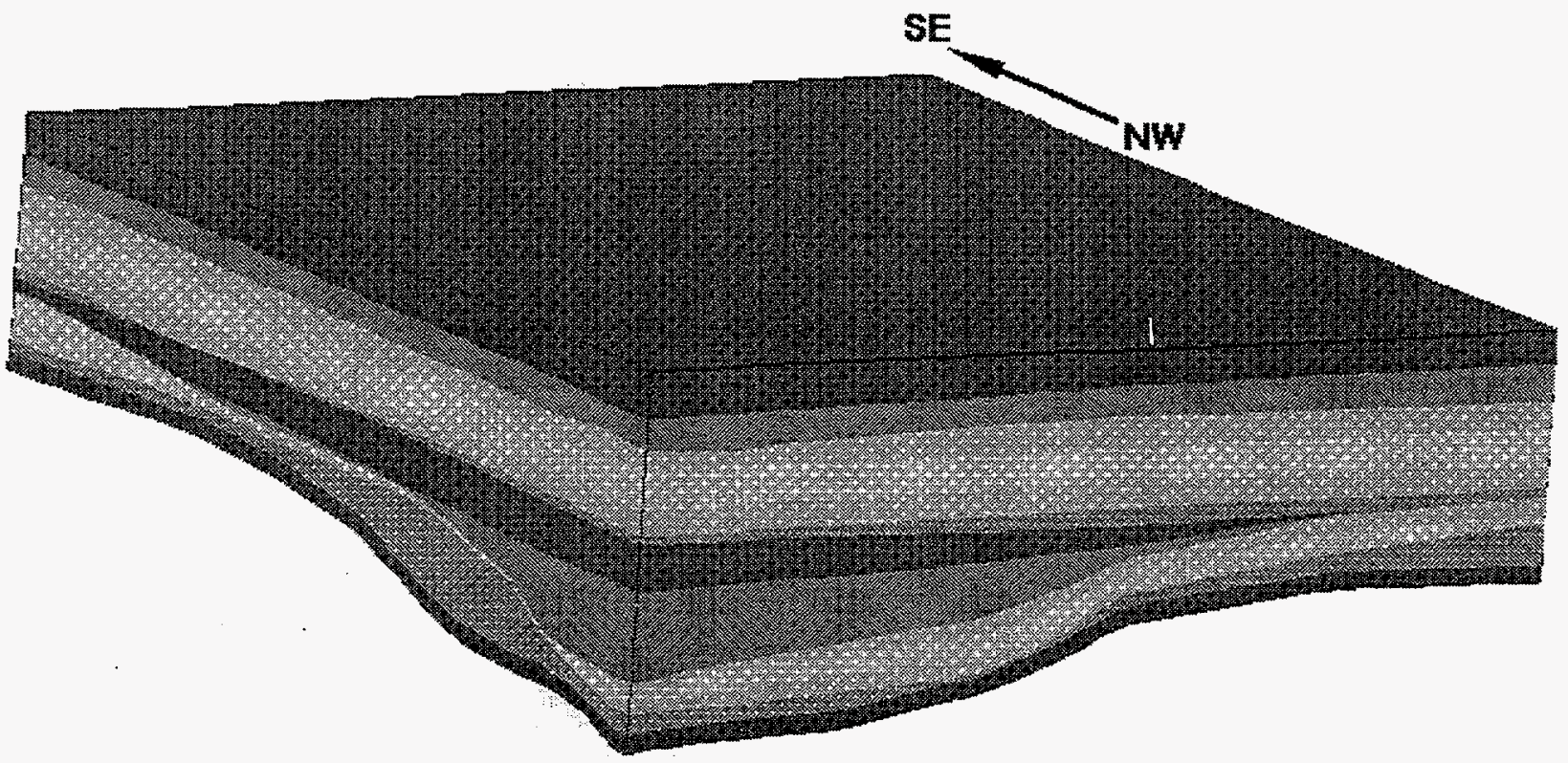

Fig. III-4 3-D prospective of the stratigraphy for Andector Field, gray level variations suggest stratigraphy starting with the Ellenburger at the bottom. See Figs. III-5 and 6 for more stratigraphic detail. In all, fifteen formations were distinguished in our simulations.

\section{$\mathbf{N}^{\prime}$}

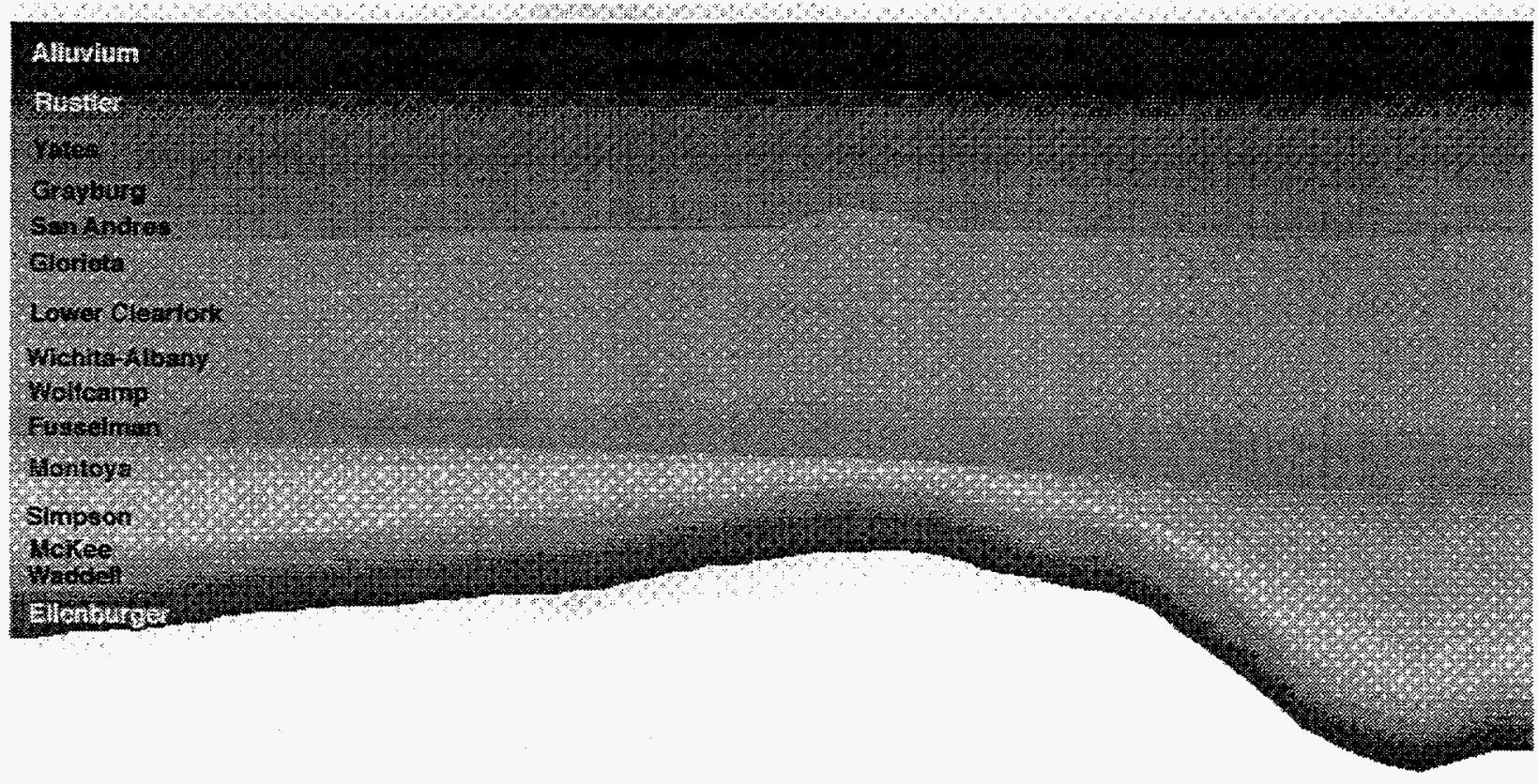

Fig. III-5 NN' stratigraphic cross-section (see Fig. III-3), vertically exaggerated by a factor of 2 to show all formations, going N-S through the north and south fault block shown in detail in Fig. III-9. All formations are labeled. 
W

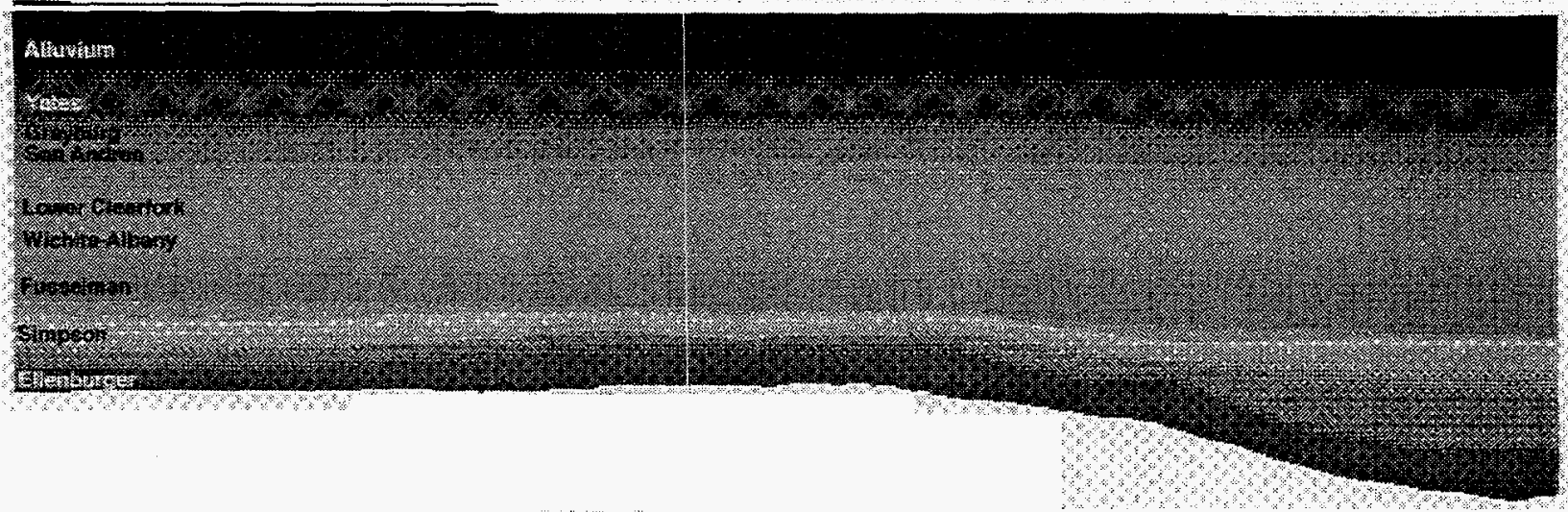

Fig. III-6 Stratigraphic cross-section WW (see Fig. III-11) going W-E along the saddle between the north and south fault block shown in Fig. III-9. Only significant formations are labeled.

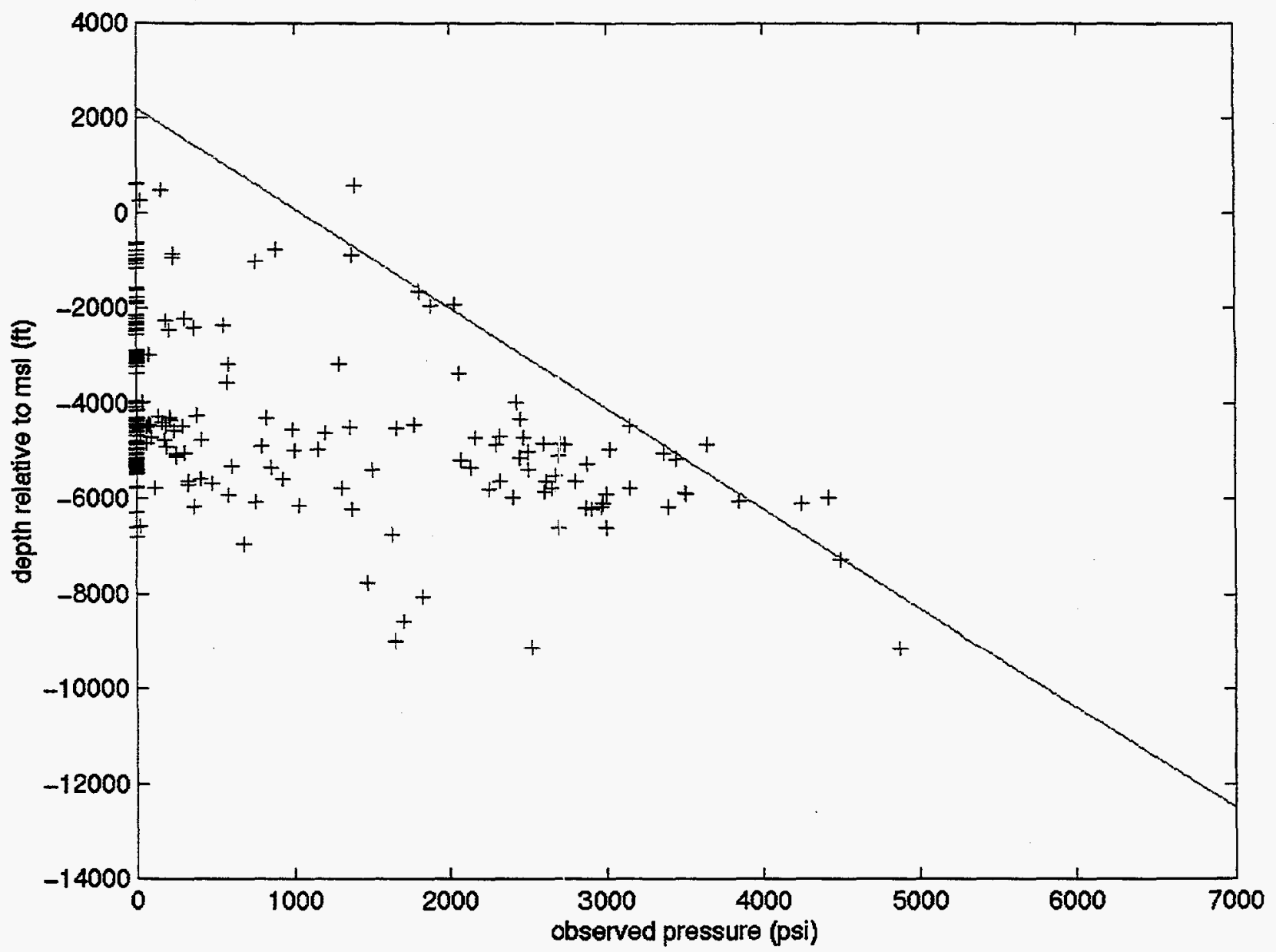

Fig. III-7 Pressure data from Ector County on the Central Platform of West Texas, where depth is relative to mean sea level. The surface elevation is approximately $2,200 \mathrm{ft}$. The straight line indicates a hydrostatic gradient of 0.43 $\mathrm{psi} / \mathrm{ft}$, a somewhat lower value than $0.46 \mathrm{psi} / \mathrm{ft}$ hydrostatic gradient indicated by Powley (private communication). The well-tested interval between -400 and $-7,000 \mathrm{ft}$ is the best indication of a hydrostatic norm. The spread of data in this interval is likely due to modifications in the production procedures (draw-down pressure, injection pressure). 


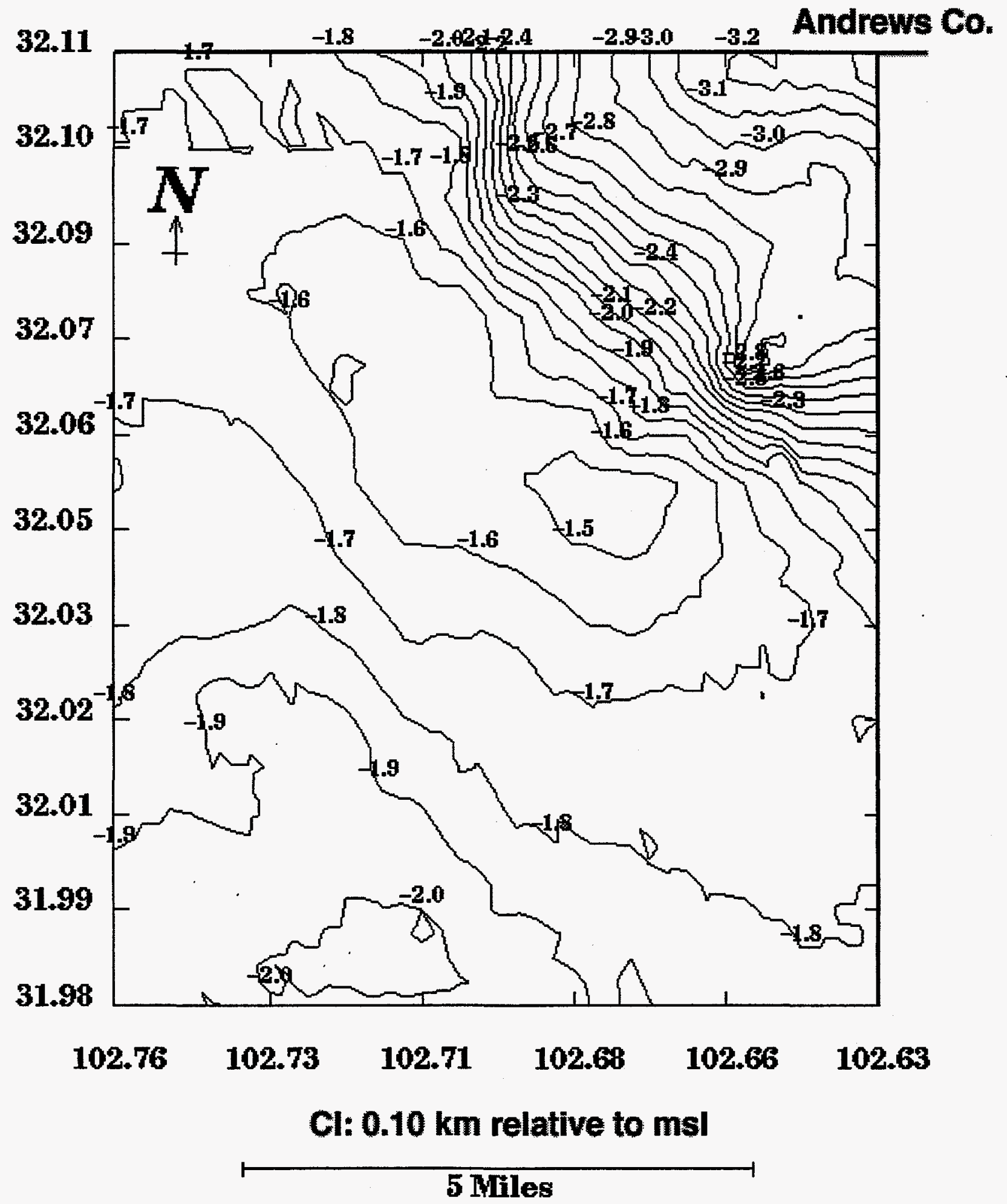

Fig. III-8 Contour map of the depth to the top of the Ellenburger Formation relative to mean sea level; the contour interval is $0.10 \mathrm{~km}$. 


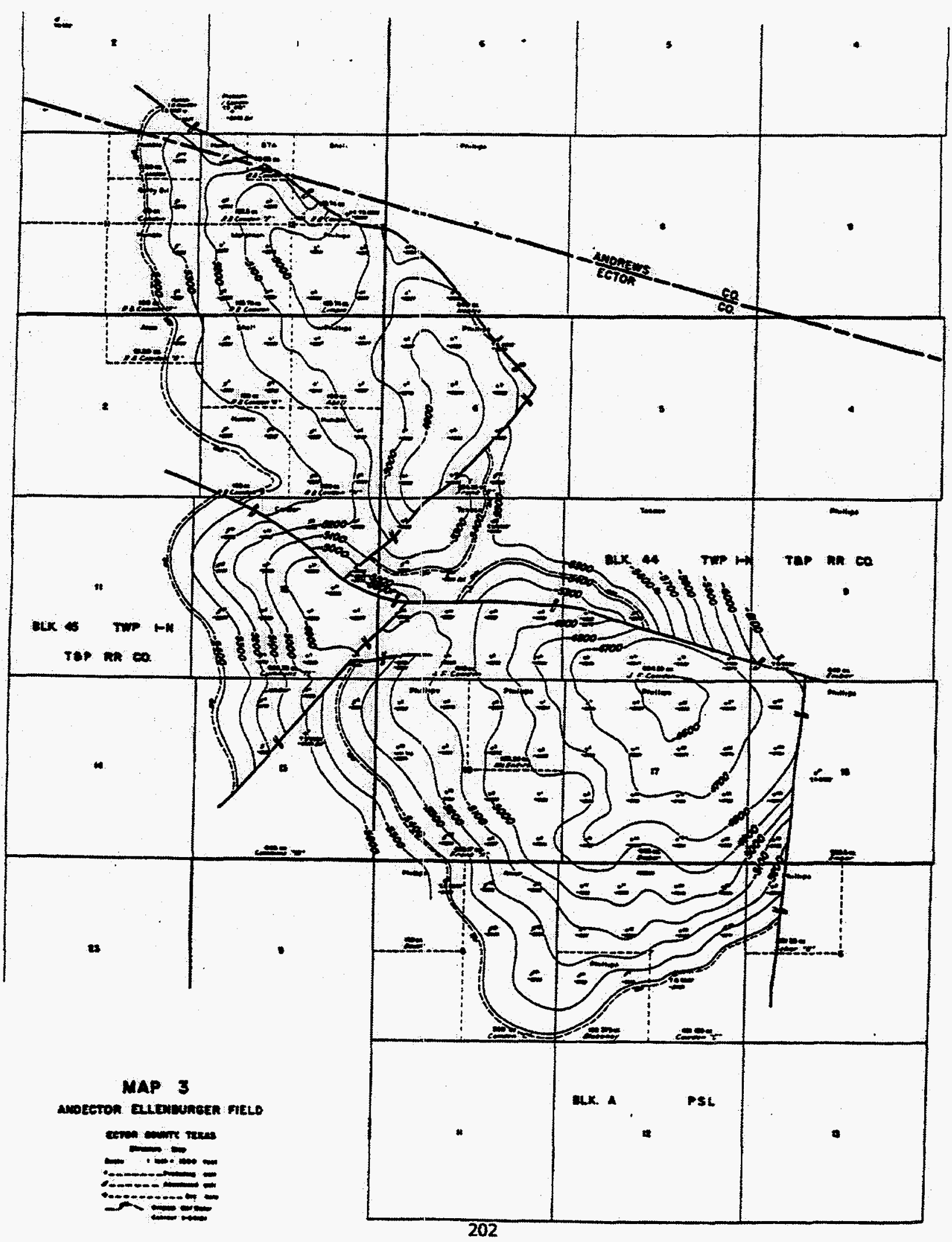

Fig. III-9 Structure map showing faults and oil wells contoured for depth to the top of the Ellenburger Formation (Andector Ellenburger Technical Committee 1972). 


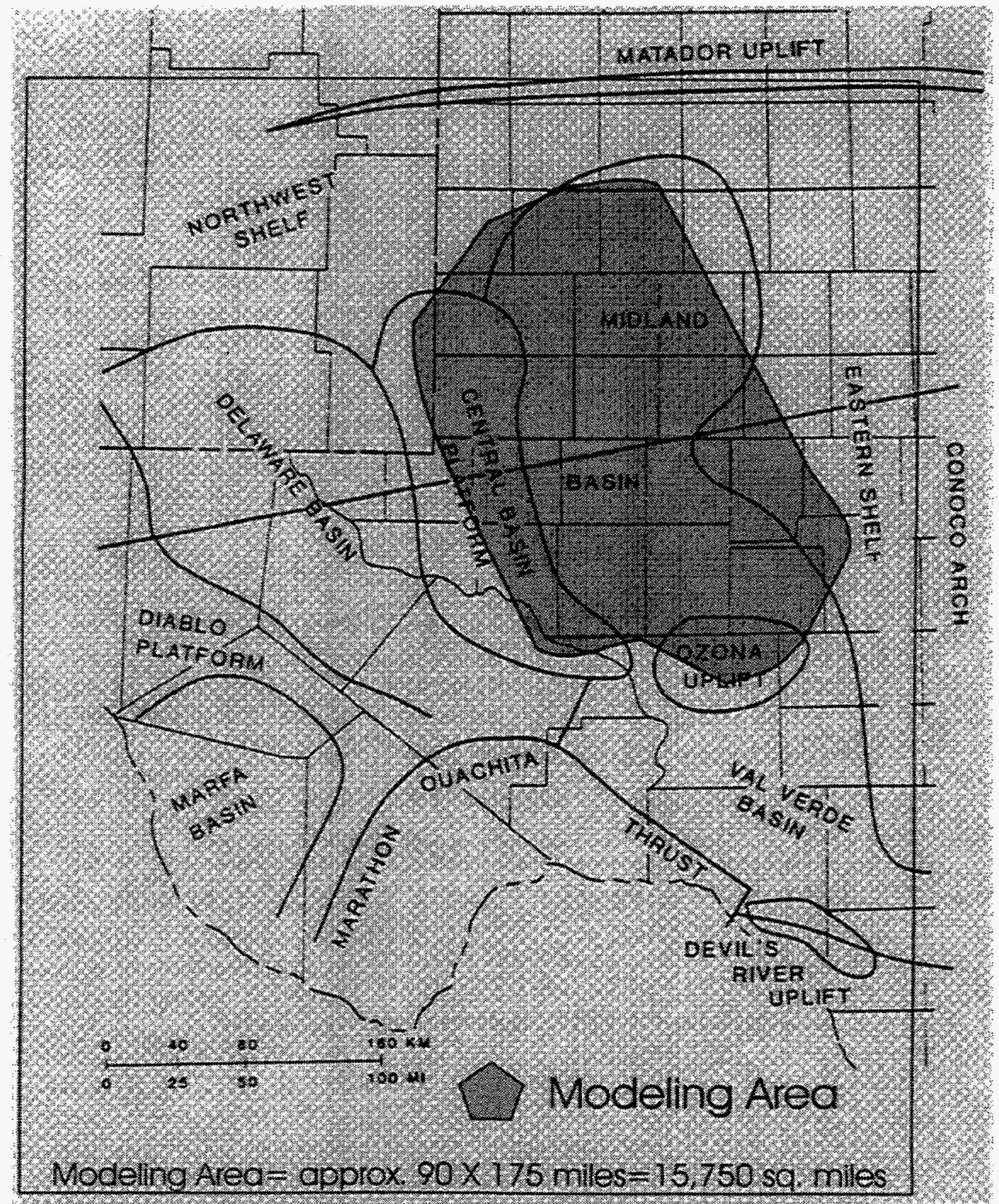

Fig. III-10 Location map of major structural elements in the Permian Basin, West Texas (after Hanson et al. 1991). 


\begin{tabular}{|c|c|c|c|c|c|c|}
\hline SYSTEM & SERIES & $\begin{array}{l}\text { MCRTHWEST } \\
\text { SHELF }\end{array}$ & $\begin{array}{l}\text { CEN:AAL BASN } \\
\text { PLATESRM }\end{array}$ & $\begin{array}{l}\text { UIDLANC EASHN } \\
\text { EASTERH SHELF }\end{array}$ & $\begin{array}{c}\text { DELAWAAE } \\
\text { BASIN } . .\end{array}$ & $\begin{array}{c}\text { YAL VERDE } \\
\text { BASIN }\end{array}$ \\
\hline \multirow{4}{*}{ PEFMIAN } & ecton & $\begin{array}{l}\text { DENEY LAKE } \\
\text { RUETEA } \\
\text { SALADO }\end{array}$ & $\begin{array}{l}\text { OEWCY LAKI: } \\
\text { AusTLER } \\
\text { SALICO }\end{array}$ & $\begin{array}{l}\text { DEWEY LAKE } \\
\text { RUSTLER } \\
\text { SALEDO }\end{array}$ & $\begin{array}{l}\text { CEYEY LAXE } \\
\text { RUSTLER } \\
\text { EANOOO } \\
\text { CASTLE }\end{array}$ & $\begin{array}{l}\text { ALSTLEFR } \\
\text { SALROO }\end{array}$ \\
\hline & Elsonorude: & $\begin{array}{l}\text { TAMBILL } \\
\text { YATES } \\
\text { SEVEN RIVEAS } \\
\text { CUCDN } \\
\text { GRAYEUAG } \\
\text { SAH ANDFES }\end{array}$ & $\begin{array}{l}\text { TANSHL } \\
\text { YATES } \\
\text { SEVEN preIRS } \\
\text { OUEE M } \\
\text { GRAY WUAO } \\
\text { SAN ANORES }\end{array}$ & 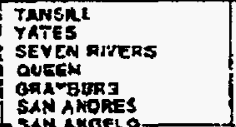 & $\begin{array}{l}\text { DELAWARE MT GAOUP } \\
\text { EELL CAMYON } \\
\text { CMERAY CANYOU } \\
\text { BAUSHYY SAKYOH }\end{array}$ & 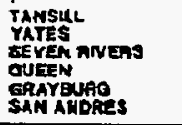 \\
\hline & LEOHAAD & $\begin{array}{l}\text { GLORETh } \\
\text { YEso OL.AR rafik } \\
\text { WICHITA }\end{array}$ & 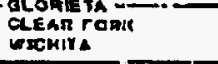 & $\begin{array}{l}\text { SAN ARGELO } \\
\text { LEOUARO } \\
\text { SPRAYSERPY, DEAH }\end{array}$ & IDNE SPRWG & LEUNAPD \\
\hline & WOLFCAMP & wOCFEAWP & WORFSAMP & WOLFCANP & WOLFEAMP & WDLFGAMP \\
\hline \multirow{4}{*}{ PEMYSTEVAMUN } & MUAGL & - insed & EASCE & $\begin{array}{c}\text { TNOSENT } \\
\text { THR } \\
\text { THNSTSO }\end{array}$ & (ABSENT CA THAN) & UABSENT OF IMWO \\
\hline & DES MOINES & 3TAAWN & SThAWh & STRAWN & STRAWN & ST aAm \\
\hline & Arox $A$ & AToka & atori & ATOKA & ATOKA & Aroxa \\
\hline & MOAREพ & MORnaw & (ADSENT) & (NASENT) & Mópk ow & LASENTI \\
\hline \multirow[t]{2}{*}{ IMESTSBIPLAN } & \multirow{2}{*}{$\begin{array}{l}\text { CrESTFG } \\
\text { MEAEMEE } \\
\text { OSAGE } \\
\text { KWDEA- } \\
\text { HanK }\end{array}$} & \multirow{3}{*}{ 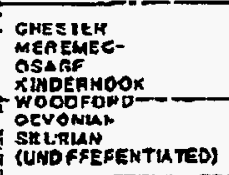 } & $\begin{array}{l}\text { GHESBFE } \\
\text { MEREMEC- } 4 \text { AMe } \\
\text { OSACSE }\end{array}$ & $\begin{array}{l}\text { CKESTEA } \\
\text { MEHEMEC- } \\
\text { OSAGE }\end{array}$ & 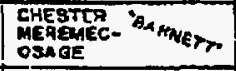 & $\begin{array}{l}\text { Mrasurec- 'Bamat } \\
\text { OSAGE }\end{array}$ \\
\hline & & & $\begin{array}{l}\text { TINDERHOOK } \\
\text { WOOORORS } \\
\text { DEVOHHN }\end{array}$ & 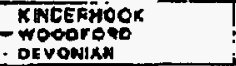 & 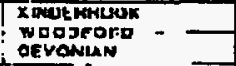 & $\begin{array}{l}\text { WOOO=OAO } \\
\text { DEVOKLAN }\end{array}$ \\
\hline SSLUAIRN & & & $\begin{array}{l}\text { 3R URTAN Fon } \\
\text { FUSSFI MAM }\end{array}$ & $\begin{array}{l}\text { GLUTLNA SN } \\
\text { : FUSSELMAN }\end{array}$ & $\begin{array}{l}\text { WiL. SRinnaw } \\
\text { FUSSELMAN }\end{array}$ & $\begin{array}{l}\text { WD. ST. IHAThN } \\
\text { FUSSEL MAN }\end{array}$ \\
\hline \multirow{3}{*}{ OROOVICAAN } & UEPER & MONTOYA & MONTOYA & $\begin{array}{l}\text { svifan } \\
\text { monteya }\end{array}$ & $\begin{array}{l}\text { SYLEAN } \\
\text { HONTOYA }\end{array}$ & $\begin{array}{l}\text { srivan } \\
\text { nowrova }\end{array}$ \\
\hline & MPOLE & 9nNoson & sapanin & $\operatorname{sanFSON}$ & seles & Smpson \\
\hline & LEWEA & ELLENOUTOER & ELLERgUACIER & EILENEUACEA & 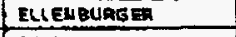 & ELEHUUAOER \\
\hline CAnepian & UPPEA & Lamsнй & LMmeจixy & CAmbaian & OANERIAN & EAMEALAN \\
\hline
\end{tabular}

Fig. III-11 Stratigraphic nomenclature of the Permian Basin (modified after Hanson et al. 1991). 


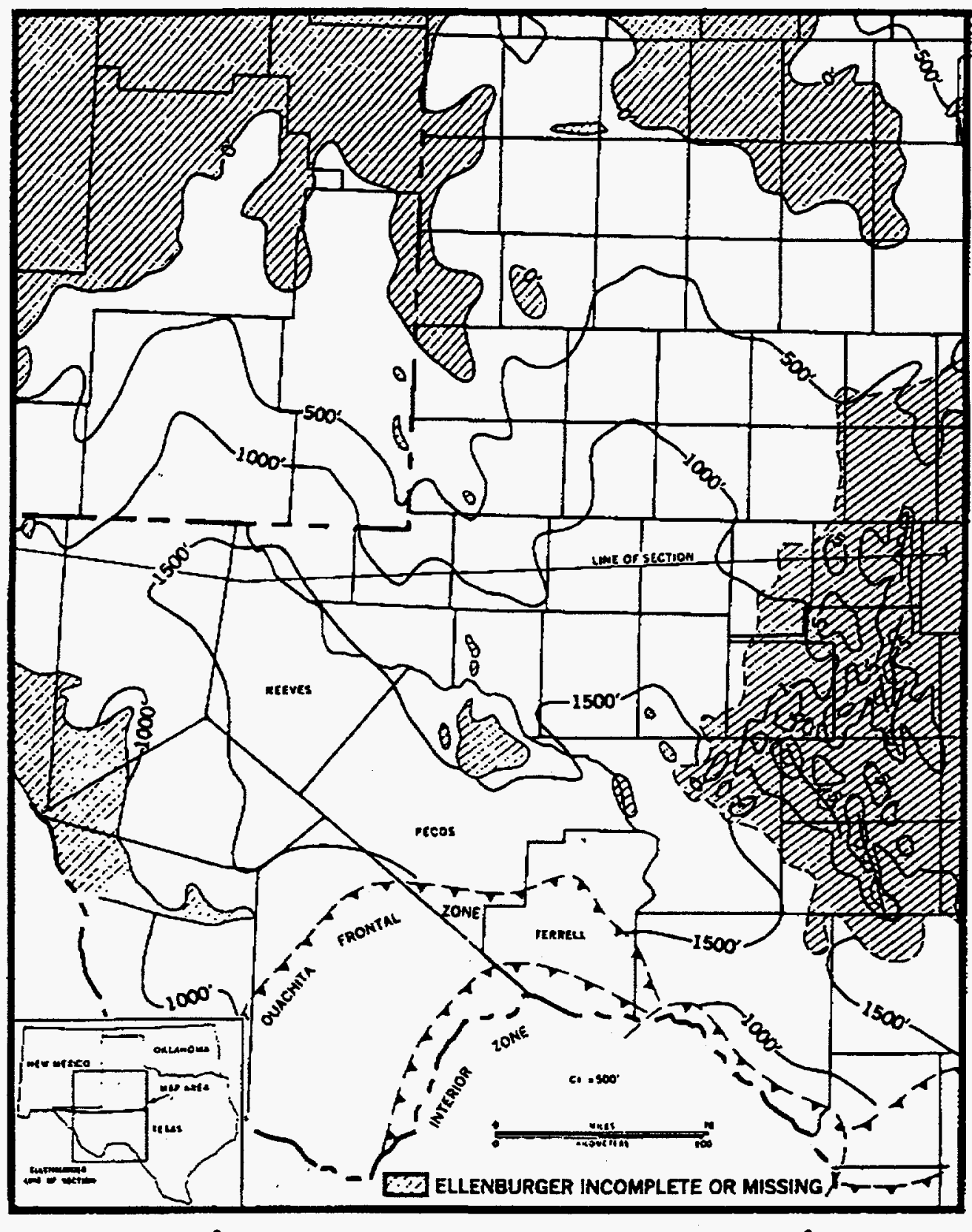

Fig. III-12 Isopach map of the Ellenburger Formation and an E/W stratigraphic section across the region. Datum is top of lower Ellenburger (modified after Hanson et al. 1991). 


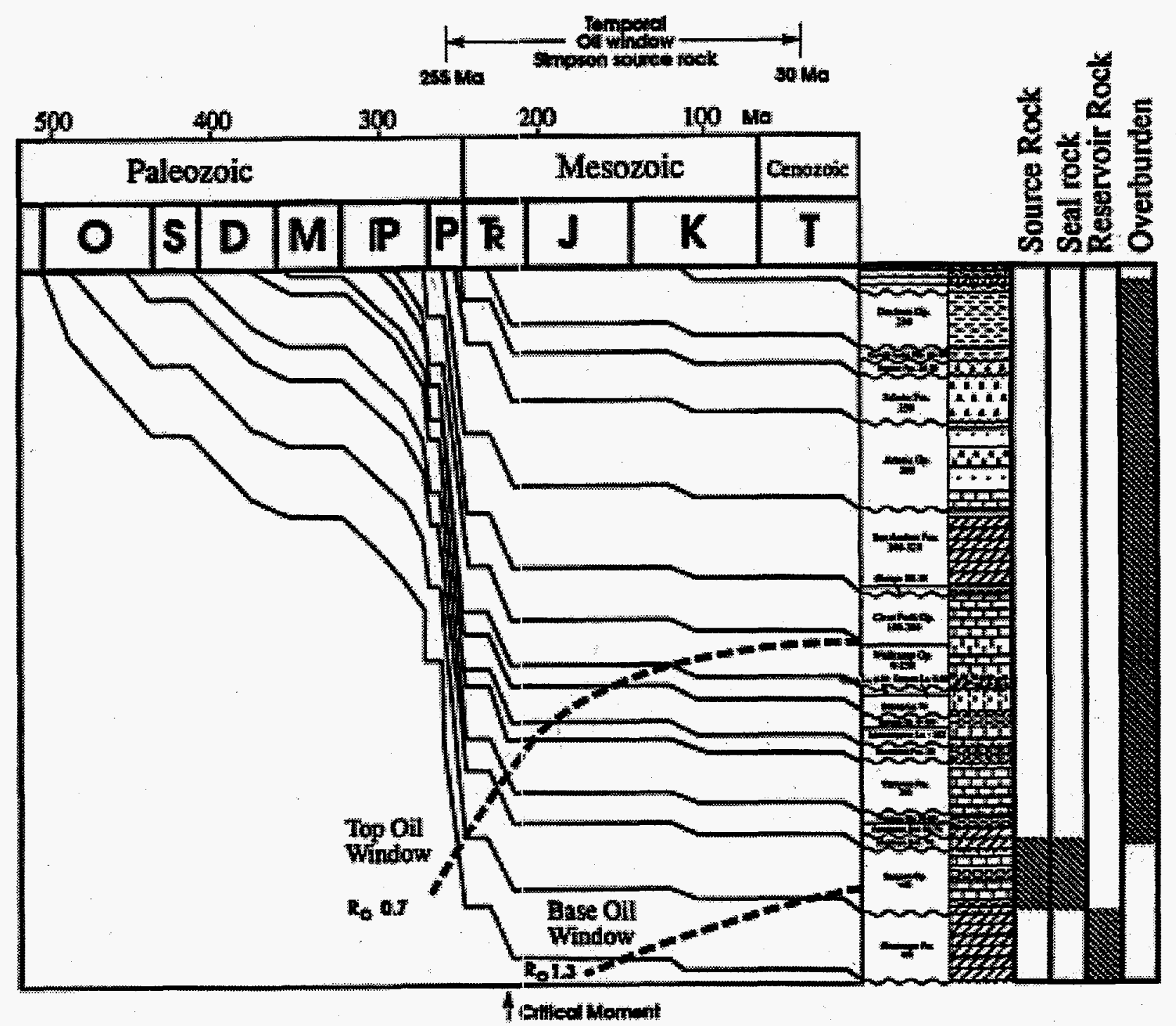

Fig. III-13 Idealized burial history of a Central Basin Platform well (Katz et al. 1994). Not rapid deposition at the close of the Paleozoic and relative stability thereafter. 


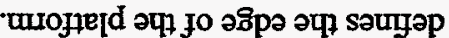

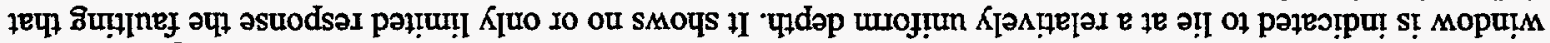

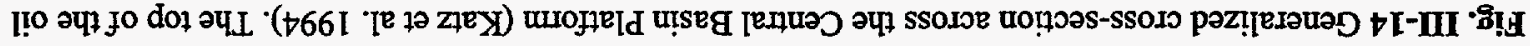

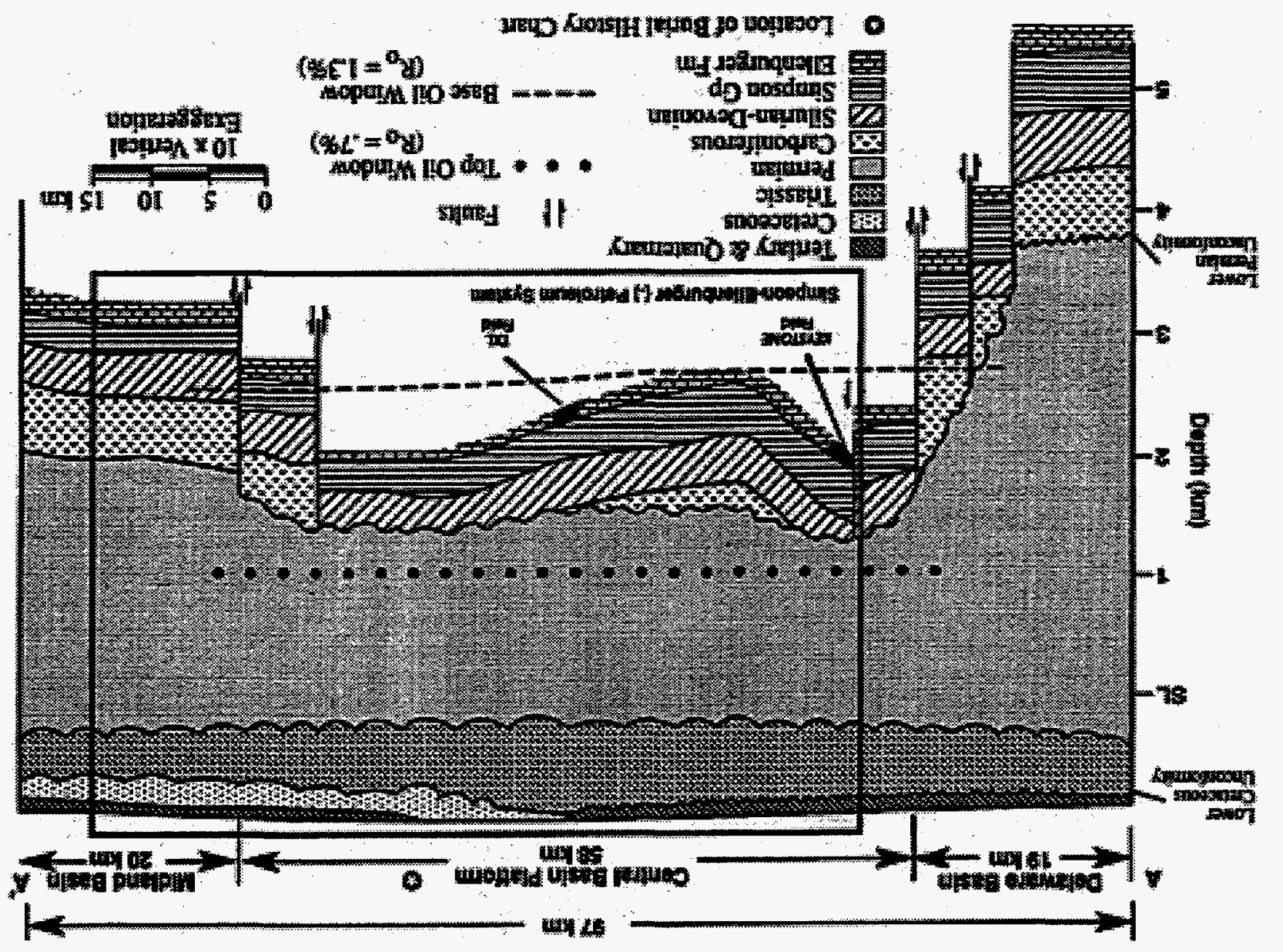




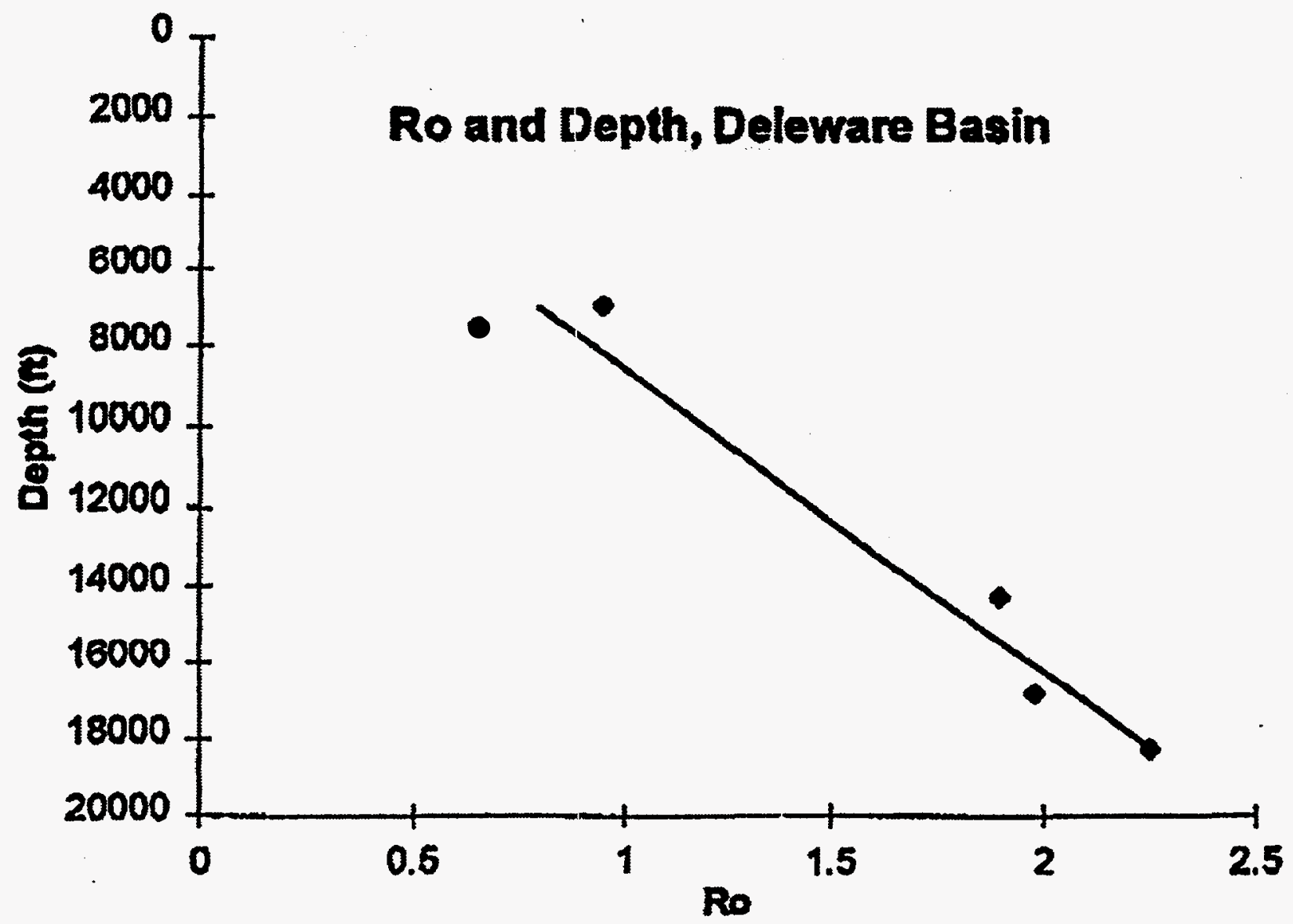

Fig. III-15 Vitrinite reflectance as a function of depth for selected Delaware Basin Wells.

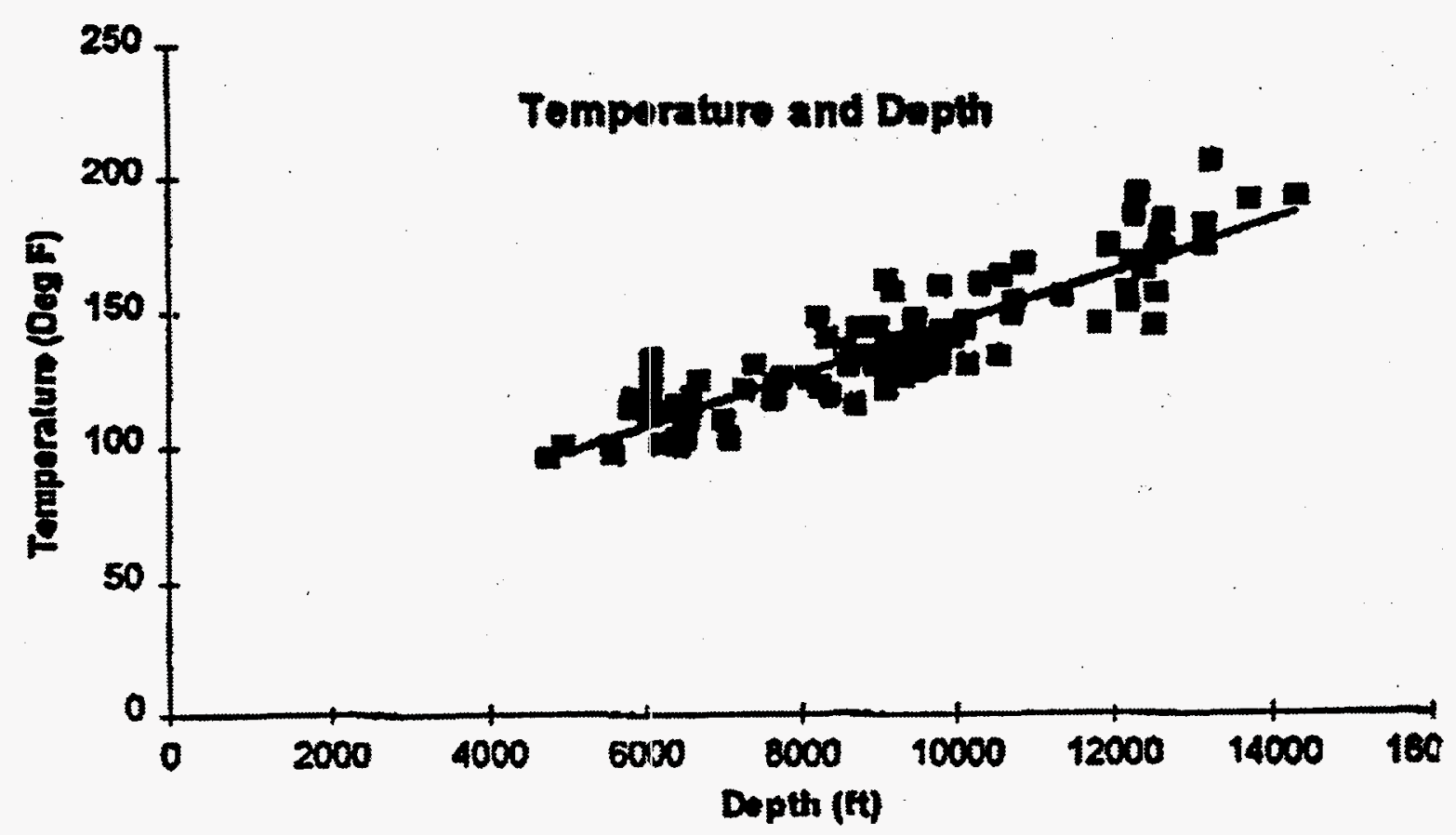

Fig. III-16, Model temperature (Bostick 1971) of the Ellenburger formation in the Delaware Basin. Permian Basin 
bottom hole temperatures and least squares fit to produce an effective geothermal gradient.
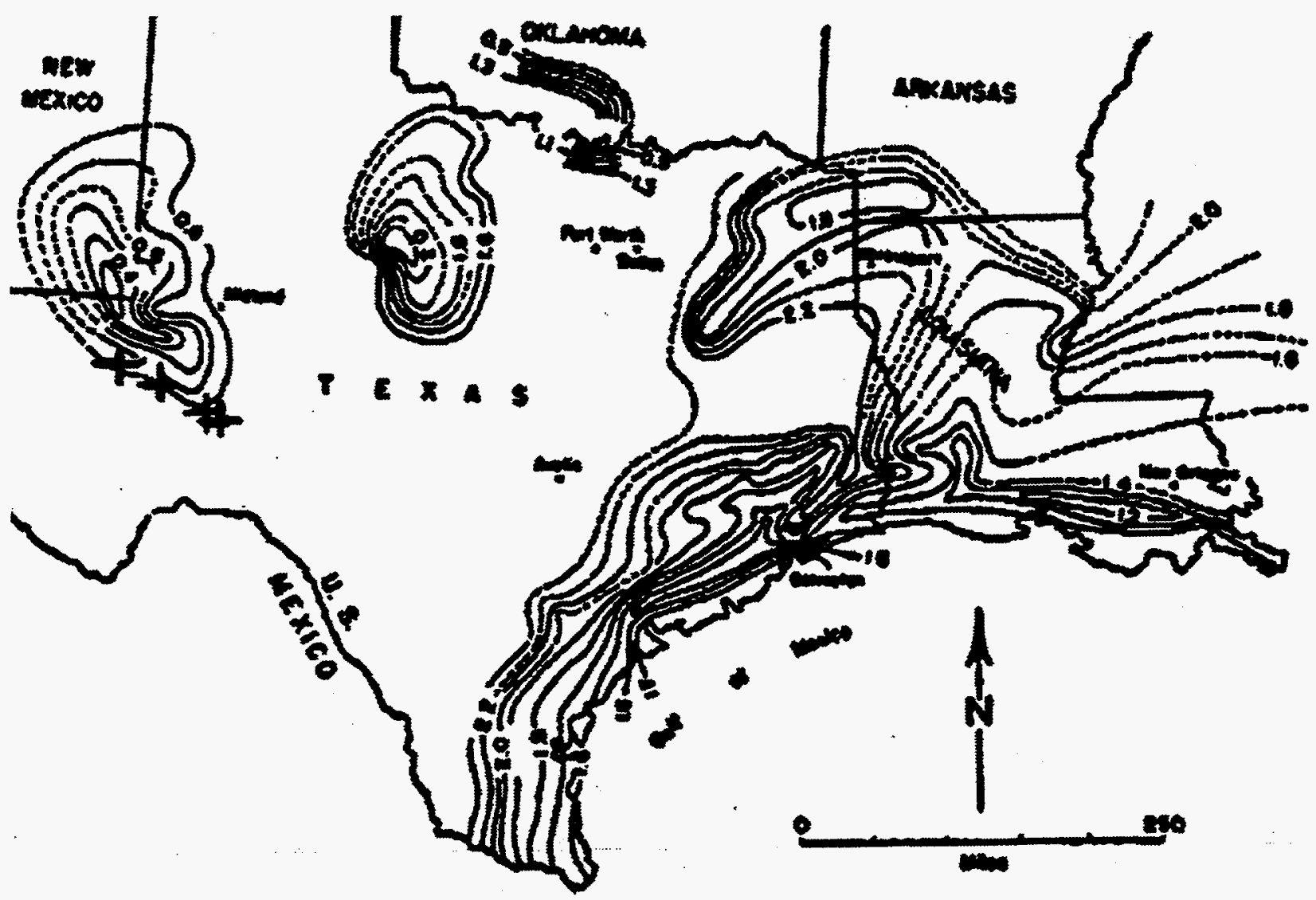

Fig. III-17 Location of the Permian Basin wells from the Stahl and Carey data. 



\section{ORGANIC KINETICS AND TRANSPORT}

\section{A. THE OIL GENERATION/EXPULSION/TRAPPING PROBLEM}

Understanding the preproduction state of the petroleum system certainly includes an estimate of the in-place petroleum. To do so we used our basin model, recognizing that the expulsion, migration and leakage timing depended both on the time window of generation and the history of fracturing thereafter. In this section, we briefly discuss the conceptual model used (namely the Uplift was a closed petroleum system) and the specific oil generation kinetic model used.

\section{B. SIMPSON AND ELLENBURGER SOURCE ROCKS}

Source rock is believed to exist in the Simpson Group (Katz et al. 1994) and possibly in the Ellenburger Formation (Hanson et al. 1991) on the Central Basin Platform. Since the Ellenburger Formation is also a reservoir, we have decided to include it as a source rock because of the following problems:

a. there is the possibility of a vertical seal separating the Delaware Basin from the Central Basin Platform (Yang and Dorobek 1995);

b. thus, our Andector study region does not include the Delaware Basin wherein the Ellenburger Formation is known to be a source rock (Stahl and Carey 1975);

A. thus, we neglected Delaware Basin Ellenburger and Simpson sourcing petroleum that migrated to Central Uplift reservoirs, i.e., the Ellenburger and Simpson in the Andector field did not receive any petroleum from the Delaware and (also by assumption) the Midland Basins; and

c. the buoyancy of oil relative to water prevents oil migration downward from the higher lying Simpson Group source to Ellenburger reservoir, a further argument for Ellenburger selfsourcing.

Simpson original organic content was estimated from Katz et al. (1994) while that for the Ellenburger source was estimated from data in Andector Ellenburger Technical Committee (1972).

\section{ORGANIC KINETIC FORMULATION}

In this study, petroleum generation is described by a new model wherein kerogen molecules are assumed to be specified by a set of integers $\underline{m}=\left\{m_{1}, m_{2}, \ldots m_{N}\right\}$ where $m_{i}$ is the number of $i$-type subunits (or "bonds" of type $i$ ). The theory is based on the development in time of the concentration (moles/rock volume) of $\underline{m}$-type molecules. A special case of the model is that based on the assumption that the rate limiting step for the generation of an "average" molecular weight petroleum molecule is for release of one such molecule at a time from the end of a large kerogen polymer. The result of this model is the production rate $R$ (moles/rock volume-time) for these average molecule. One finds:

where

$$
R=\frac{2 \omega \rho_{c} \chi}{m_{x}} \sum_{m=1}^{m_{x}}\left(m_{x}+1-m\right) \frac{\tau^{m-1}}{(m-1) !} e^{-\tau}
$$


$\rho_{c}=$ moles/sediment volume of TOC at sediment input;

$\omega=$ the fraction of TOC that will, after long times, become average petroleum molecules, divided by the number of carbon atoms in the average petroleum molecule;

$m_{x}=$ the maximum number of equivalent (long time releasable) average petroleum molecules in the original kerogen molecule; the latter are assumed to have anywhere from 1 to $m_{x}$ such units with equal probability at the time of sediment deposition.

The parameter $\tau$ increases monotonically with time and is given by

$$
\tau=\int_{0}^{1} k d t
$$

where $k$ is the rate coefficient for the reaction liberating the average petroleum molecule from the kerogen precursor; note $k$ depends on temperature through the formula:

$$
k=k_{o} \exp \left(-E_{a} / R_{g} T\right)
$$

for prefactor $k_{o}$, activation energy $E_{a}$ and gas constant $R_{g}$. The values used for $k_{o}$ and $E_{a}$ are from Hunt, Lewan, and Hennet (1991) for Type IIA kerogen:

$$
\begin{aligned}
k_{o} & =2.7 \times 10^{13} \mathrm{sec}^{-1} \\
E_{a} & =180 \frac{\mathrm{kJ}}{\mathrm{mol}}
\end{aligned}
$$

For the Simpson and Ellenburger source rocks considered here we assumed that

$$
\begin{aligned}
& \rho_{c}=7 \mathrm{~mol} / \mathrm{lt} \\
& \omega=I^{\prime} / 3 \\
& m_{x}=1000 \mathrm{gm} / M_{\text {avg }}
\end{aligned}
$$

where $M_{\text {avg }}$ is the average molecular weight of Andector Field crude oils (102gm $<M_{\text {avg }}<202 \mathrm{gm}$ ).

The above data yields a window of oil generation that manifests itself as a pulse or broad period of oil production rate. A set of cases is seen in Fig. IV-1 where $R(t)$ is plotted vs. time. 


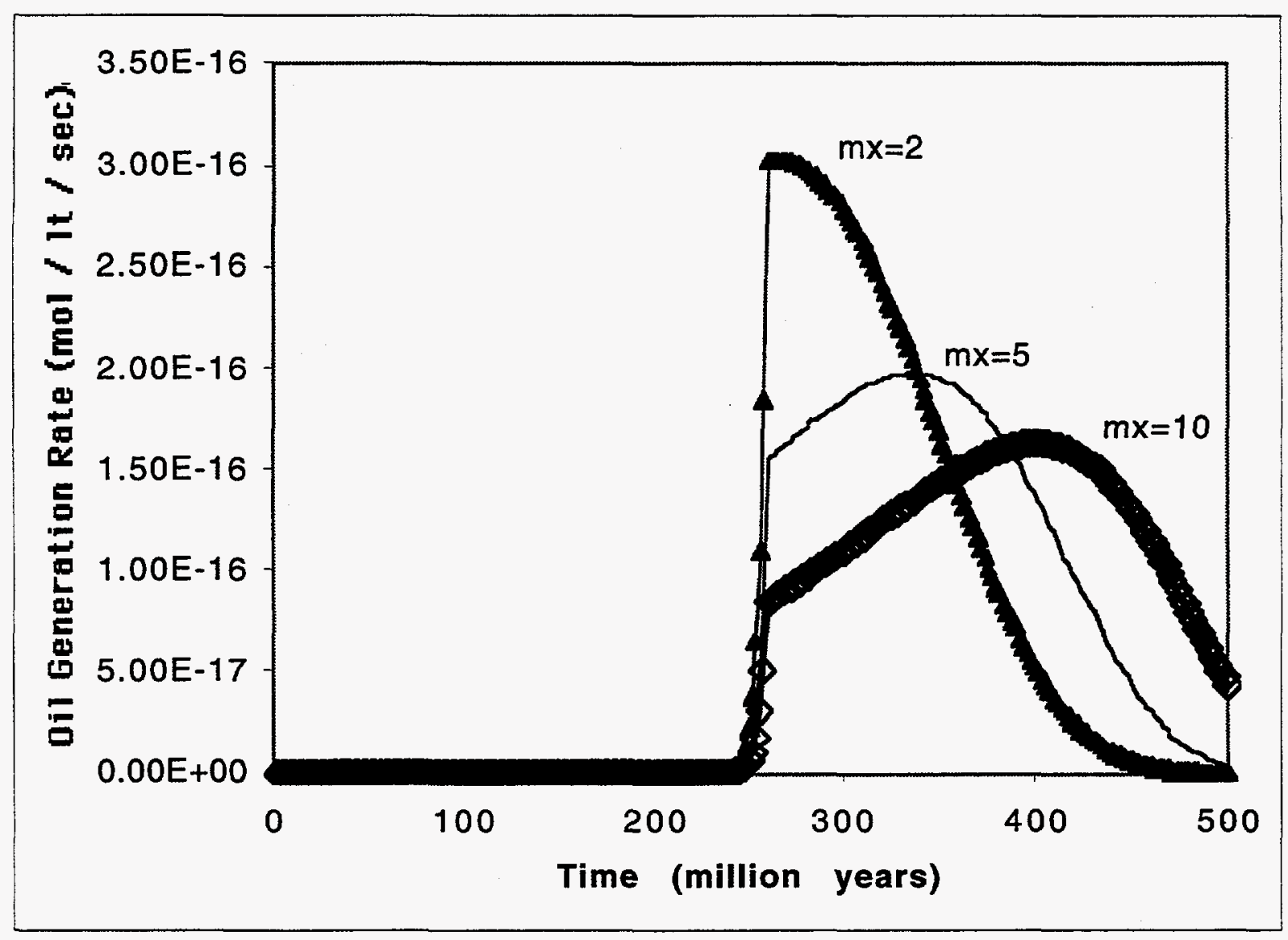

Fig. IV-1 The rate of oil production $R$ according to the model of Section IV can be as a narrow pulse or a broad peak depending on the values of parameters used. 



\section{1-D SIMULATIONS}

\section{A. Overview}

A series of 1-D simulations was carried out to investigate the role of a number of factors in creating naturally fractured petroleum reservoirs. These include:

- paleo-overpressuring;

- sources of petroleum presently in Ellenburger and overlying Simpson reservoirs;

- brittleness/ductility;

- evolution of natural fracturing over the basin's history and its role in expulsion, and migration/seal breaking; and

- importance of multi-phase flow characteristics in the characteristics and location of the fracture network.

Results are as follows.

1-D simulations are not computationally demanding (taking from 2-48 hours) so that many experiments were carried out to insure that some poorly constrained rheological and other physico-chemical data were reasonably chosen. Due to the symmetry of a 1-D simulation, the following limitations are encountered:

- principal stress axes are vertical and any two (equivalent) horizontal directions;

- fractures are therefore vertical and in any orientation with respect to north;

- flexure plays no role; and

- fluid flow and thermal transport are purely vertical.

With these cautions, 1-D simulations are found to be instructive as follows.

\section{B. Case 1 (Site a)}

In these simulations and those to follow, time is indicated as time elapsed from the origin of the simulation, e.g., 500 million years ago. Thus, time zero represents 500 million years ago. The designation $\mathrm{My}$ indicates the number of millions of years of simulated evolution. Thus, $350 \mathrm{My}$ means 150 million years ago.

This simulation was carried out using the sedimentation and subsidence history appropriate for Site a of Fig. V-1. Fig. V-2a shows the evolving porosity/depth profile. As suggested in the final time (present-day) profile $(500 \mathrm{My})$, the lithologic control on porosity is strong. This is simply related to the strong dependence of compaction rate on grain size, porosity and mineralogy.

The history of porosity at the bottom of the Ellenburger formation is seen in Fig. V-2b for this case. The inflection point at around $230 \mathrm{My}$ reflects the burial rate's increase at that time. Note that the rate of burial therefore affects the rate of compaction and thereby the rate of petroleum expulsion and overpressure-driven fracturing. Clearly, the scenario of many key parameters determining present-day reservoir characteristics depends on the evolving history and not only on the present-day state.

A key parameter for understanding nontectonic fractures is found to be $\xi$,

$$
\xi=\frac{\text { shear vis cosity }}{\text { bulk vis cosity }}
$$


Low $\xi$ rocks tend not to fracture in the absence of tectonic effects (flexure or overall extension). Low $\xi$ rocks can arise either:

i) due to low shear viscosity as for rock salt or poorly lithified shales; or

ii) high bulk viscosity as occurs even in sandstones as porosity becomes small.

Low $\xi$ rocks derive their brittleness from their inability to deform so as to equalize least compressive stress with greatest compressive stress.

Operation of this viscosity ratio principle is seen in the simulated fracture permeability for this rheologic calibration. Note that $\xi$ was relatively large early on and, hence, the Ellenburger (lowest segment) is seen to have fractured (i.e., fracture permeability is fairly large). However, in Fig. V-4c(3), the Ellenburger fracturing is lost and $\xi$ has decreased markedly because bulk viscosity increases faster with porosity than does shear viscosity.

The overpressure (Fig. V-2d) is seen to develop significantly in this simulation. This is in disagreement with the observed, preproduction fluid pressure for this field (see Fig. III-7). There are three likely reasons for this discrepancy:

- overpressured fluids cannot escape laterally in a 1-D simulation;

- it is difficult to fracture ductile layers without tectonic effects (or chemically- or thermallyinduced rock shrinkage) in 1-D as any increase in fluid pressure is met with a corresponding increase in lateral stress (and thereby repressing extensional fracturing)-see Fig. V-2c; and

- inadequate rock rheological calibration.

These problems are addressed in later simulations.

Finally, the stress profiles seen in Fig. V-2e illustrate another deformation principle. In brittle zones, the lateral stress tends to mirror the fluid pressure. This is another manifestation of a 1-D effect.

These 1-D results illustrate that while 1-D simulations can be used as a rough calibration, there is danger in relying on them completely as they introduce mechanical (and hydrologic) artifacts that may result in inappropriate calibration, i.e., making the rocks artificially brittle to capture known fractures that are actually flexure-derived.

\section{Case 2 (Site b)}

These results were obtained using the same calibration as for Case 1. The predictions (see Fig. V-3), are similar to those for Site a.

\section{Calibration Runs}

Many 1-D simulations were carried out to help establish reasonable values for the rheologic and organic kinetic parameters. Over 250 simulations were done. Parameters used to check the reșults with observed Andector Field behavior were

- porosity;

- presence of fractures;

- fluid pressure; and

- permeability.

\section{E. Pulsatile Petroleum Expulsion}

The improved calibration was used to revisit Site a, now including oil generation in the model. An important phenomenon was observed when the lithologic character of the lower Simpson was 
modified to reflect its sealing properties for the Ellenburger, i.e., the grain size in the lower Simpson was reduced to reflect the presence of mudstones there.

The results are seen in Fig. V-4. A pulsatile oil expulsion form the Ellenburger formation is seen to be the result of coupling of fracturing and overpressure. The latter is derived from oil generation, compaction and fluid thermal expansion. This phenomenon has been observed in other contexts (see Ortoleva 1994; Dewers and Ortoleva 1994; Ortoleva 1998; and references cited therein). This fracture-flow cycling has been termed the OFEC cycle (overpressuring, fracturing, escape of fluids, and closure [or healing] of fractures). 


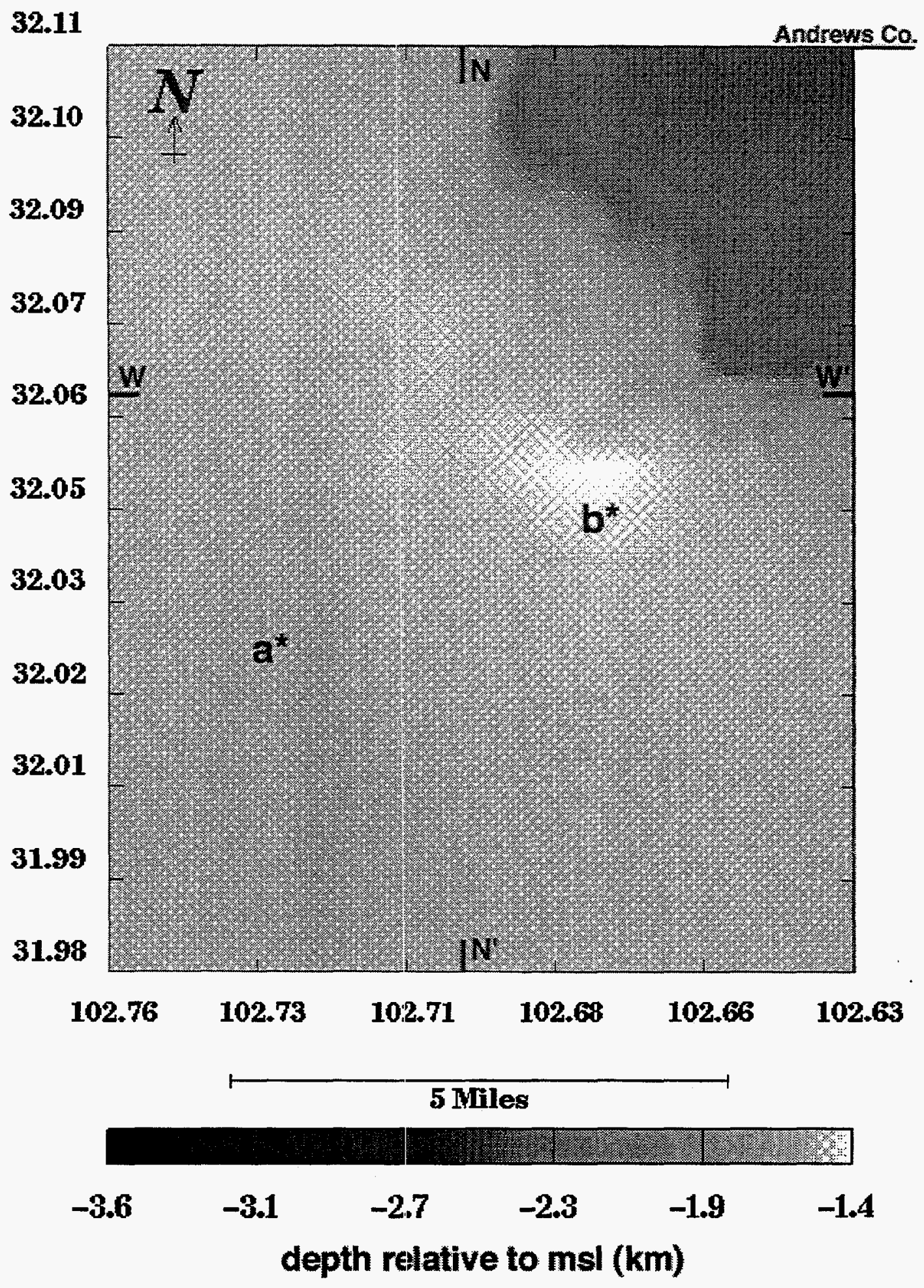

Fig. V-1 Map of Andector Field showing the locations of cross-sections NN' and WW' and the shading is the depth from MSL to the top of the Ellenburger structure (see Fig. III-9 for a detailed Ellenburger structure map). The map also shows the locations of 1-D simulations $a$ and $b$. 


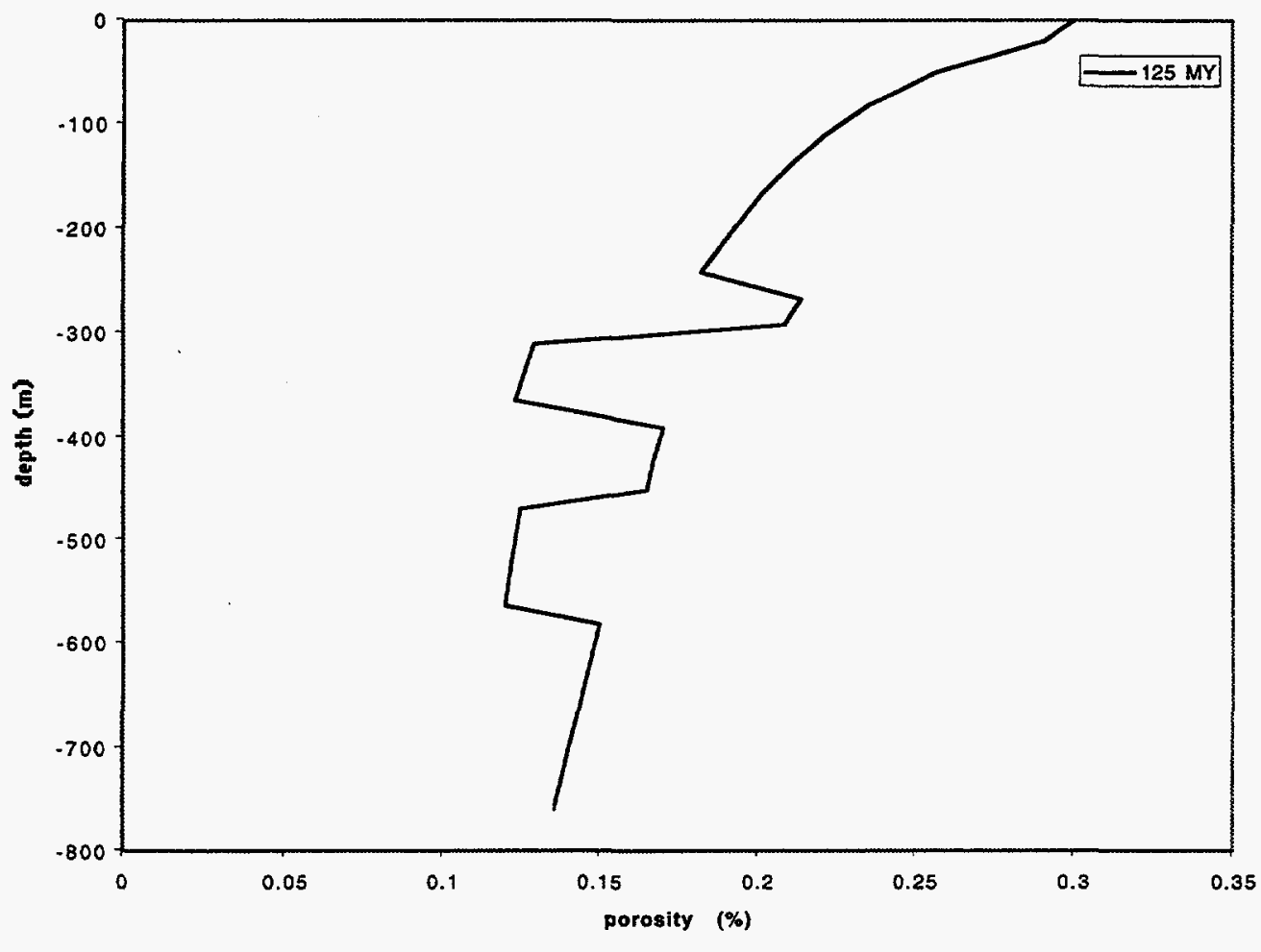

$\mathrm{V}-2 \mathrm{a}(1)$

Fig. V-2a Results of 1-D simulation for location $A$ in the Andector field (see Fig. V-1). Temporal sequence showing porosity/depth profiles at indicated times. The variations with depth reflect a strong lithologic control associated with the strong dependence of rheologic properties on grain size, porosity and mineralogy. The simulated presentday $(500 \mathrm{My})$ porosity profile is in agreement with the porosity ranges in the Ellenburger, McKee, Simpson, Montoya, Wolfcamp, Glorieta, and San Andres formations. 


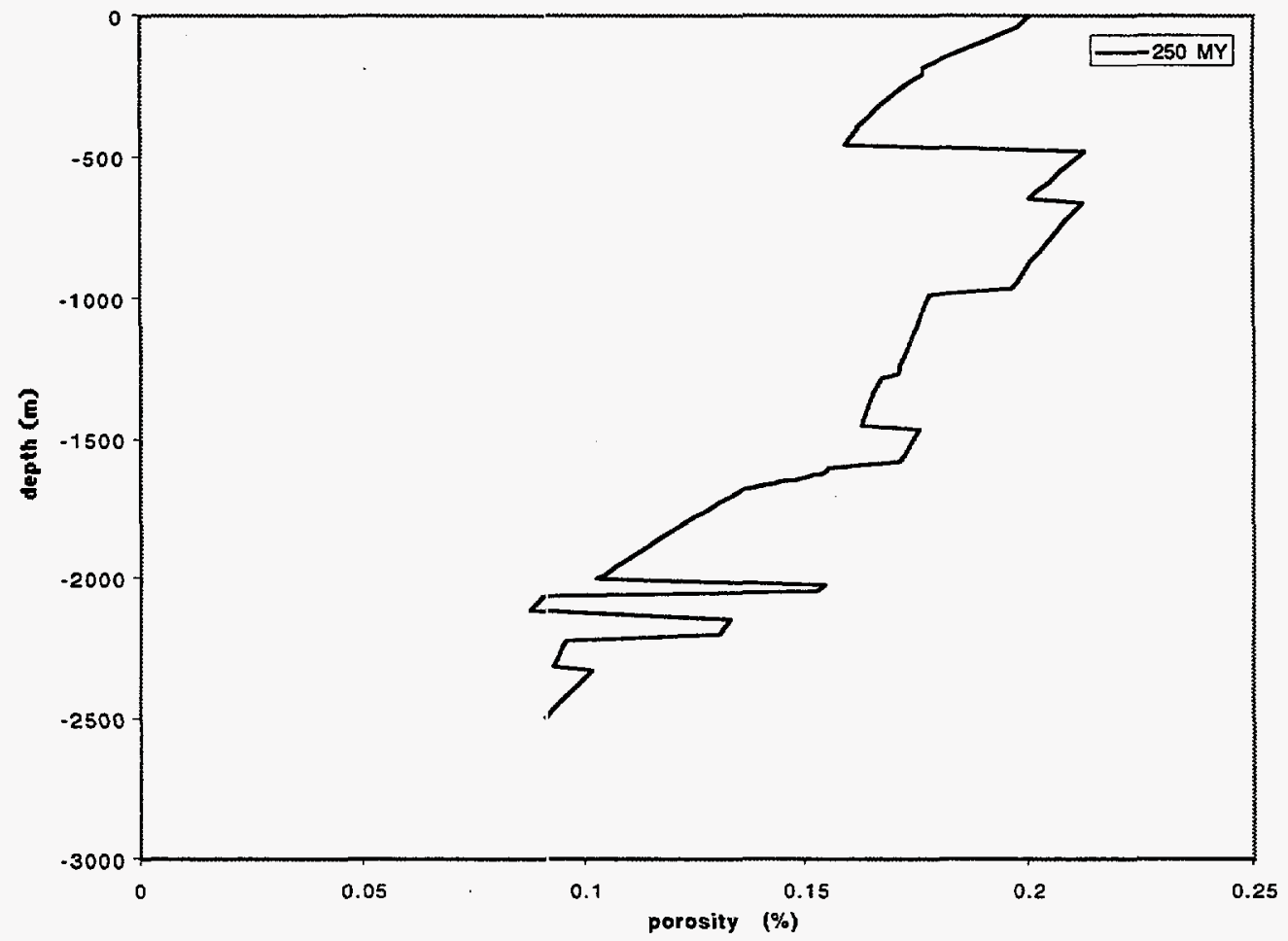

$\mathrm{V}-2 \mathrm{a}(2)$

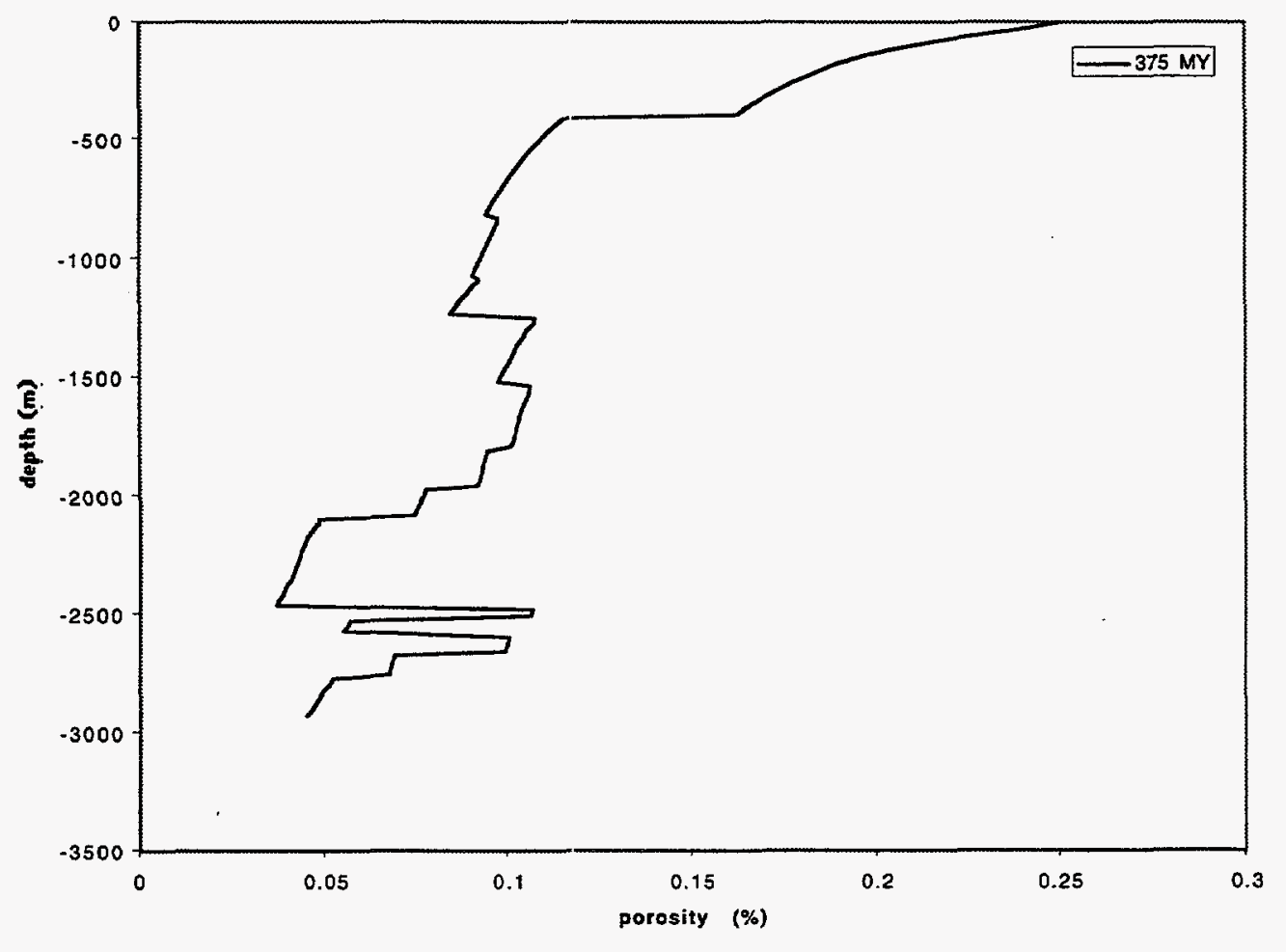

$\mathrm{V}-2 \mathrm{a}(3)$ 


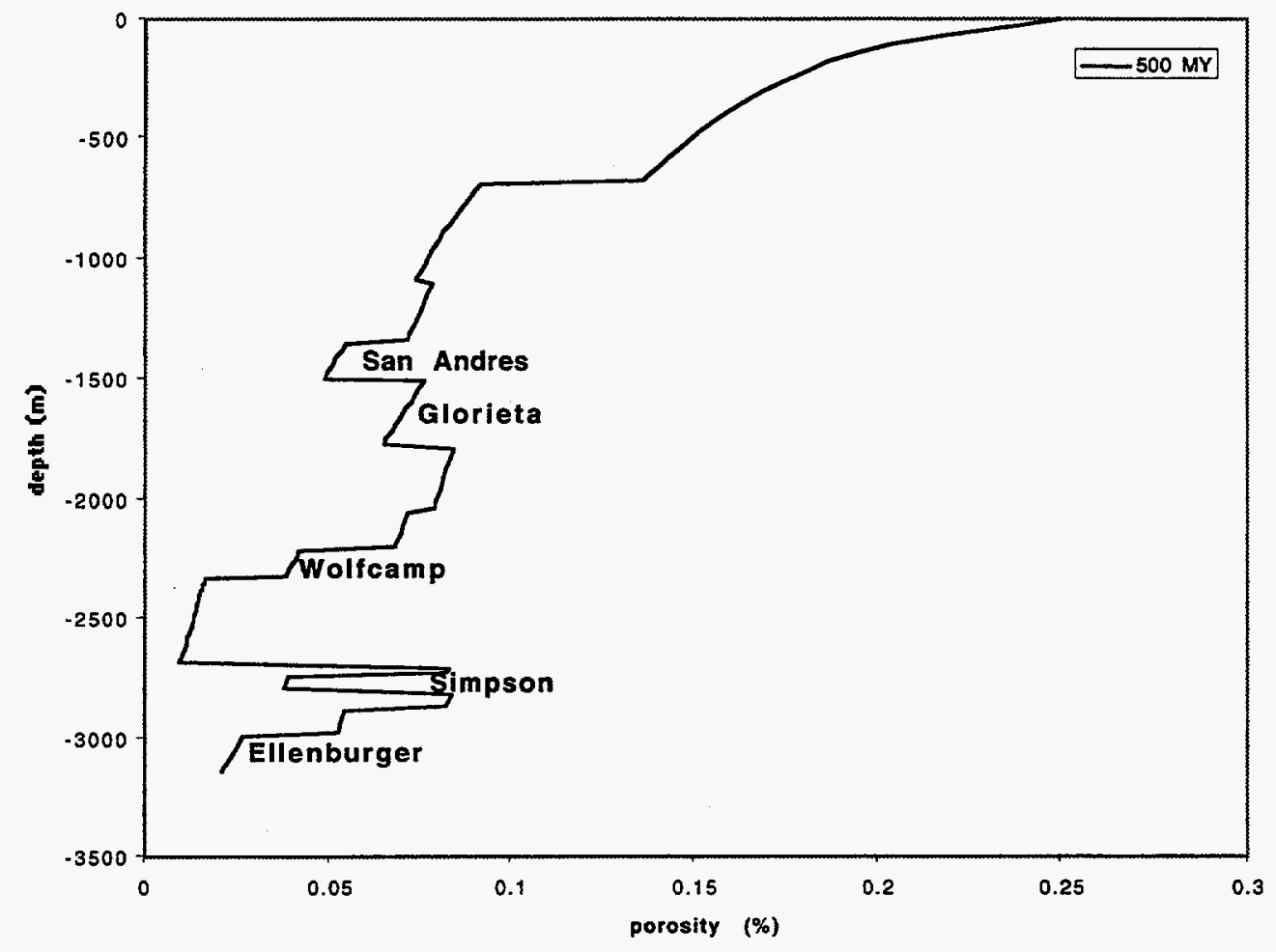

V-2a(4) 


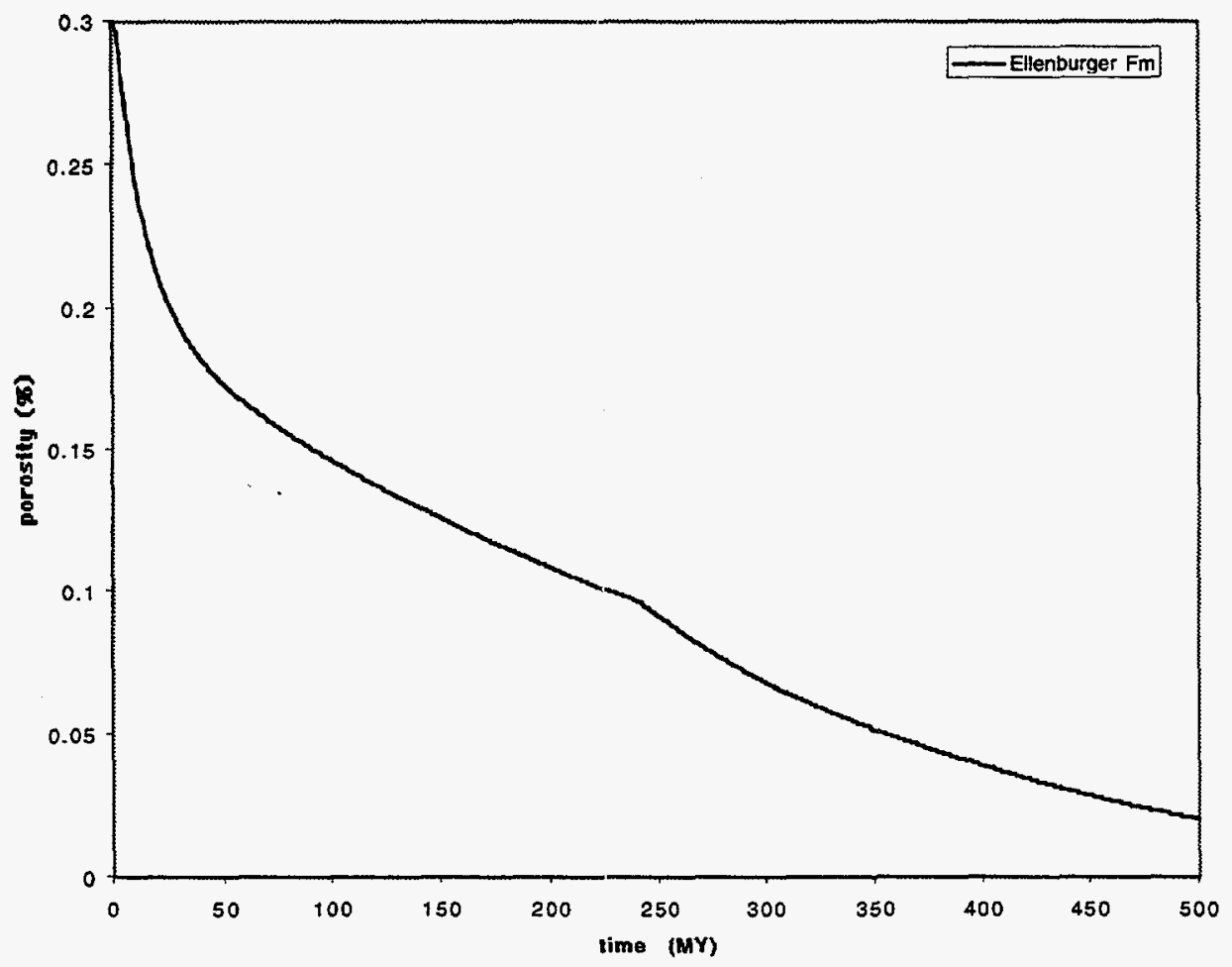

Fig. V-2b Evolution of porosity at the bottom of the Ellenburger formation. $40 \mathrm{My}$ after deposition started, the deformation slowed down because of increased stiffness. The inflection point around $230 \mathrm{My}$ is the onset of a high rate of sedimentation that started then. The final porosity is 0.03 , in agreement with the range of observed porosity in the Ellenburger formation. 


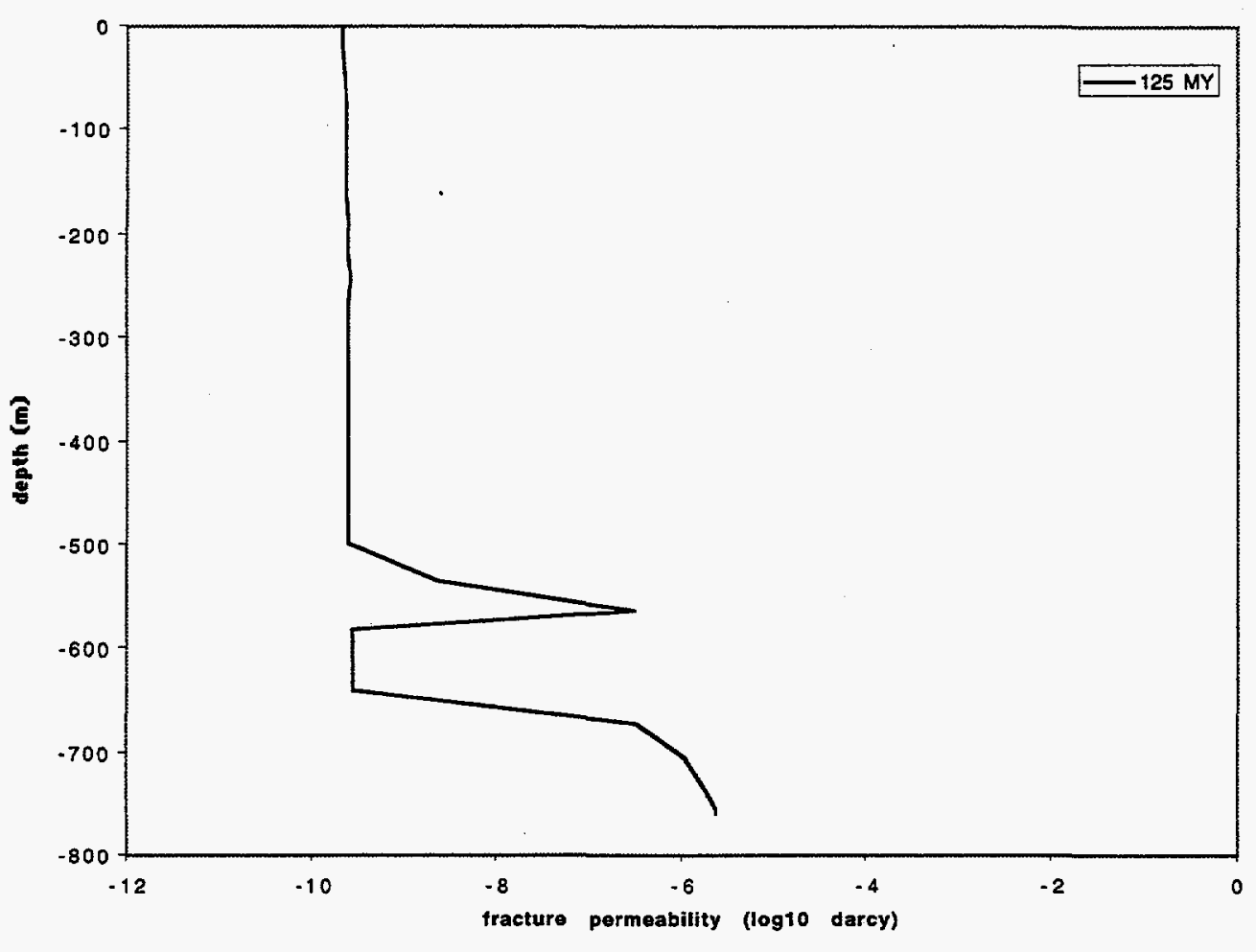

$\mathrm{V}-2 \mathrm{c}(1)$

Fig. V-2c Simulated fracture permeability profiles. As rocks lose their porosity, their shear and bulk viscosities increase. The ratio shear viscosity/bulk viscosity (denoted $\xi$ ) is a good representation of brittleness. As this ratio approaches zero, the rocks have a ductile behavior. This may be due to two reasons; high bulk viscosity caused by very low porosity, or low shear viscosity shale or rock salt. Therefore, in the absence of tectonic effects, a sandstone can fracture as it becomes more brittle (high $\xi$ ), and then heal as the porosity approaches zero. In this particular simulation, the Ellenburger formation fractured 400 million years ago, and remained fractured for 200 million years. The discrepancy between this simulation and observations can be explained by the flexural effects which are ignored in 1-D simulations, oil generation, and errors in the calibration of rheologic properties. 


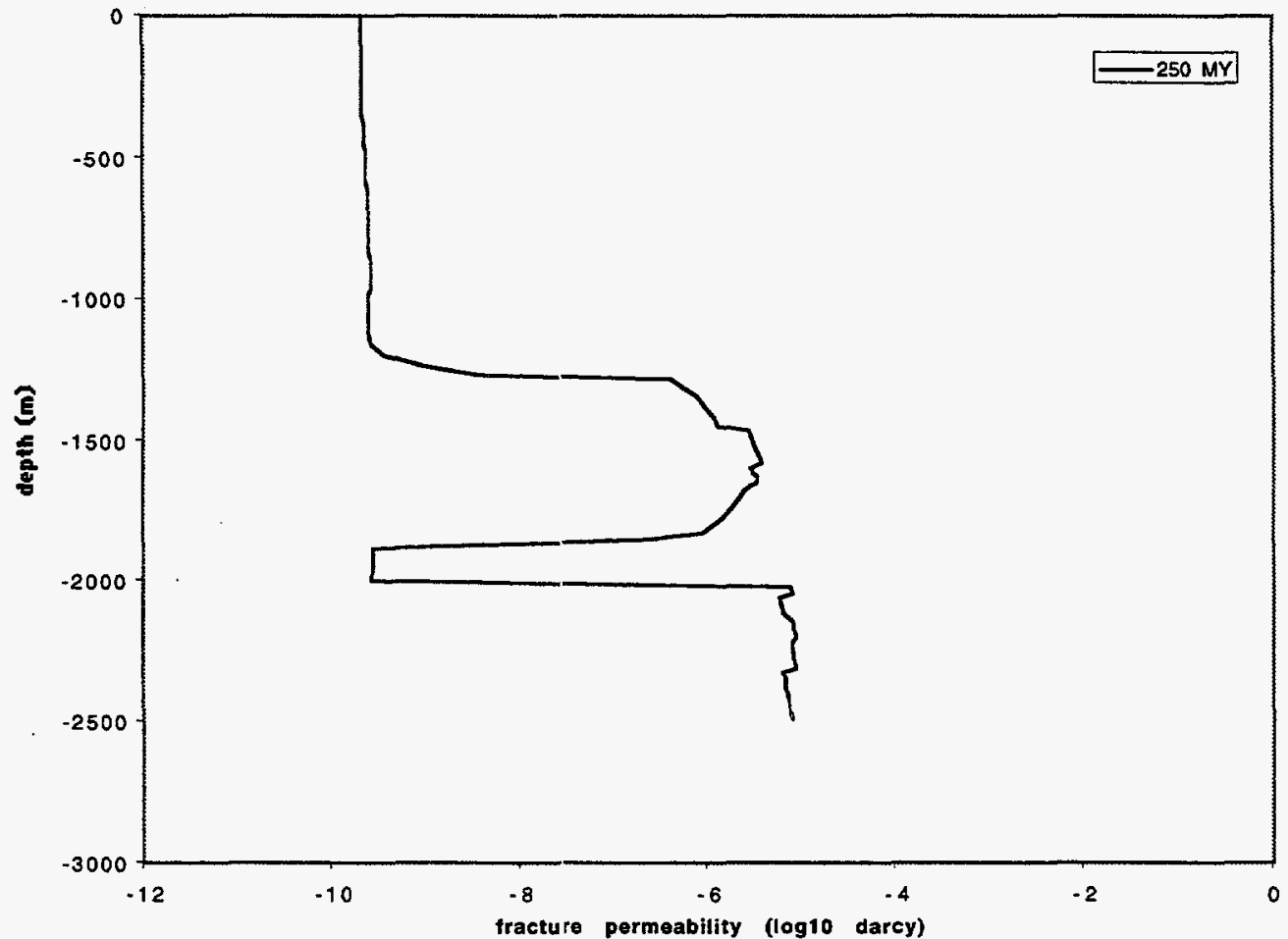

$\mathrm{V}-2 \mathrm{c}(2)$

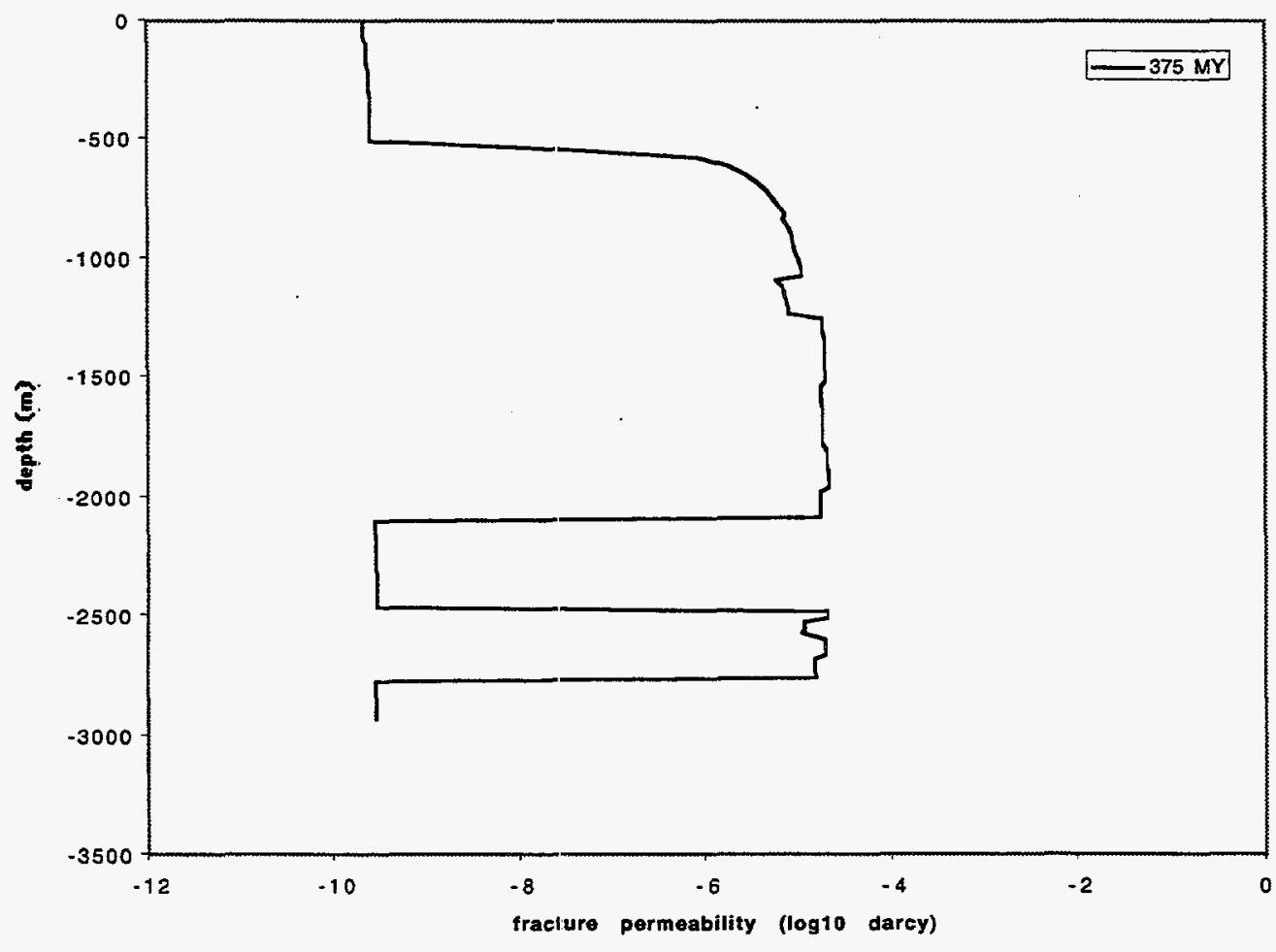

$V-2 c(3)$ 


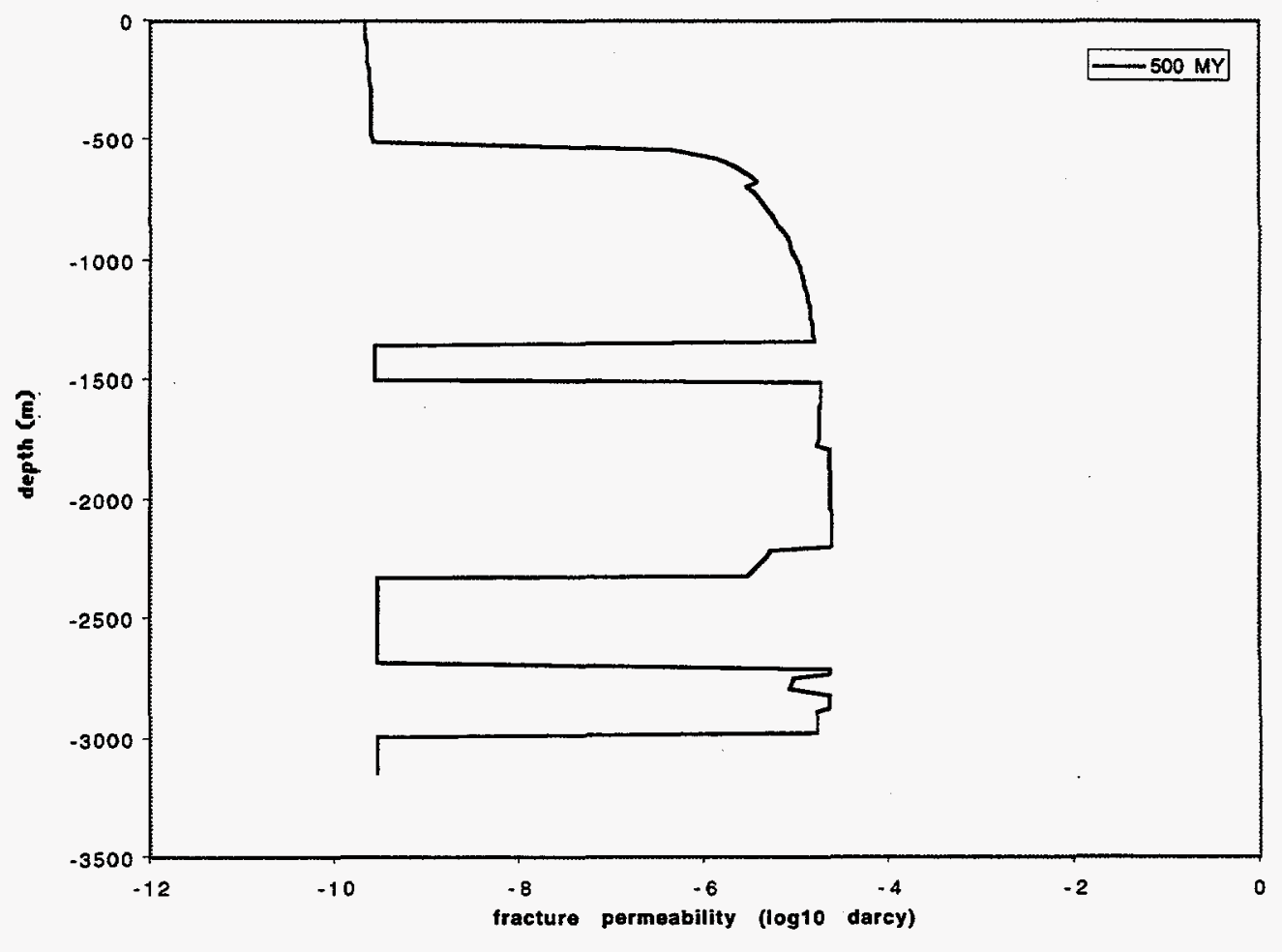

$\mathrm{V}-2 \mathrm{c}(4)$ 


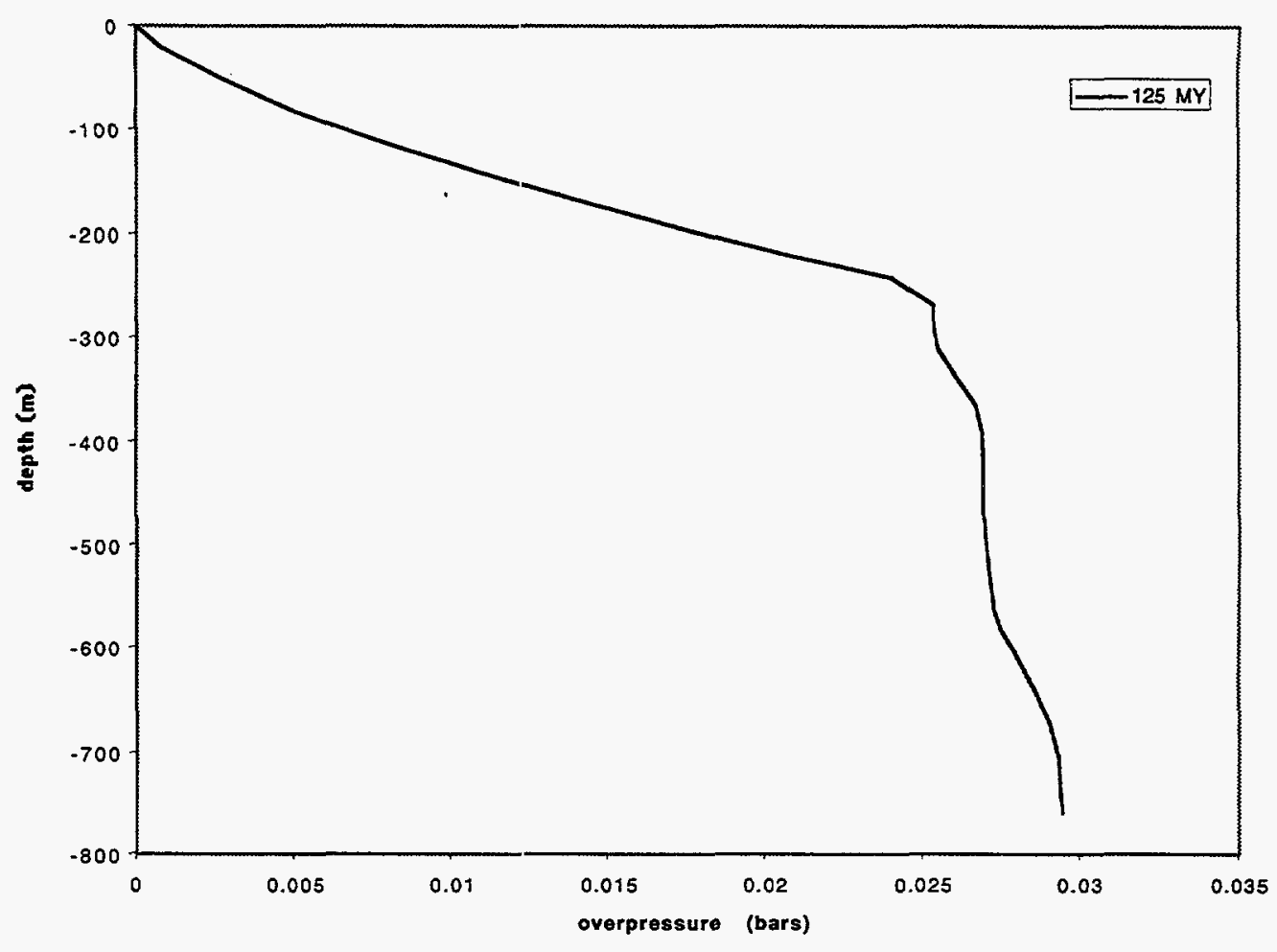

V-2d(1)

Fig. V-2d Simulated overpressure profiles. A comparison of overpressure and fracture permeability profiles show a strong correlation between fracturing and overpressuring. The present-day simulated overpressure profile indicates three seals, and the maximum overpressure is 95 bars at the bottom of the Ellenburger formation. Considering the fact that the preproduction pressure state of this fielcl was hydrostatic (see Fig. III-7) the discrepancy between observed and simulated overpressure must be addressed. In a 1-D simulation, since the geometric effects are not taken into consideration; overpressured fluids cannot escape laterally. Furthermore, in one dimension it is very difficult to fracture a ductile layer. An increase of pressure in a ductile layer will most likely increase the lateral stress as well. However, the complex subsidence alters the state of stress and results in weak zones in a 3-D simulation. An example of 3-D simulation is shown in the next section. 


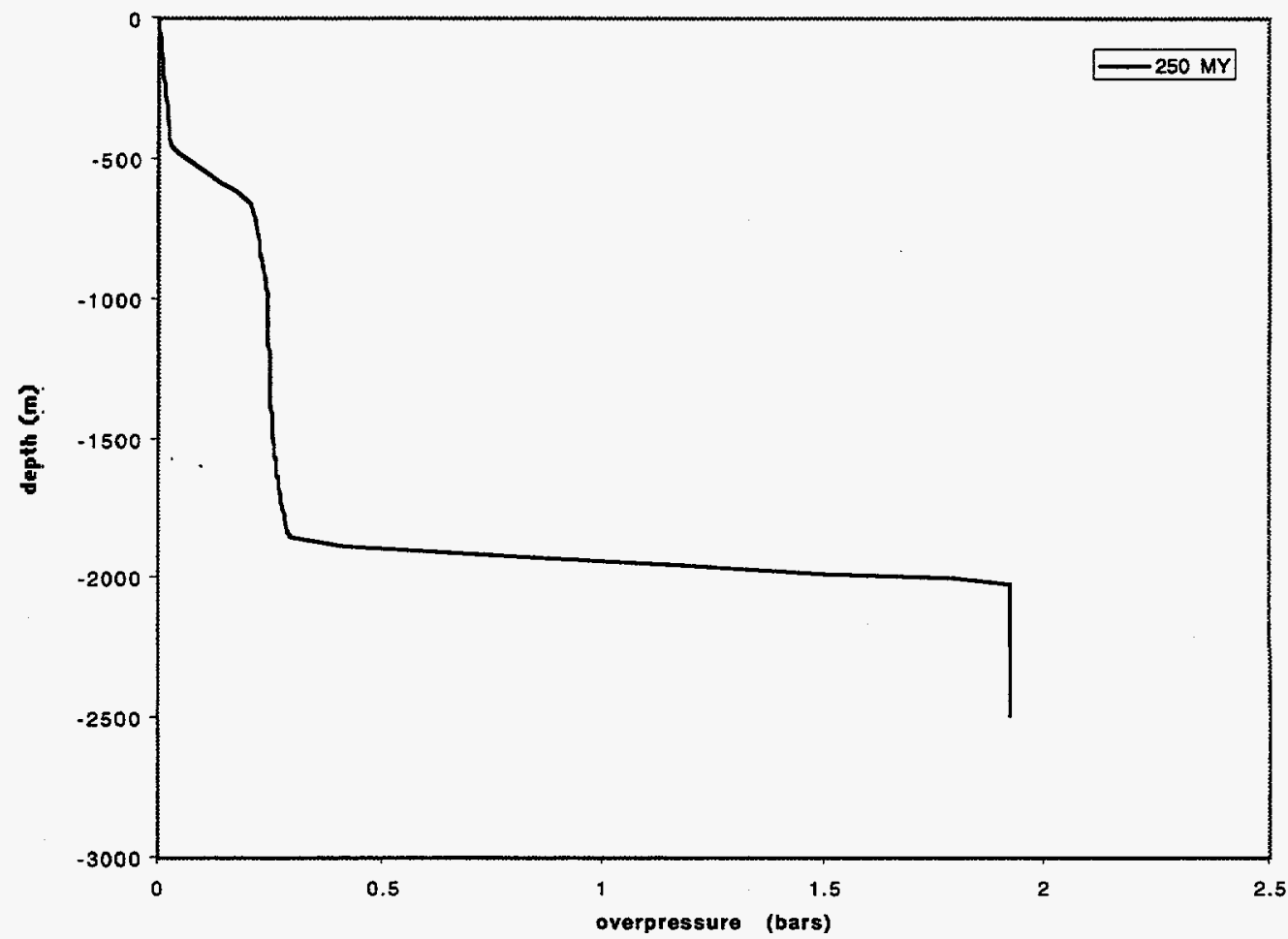

$V-2 d(2)$

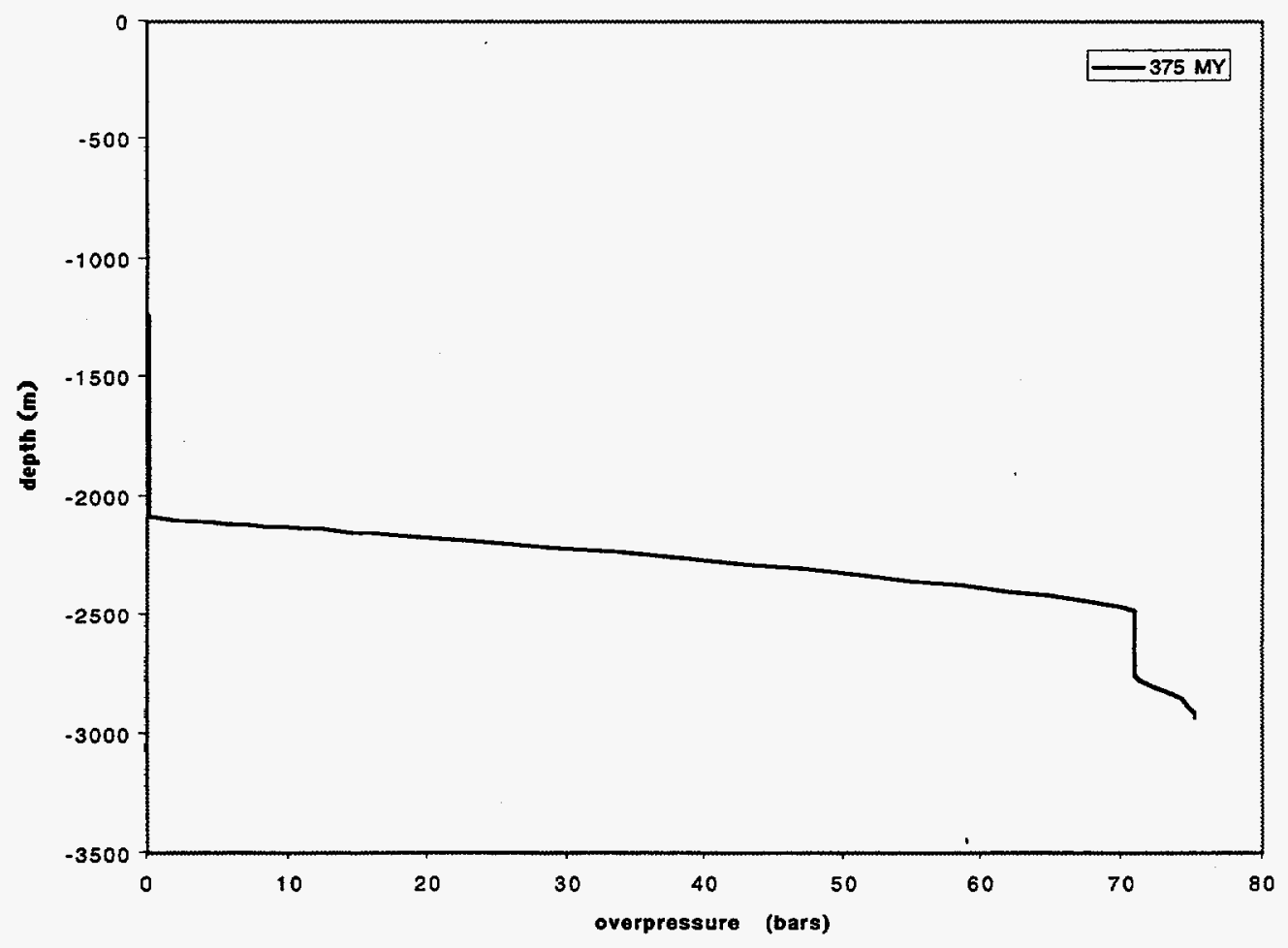

V-2d(3) 


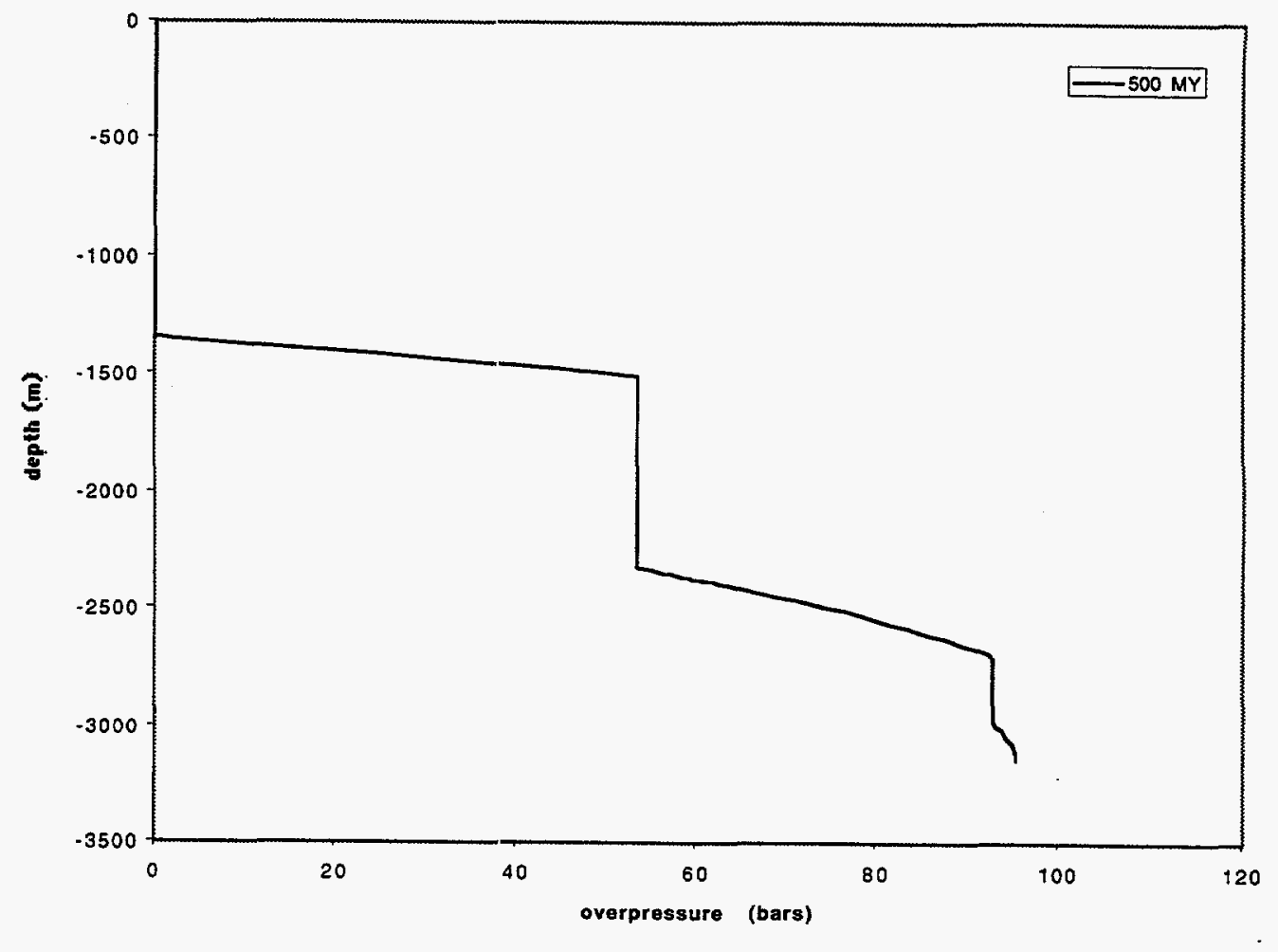

V-2d(4) 


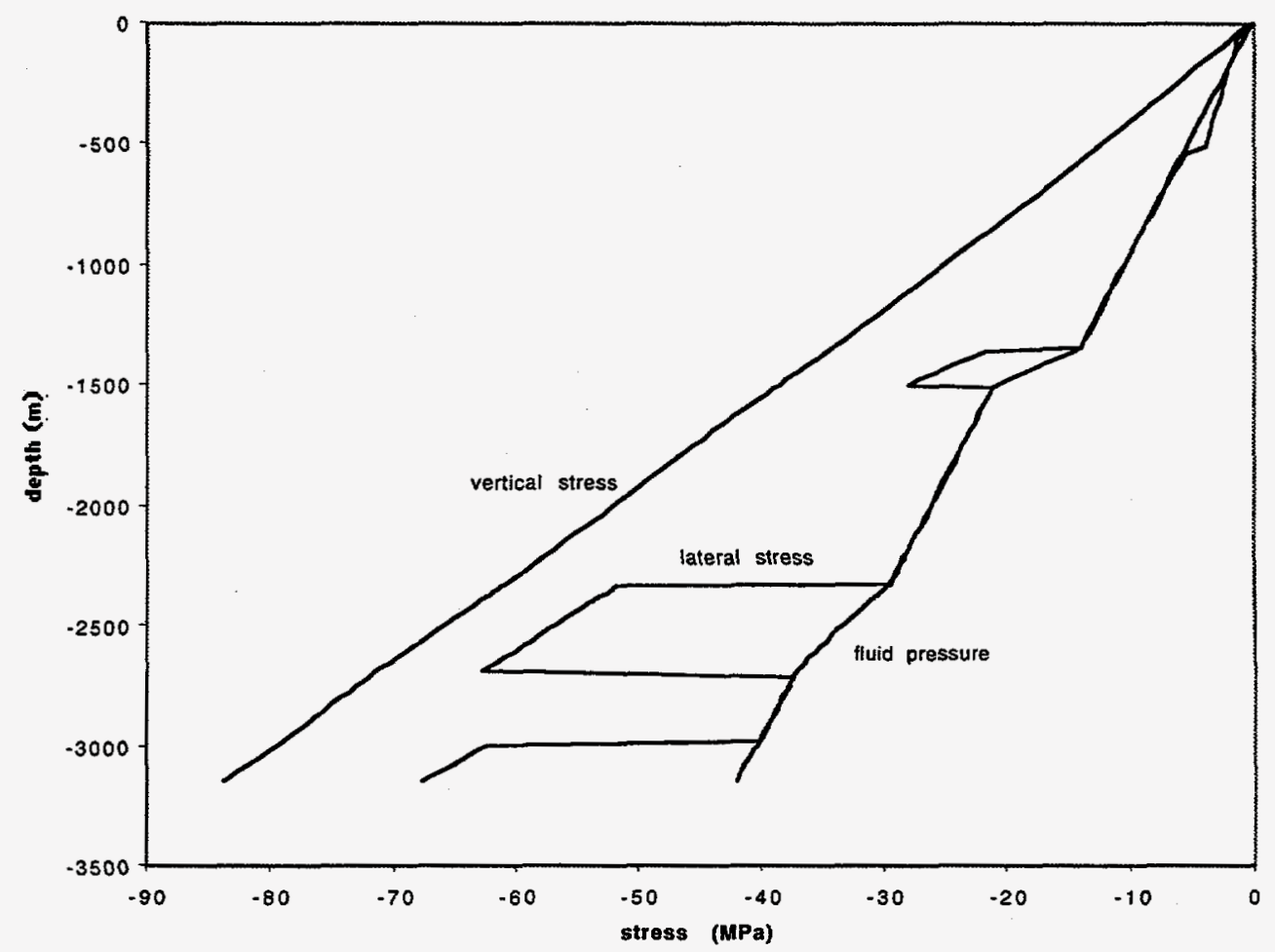

Fig. V-2e Simulated present-day fluid pressure, lateral stress and vertical stress profiles. The figure shows three high lateral stress zones. This correlates with overpressure and fracture permeability profiles. The volumetric change in the rock due to fracturing results in very similar lateral stress and pressure values for brittle zones. 


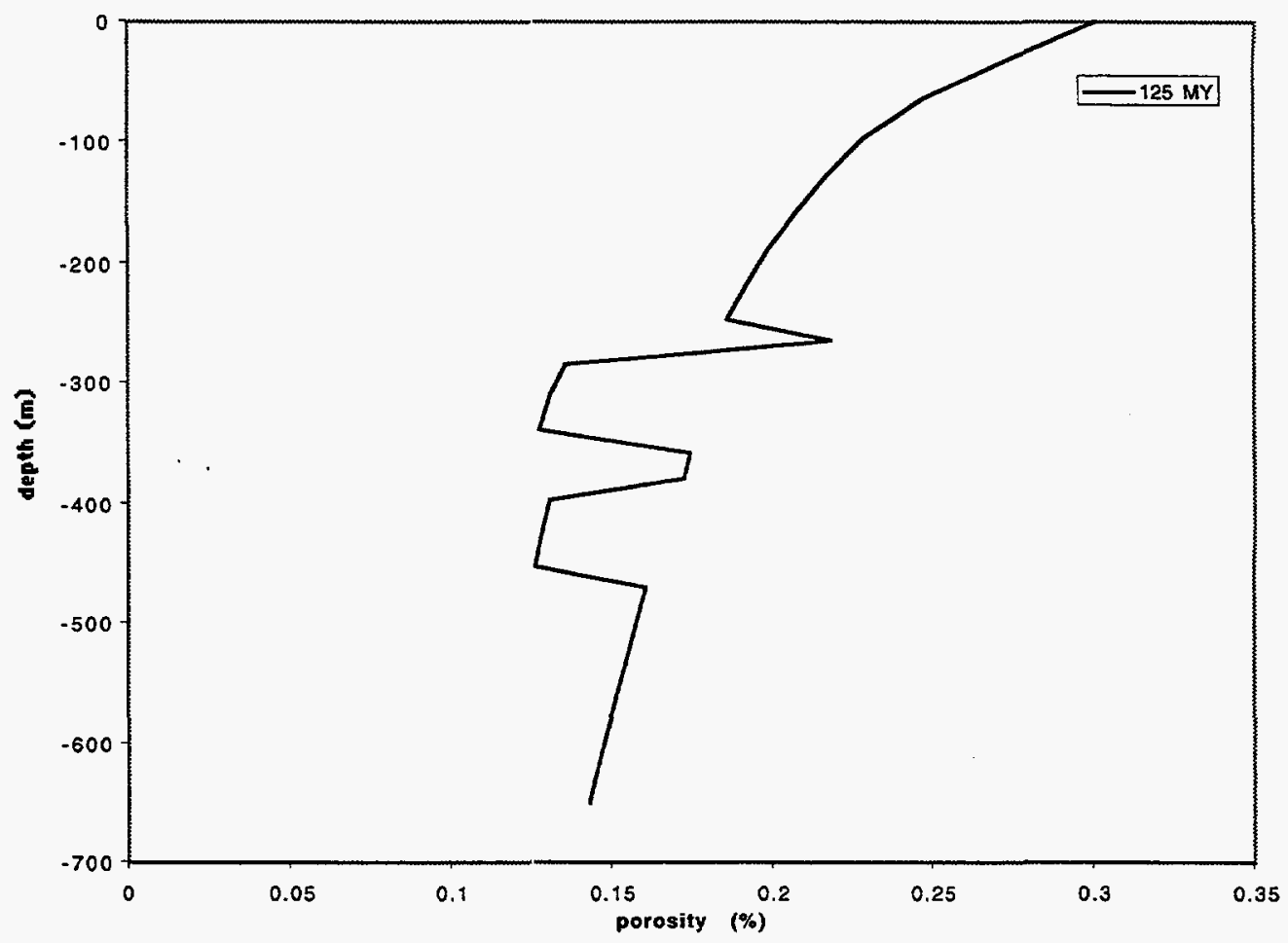

V-3a(1)

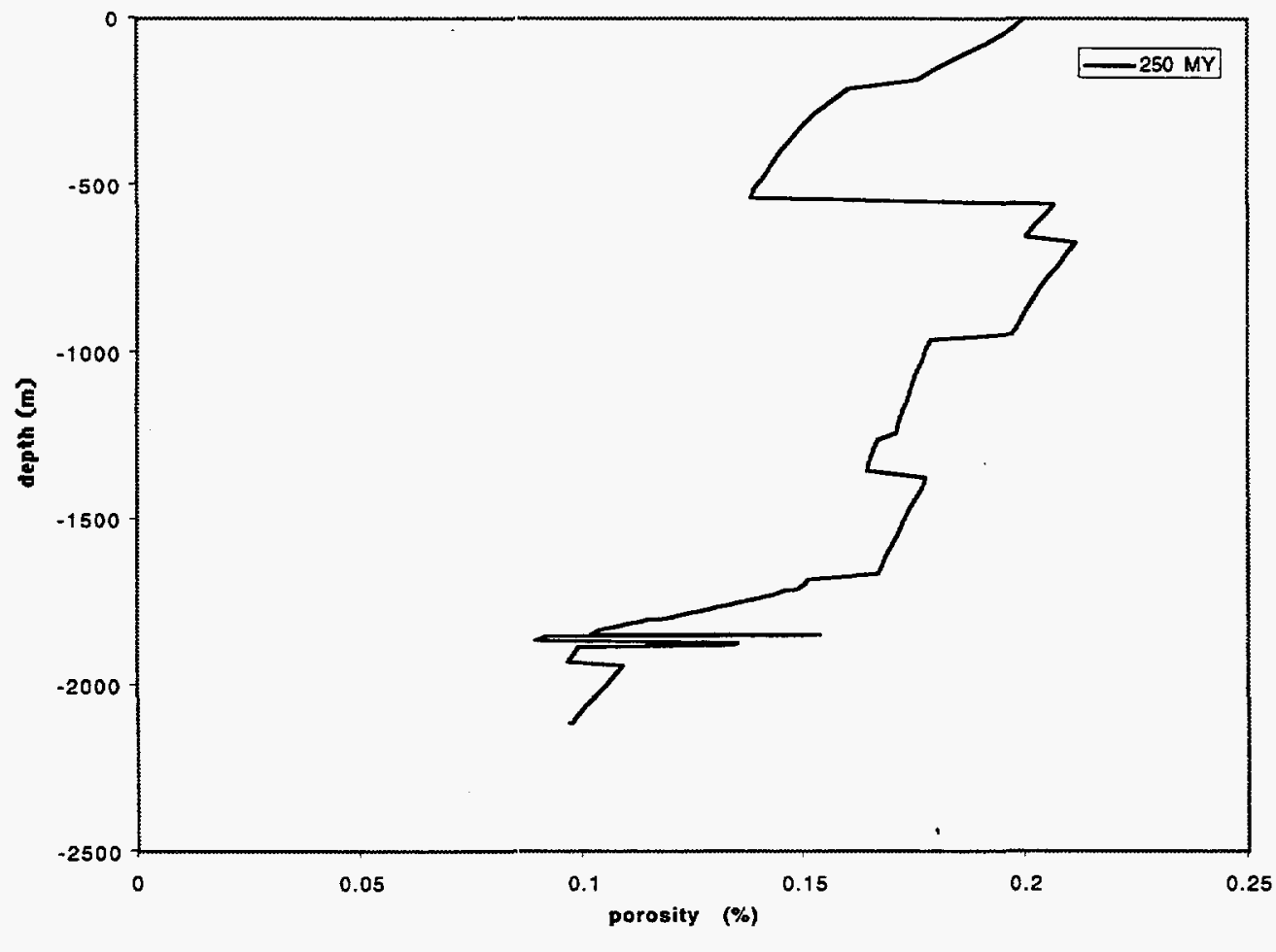

$\mathrm{V}-3 \mathrm{a}(2)$

Fig. V-3a Same as Fig. V-2a except for Site b (see Fig. V-1). In the 500 My time step, Simpson Group includes Waddell and McKee formations. 


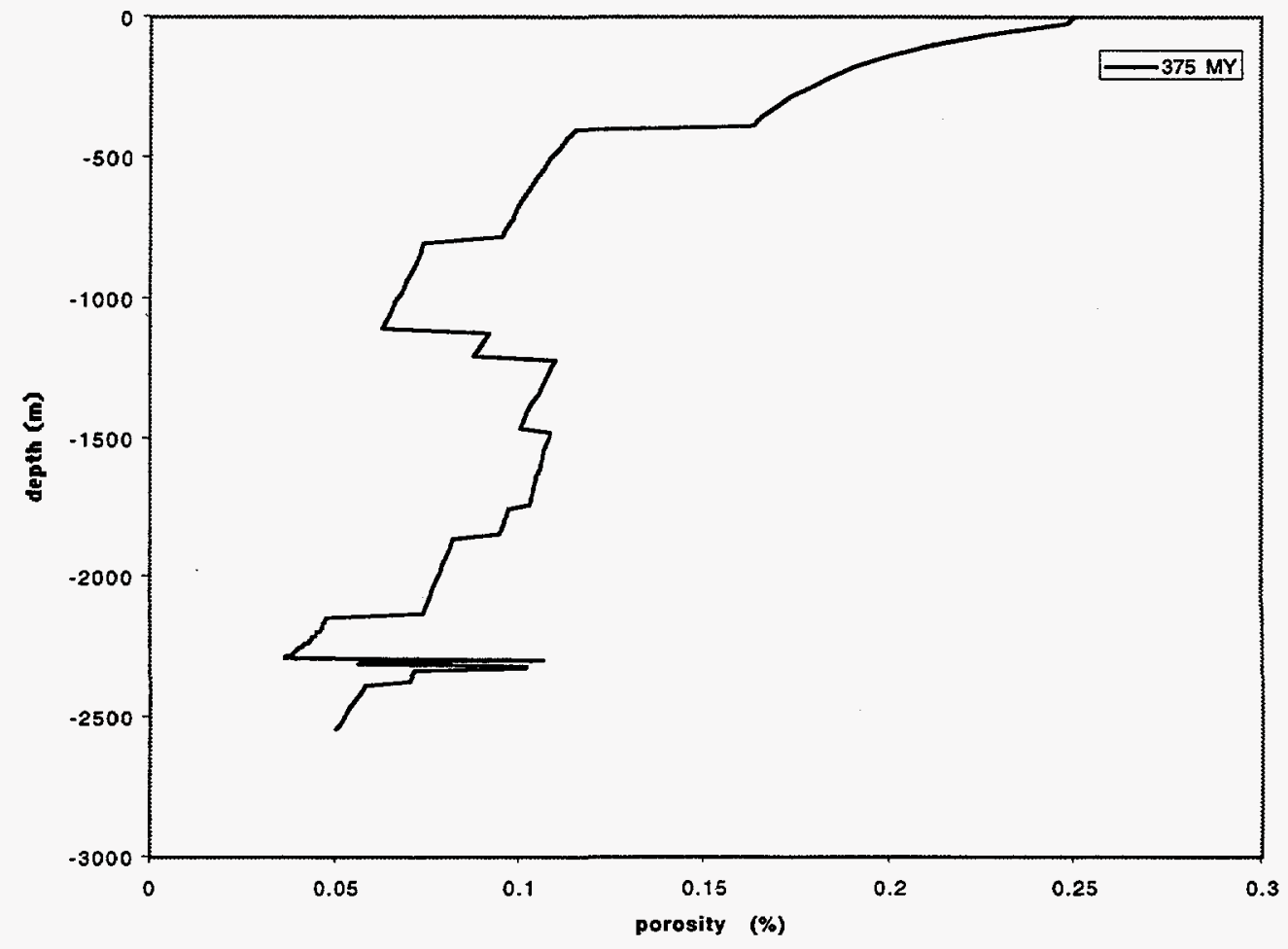

V-3a(3)

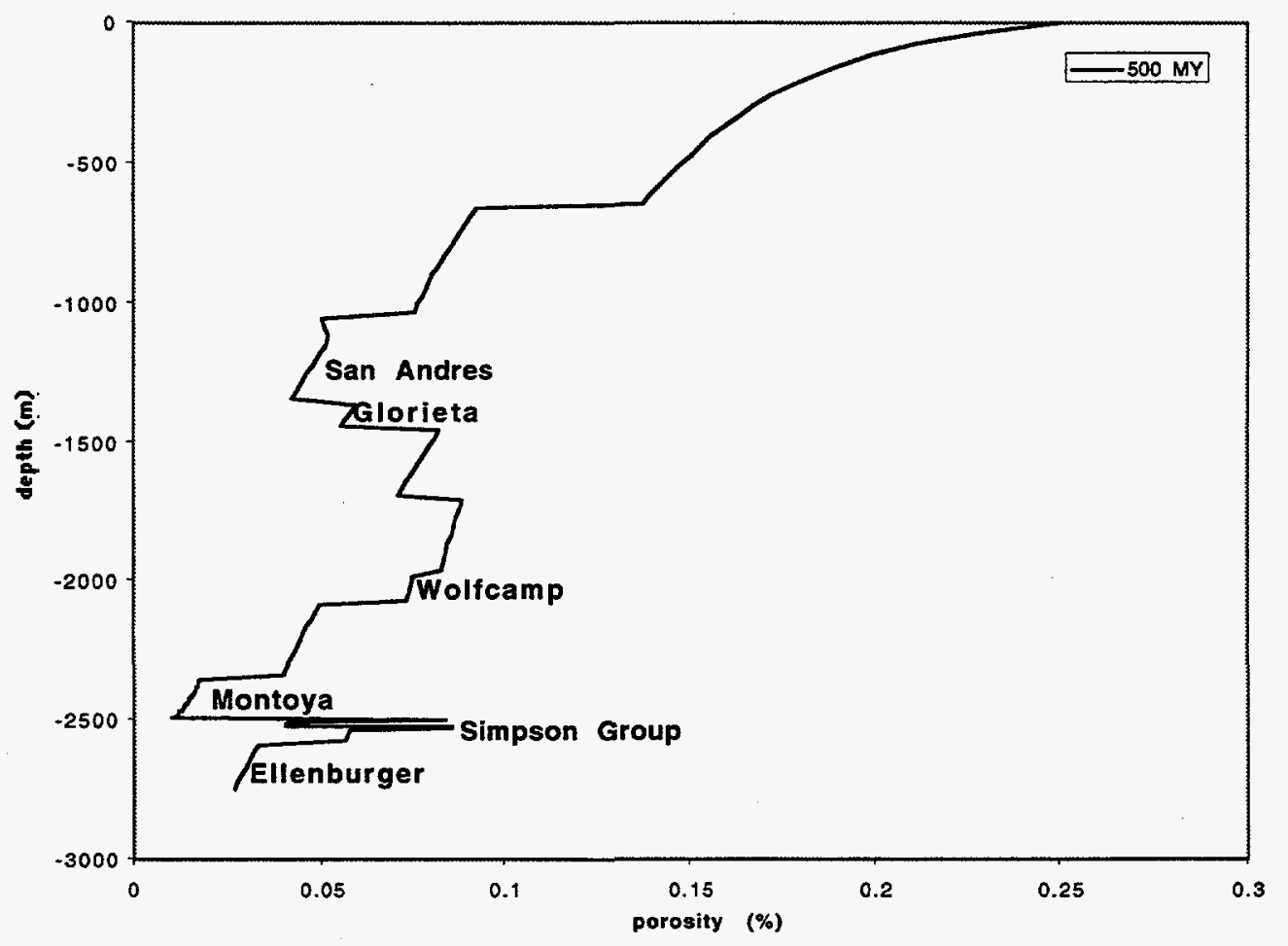

V-3a(4) 


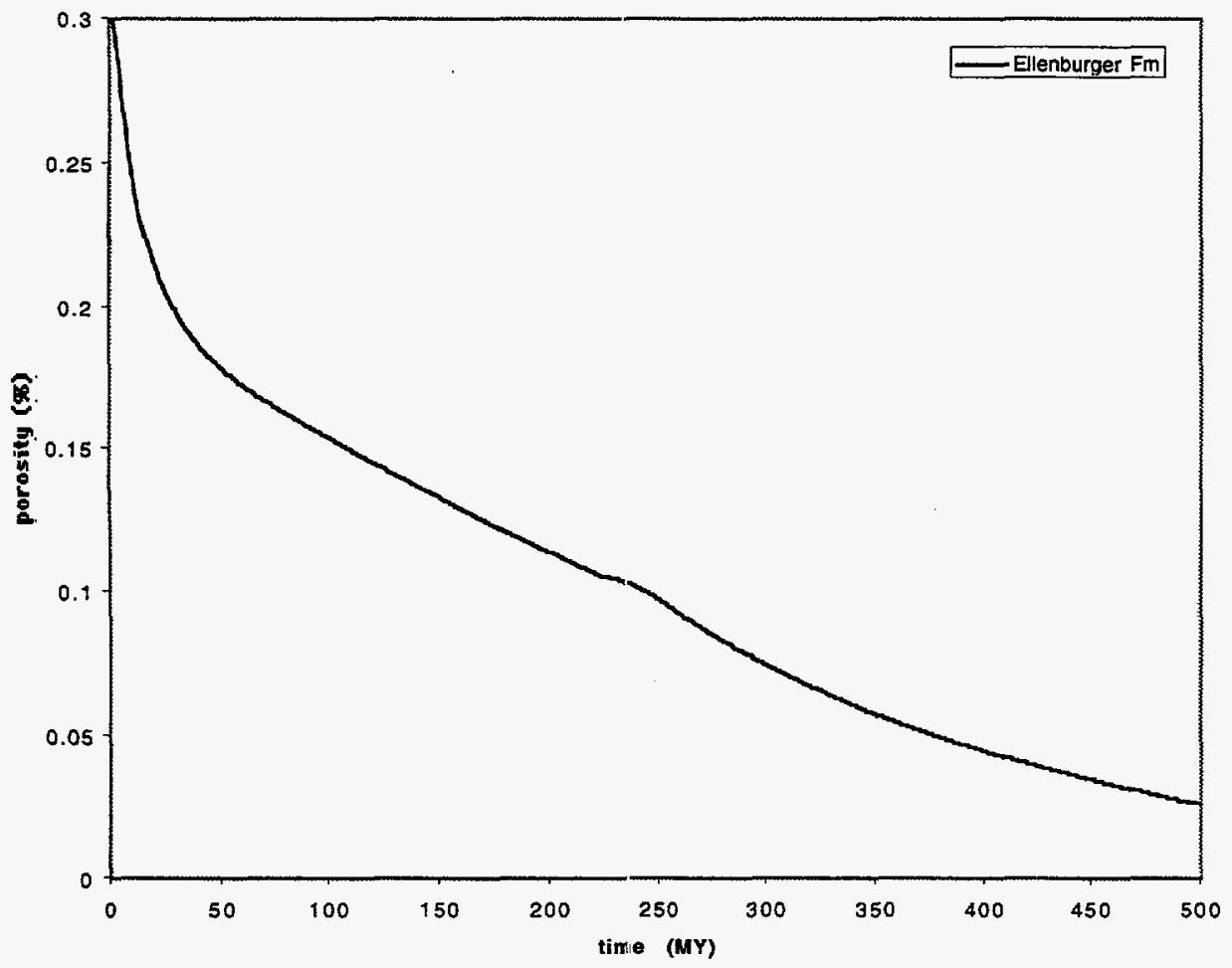

Fig. V-3b As in Fig. V-2b except for Site b (see Fig. V-1). 


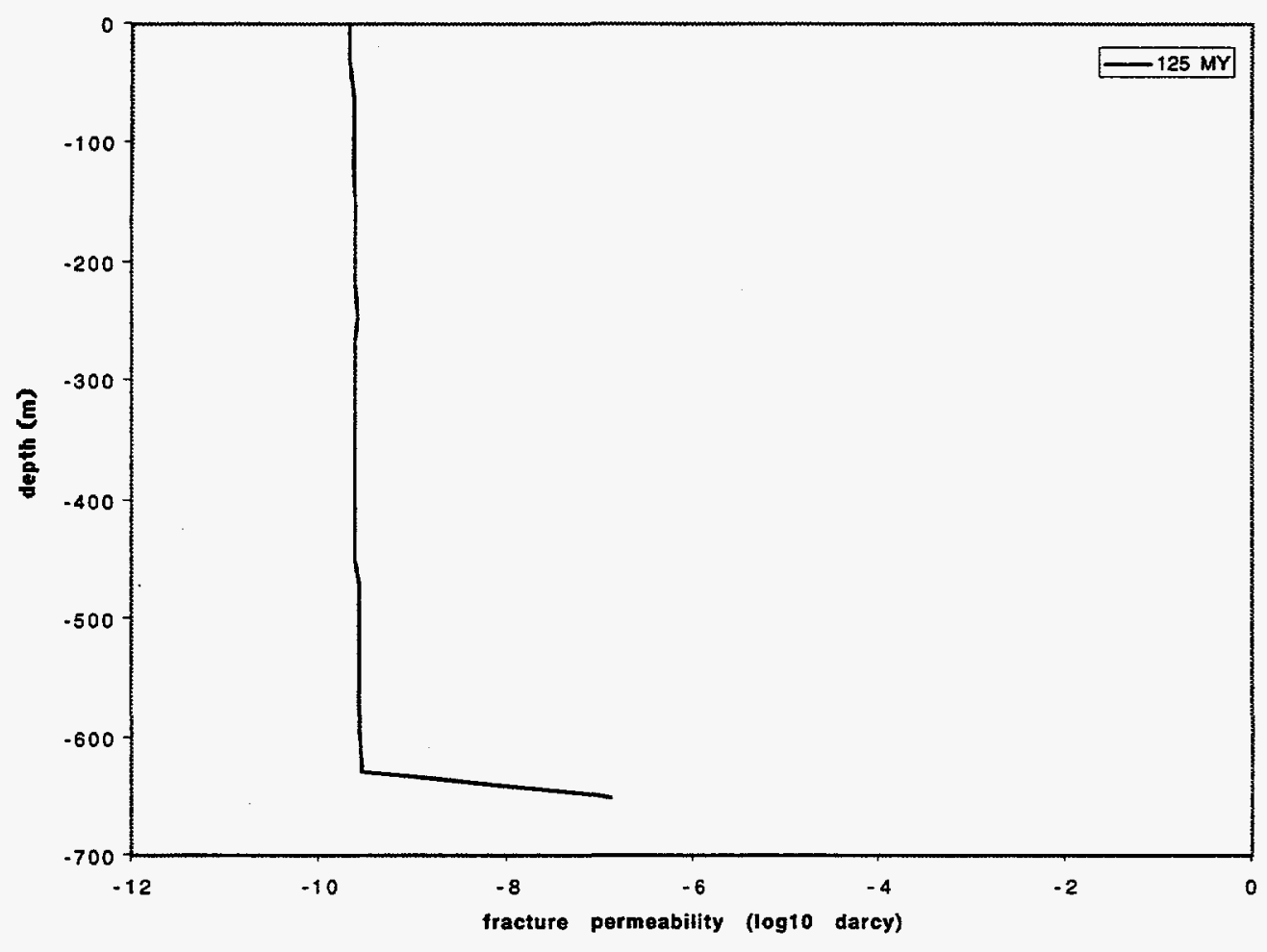

$\mathrm{V}-3 \mathrm{c}(1)$

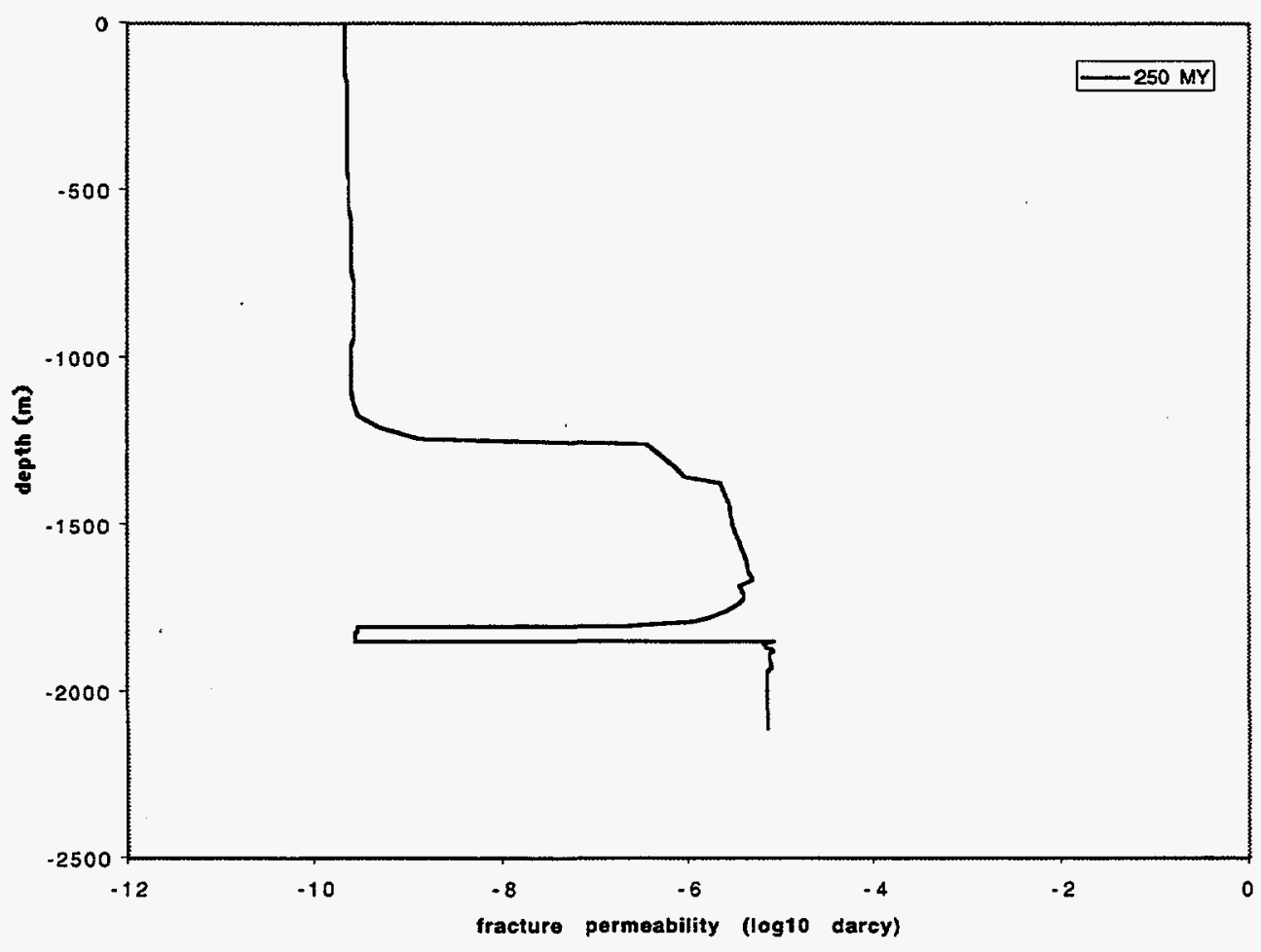

$\mathrm{V}-3 \mathrm{c}(2)$

Fig. V-3c As in Fig. V-2c except for Site b (see Fig. V-1). 


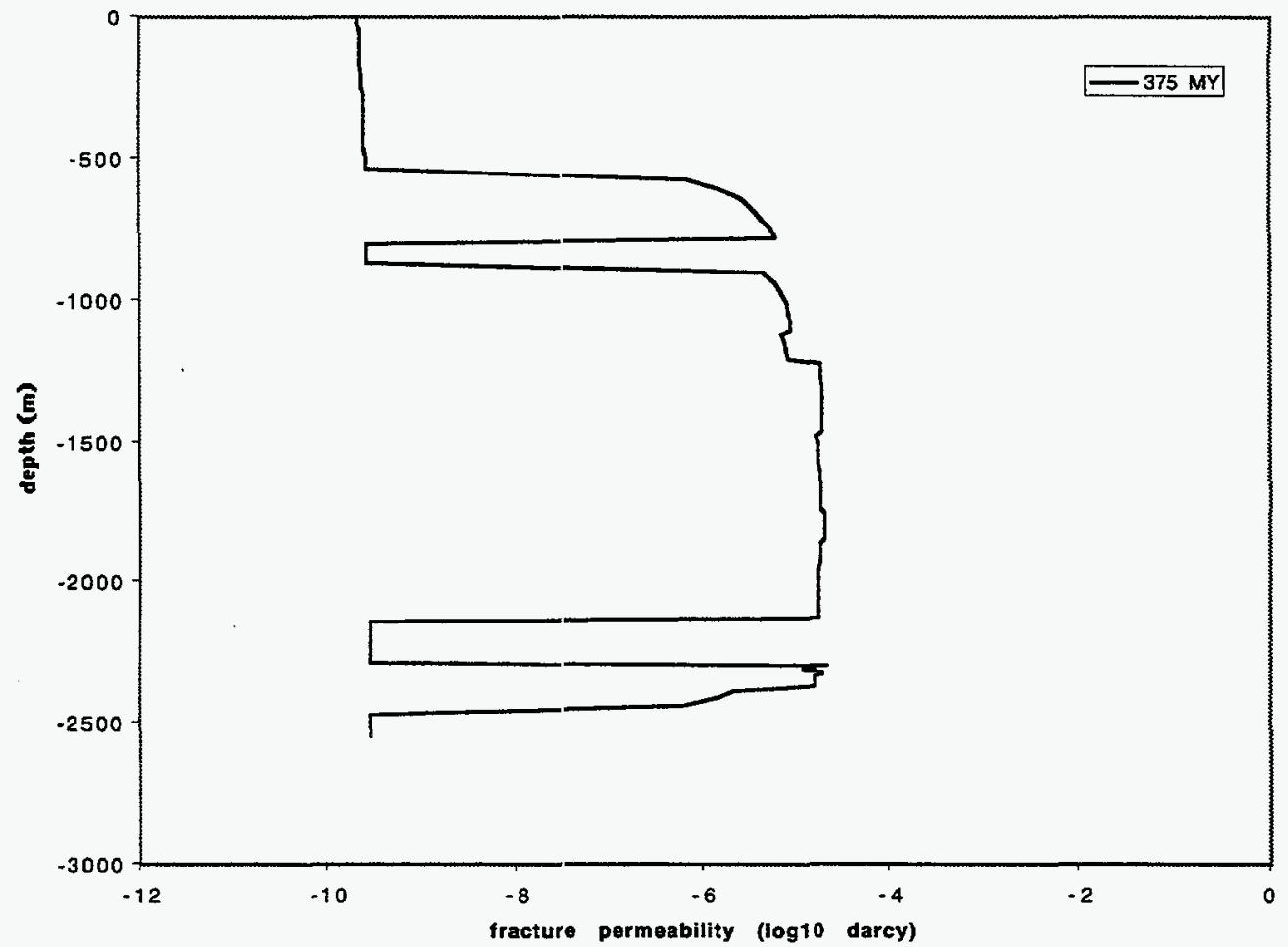

$V-3 c(3)$

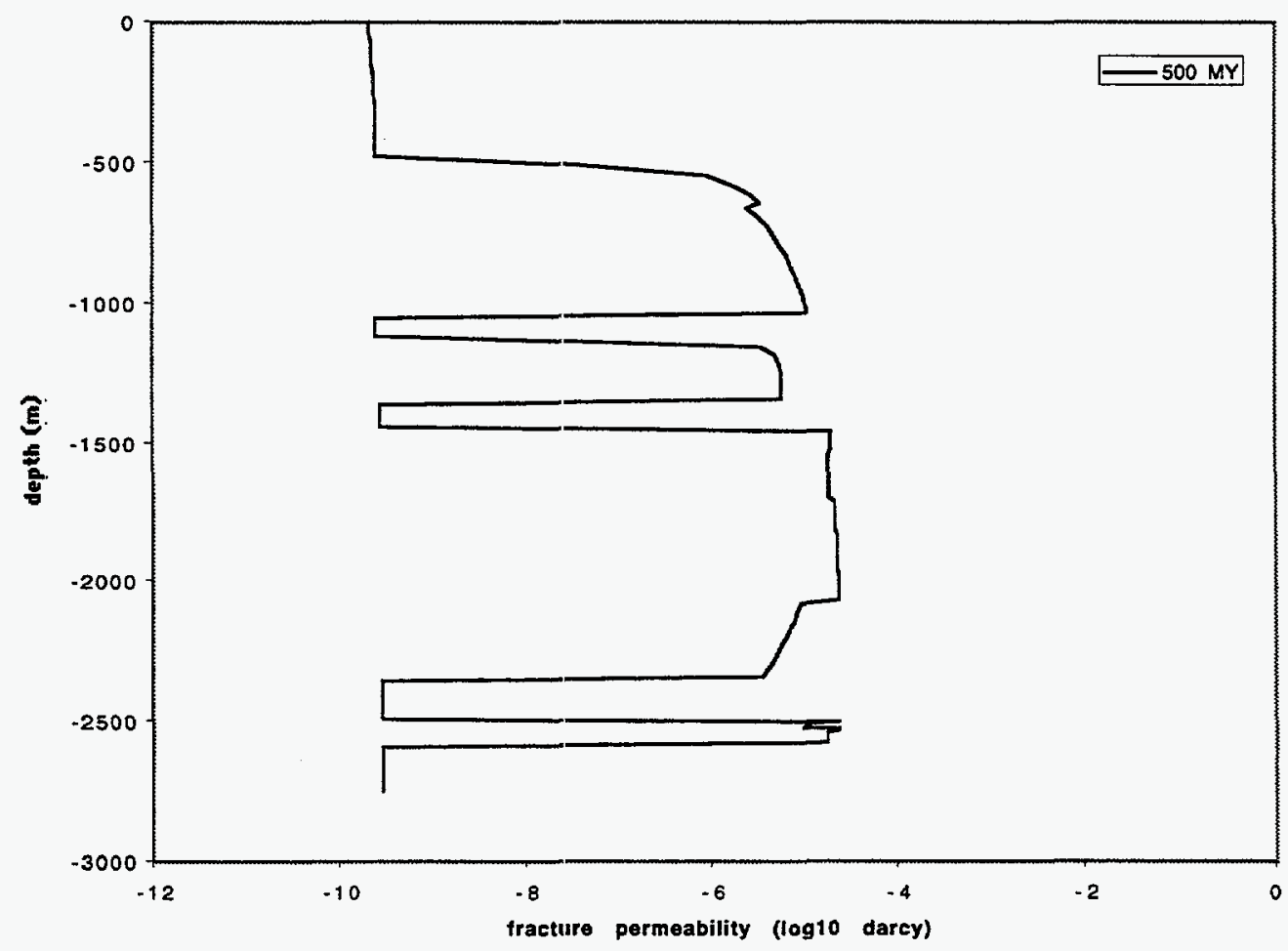

$V-3 c(4)$ 


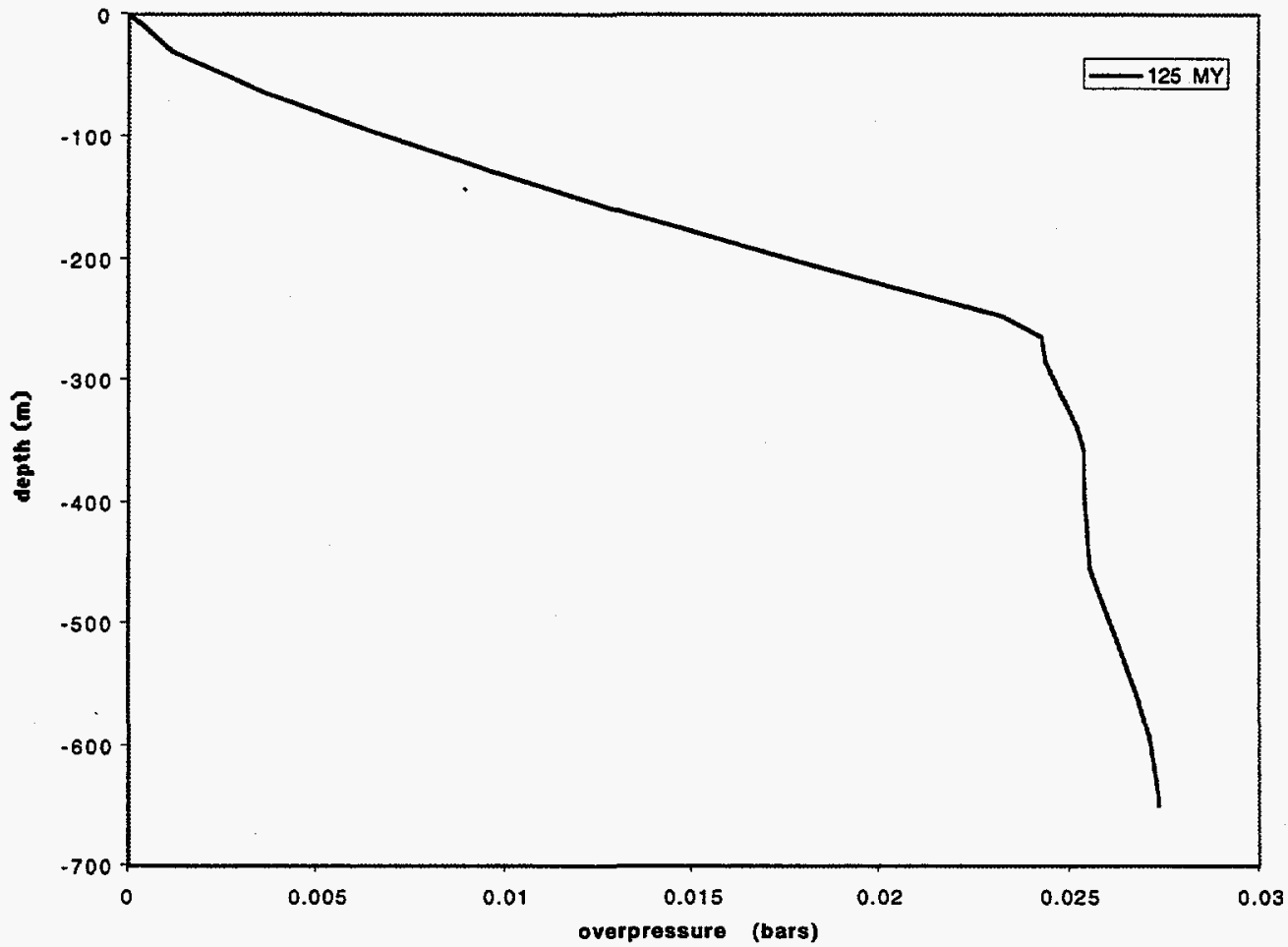

V-3d(1)

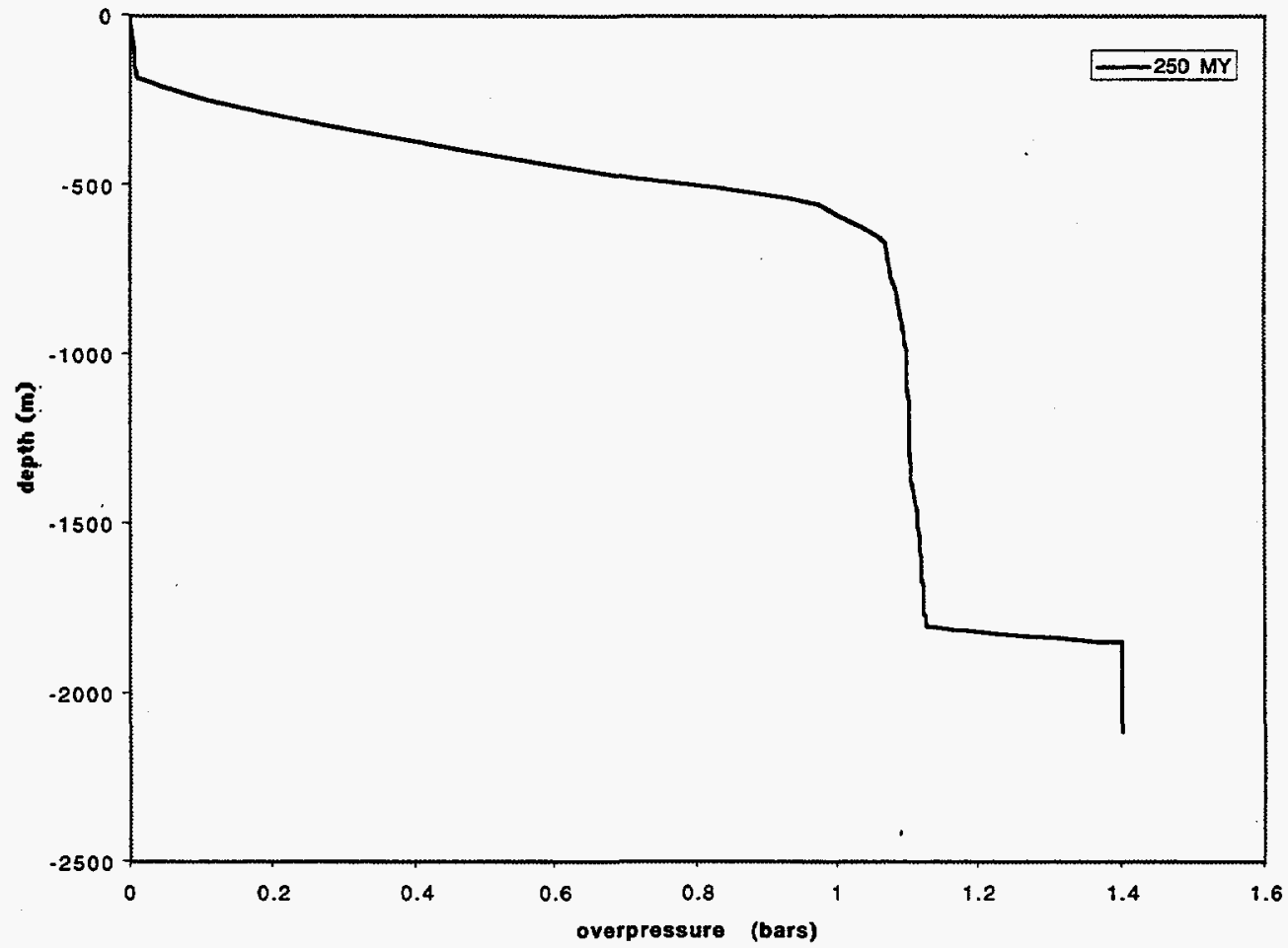

V-3d(2)

Fig. V-3d As in Fig. V-2d except for Site b (see Fig. V-1). 


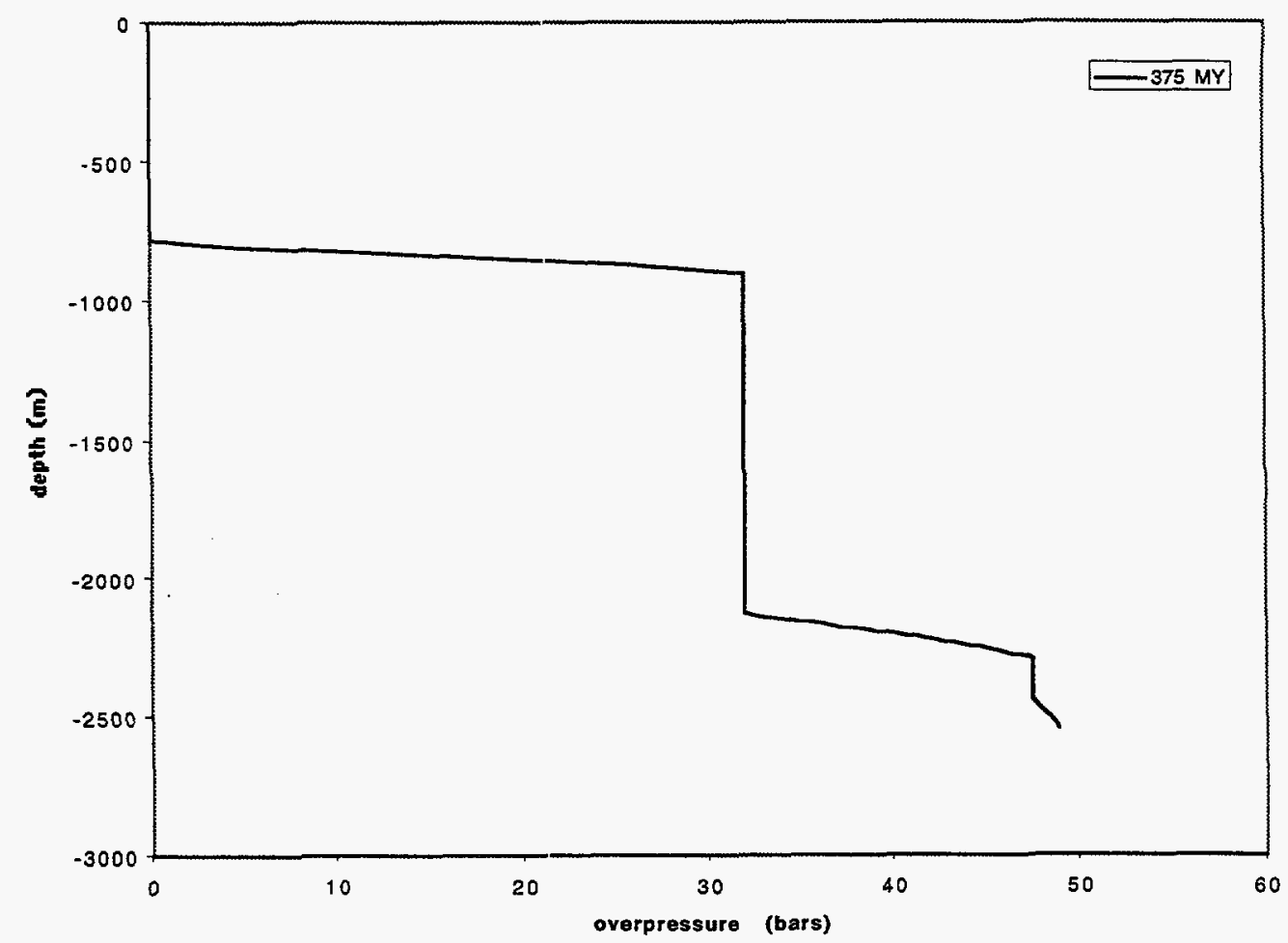

$V-3 d(3)$

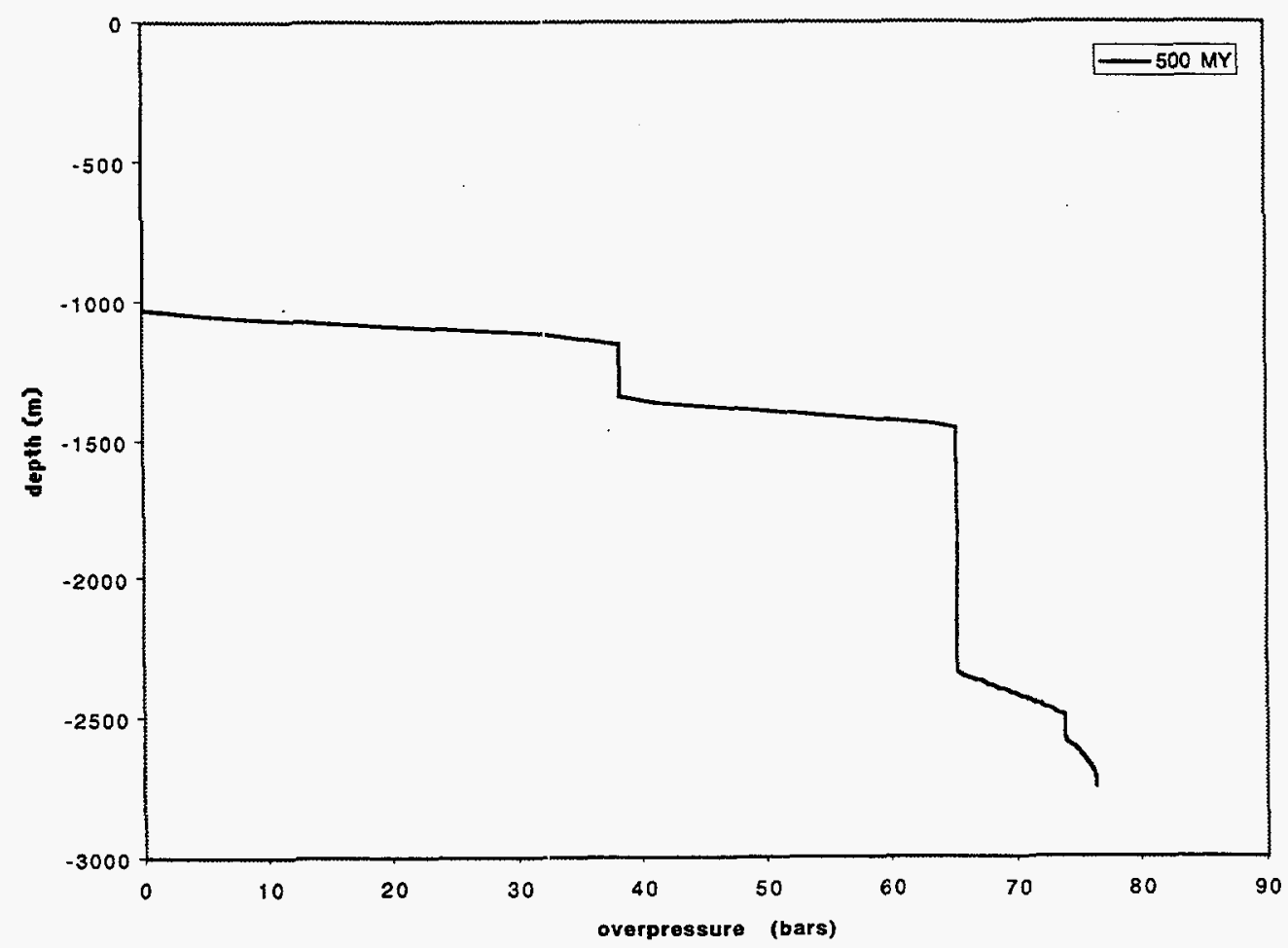

$V-3 d(4)$ 


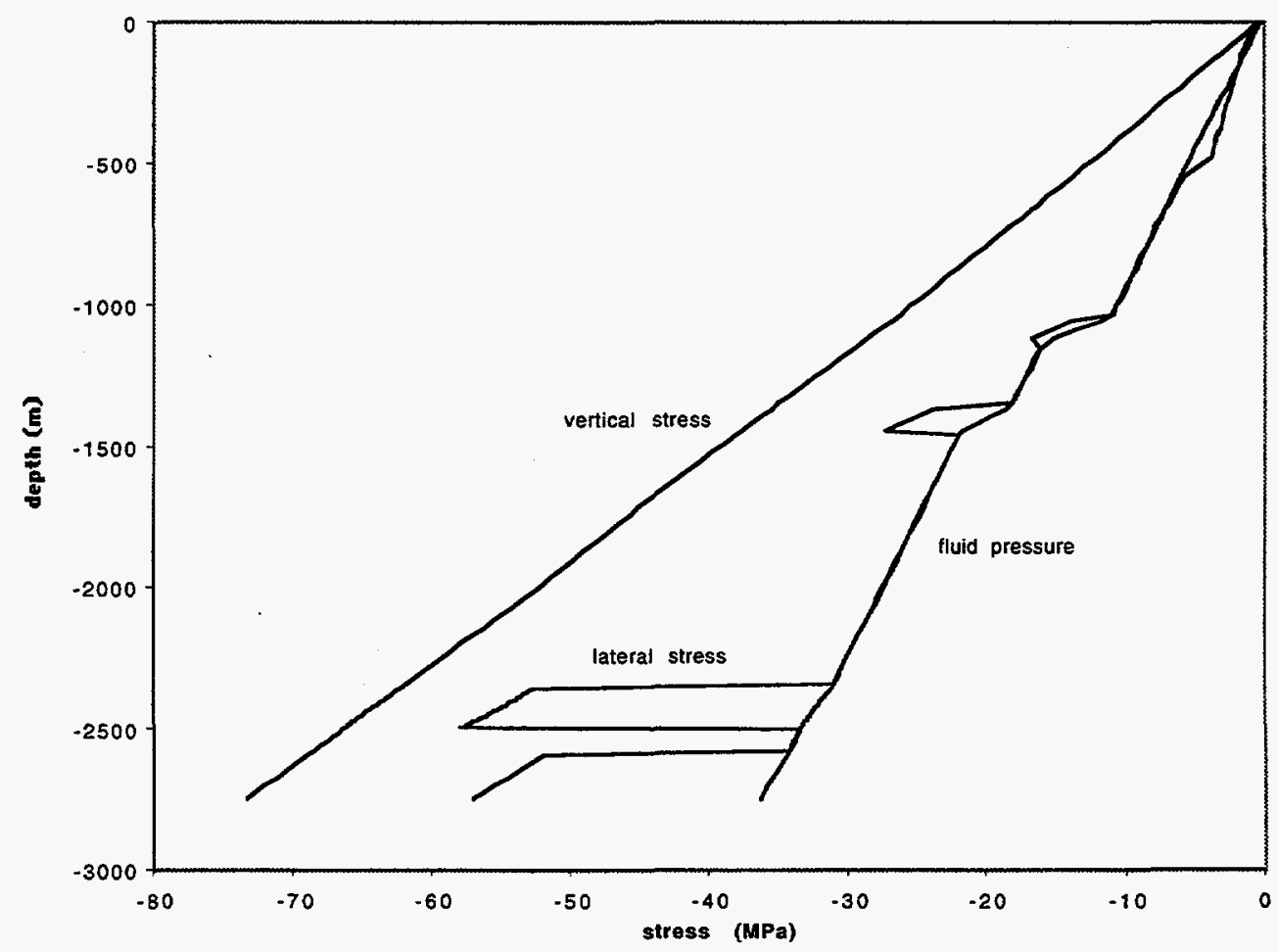

Fig. V-3e As in Fig. V-2e except for Site b (see Fig. V-1). 


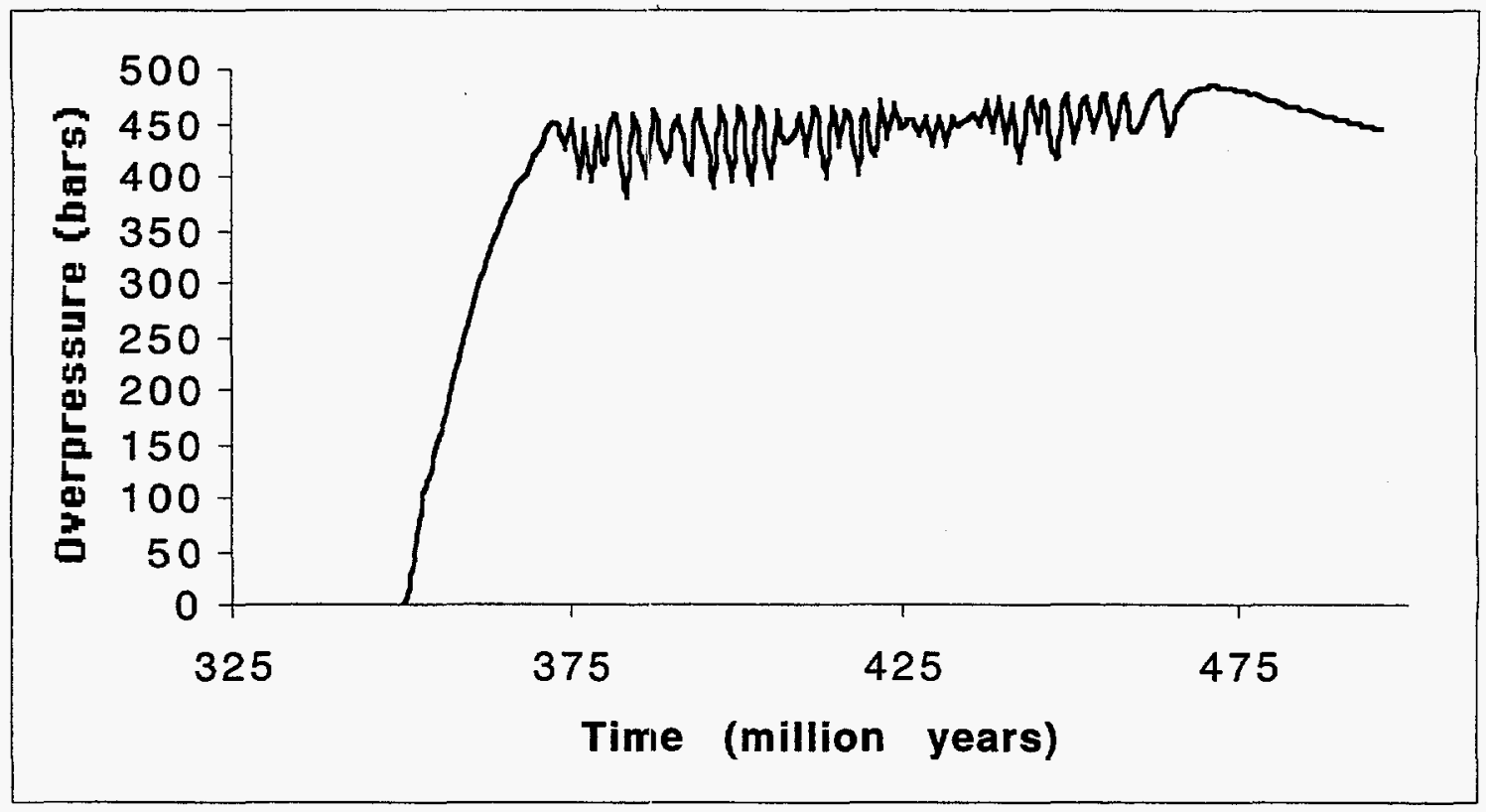

Fig. V-4a Evolution of overpressure at the bottom of the Ellenburger formation. Overpressuring starts around 350 million years, when fractures in the layer above the source rock disappear. Oscillatory behaviour is a result of cyclic fracturing of the seal (see next figure) driven by petroleum generation. After $470 \mathrm{My}$ the cyclic petroleum expulsion ceases and the pressure, oil saturation fracturing and other variables show a more steady behavior (leakage). The location of this simulation is Site b (refer to Fig. V-1.).

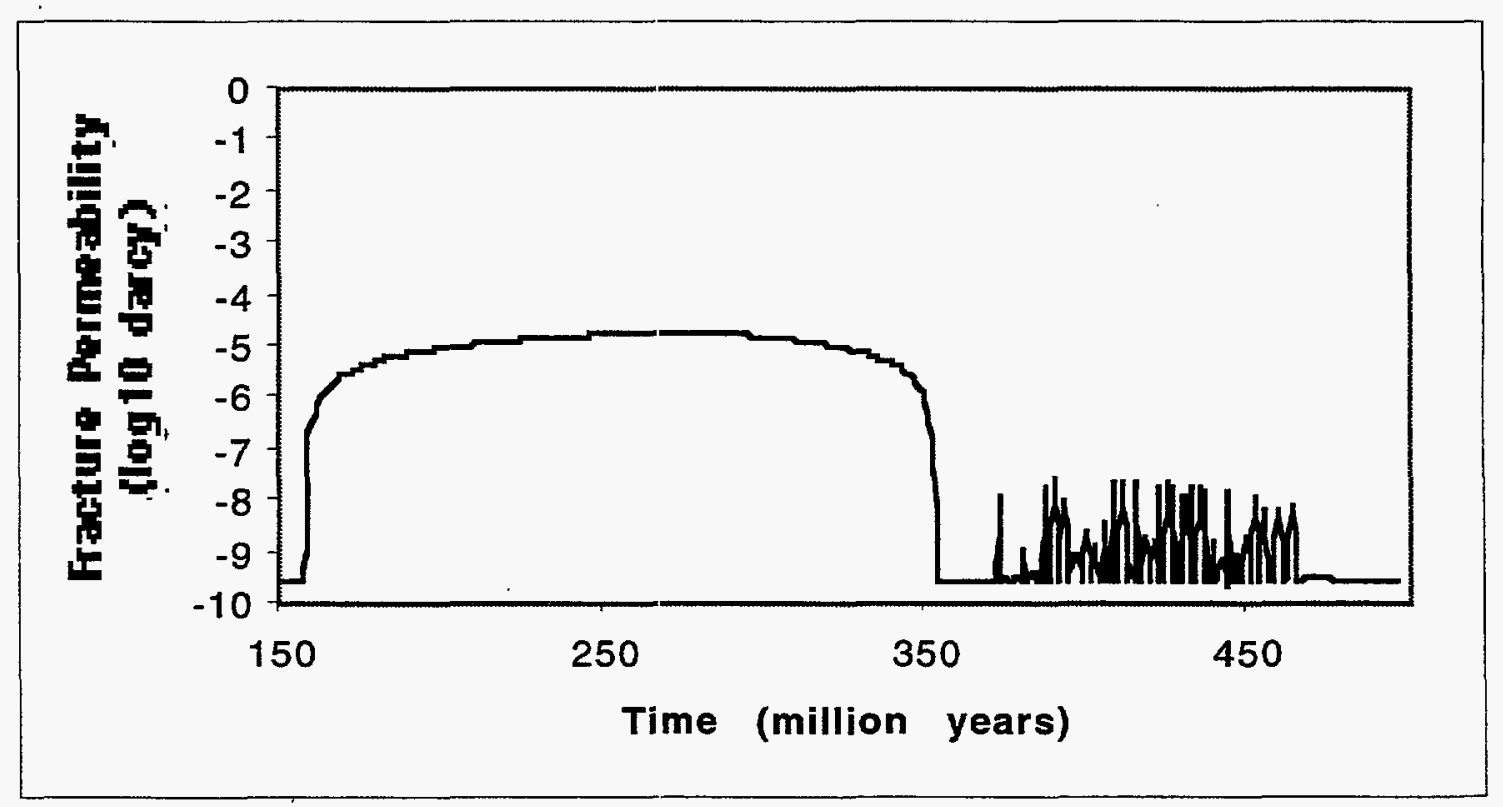

Fig. V-4b Evolution of fracture permeability for a material point in the seal overlying the Ellenburger formation. The first epic of fracturing is a result of the increase in the shear viscosity / bulk viscosity ratio. For this particular rock, as porosity decreases, the bulk viscosity increases at a higher rate than shear viscosity causing an increase in the lateral stress, hence promoting fracture closure. The following small amplitude, high frequency fracturing regime is due to petroleum generation. 

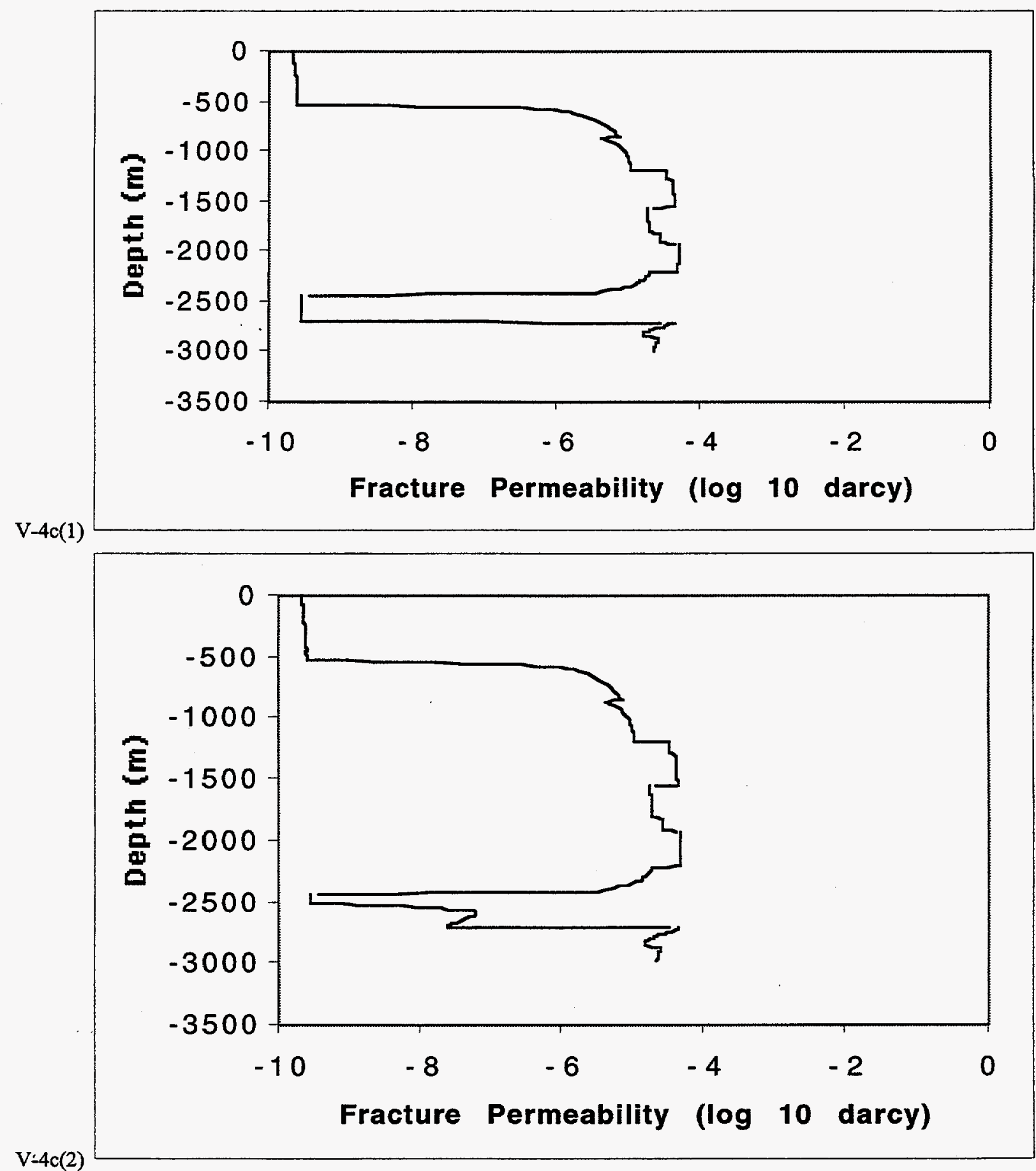

Fig. V-4c Fracture permeability profile sequence illustrating the fracture front moving through the seal (between 2450 and 2700 meters). Overpressuring of oil and water phases primarily due to oil generation creates a fracture front moving upwards through the seal. Once the overpressure is released, the fractures close, which in turn, results in descent of the fracture front and overpressuring. This cycle continues until the oil generation rate slows down, or the seal remains fractured due to tectonic effects (not included here). Each fracture front cycle corresponds to one peak in the previous figure. 


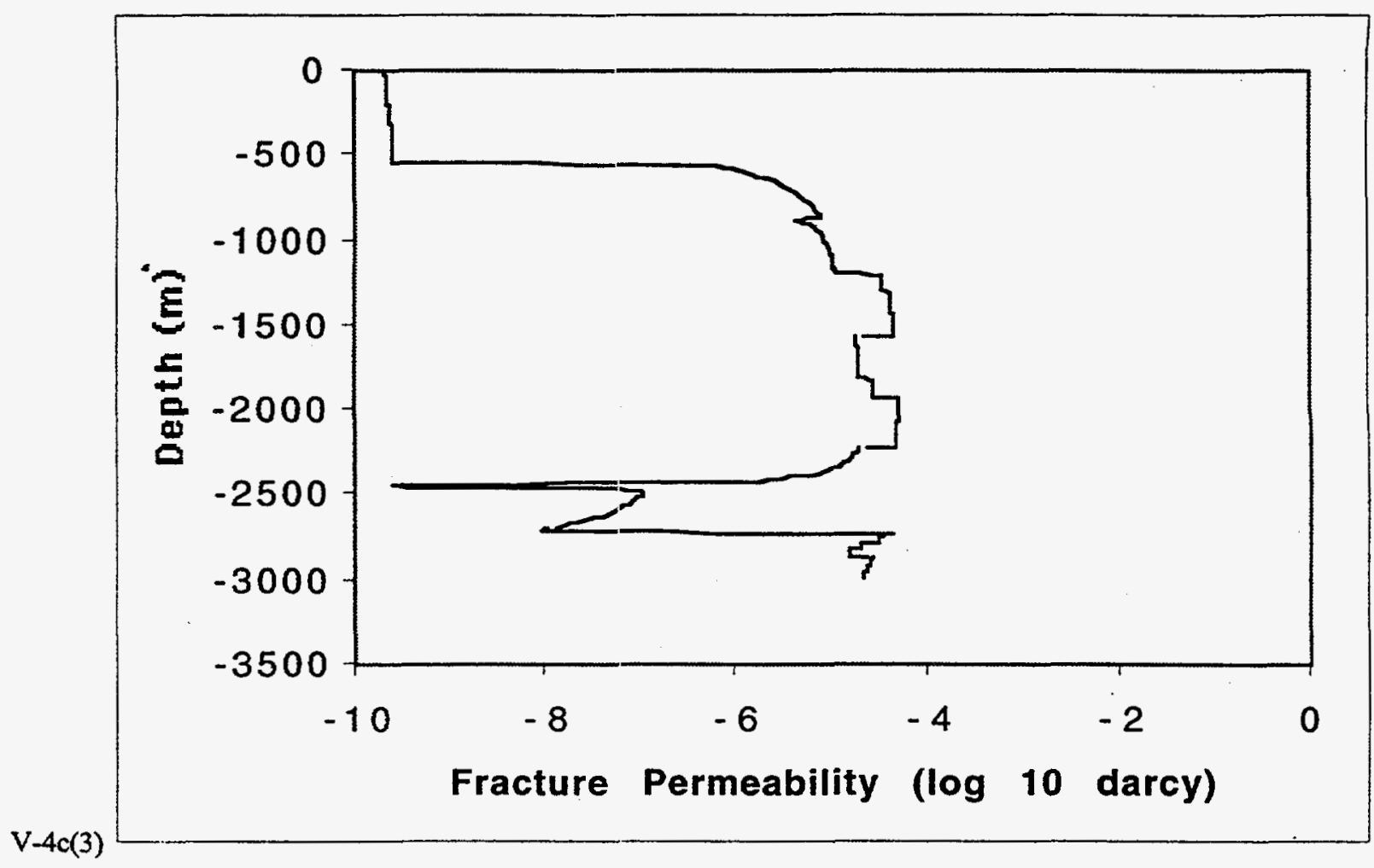




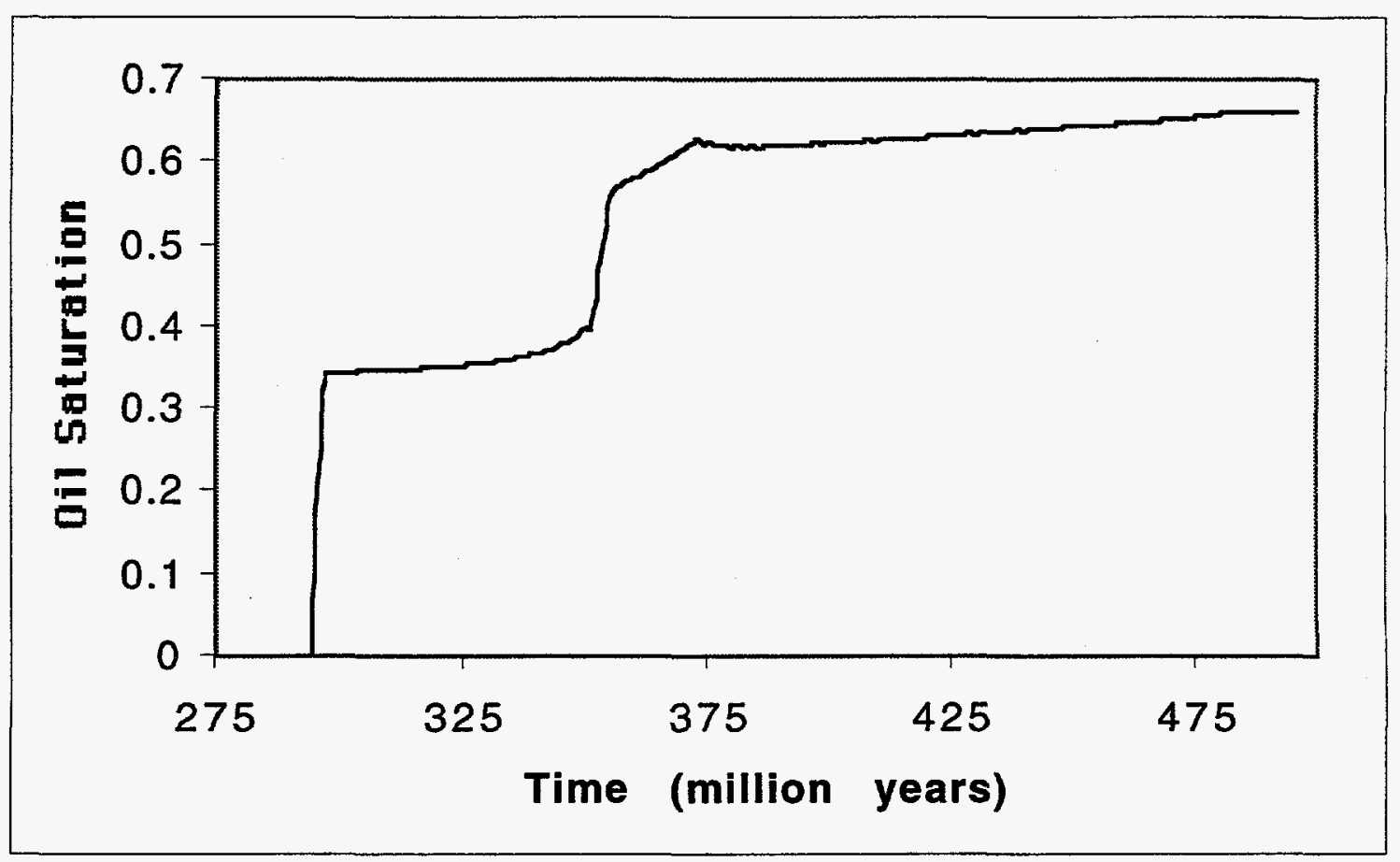

Fig. V-4d History of oil saturation in the seal overlying the Ellenburger formation. Since the seal is fractured until 350 million years, the oil saturation remains fairly constant at 0.35 . As the fractures close, the permeability drops, and the oil saturation and overpressuring increase. During the period after $375 \mathrm{My}$ the oil saturation shows a high frequency, low amplitude oscillatory behavior. 


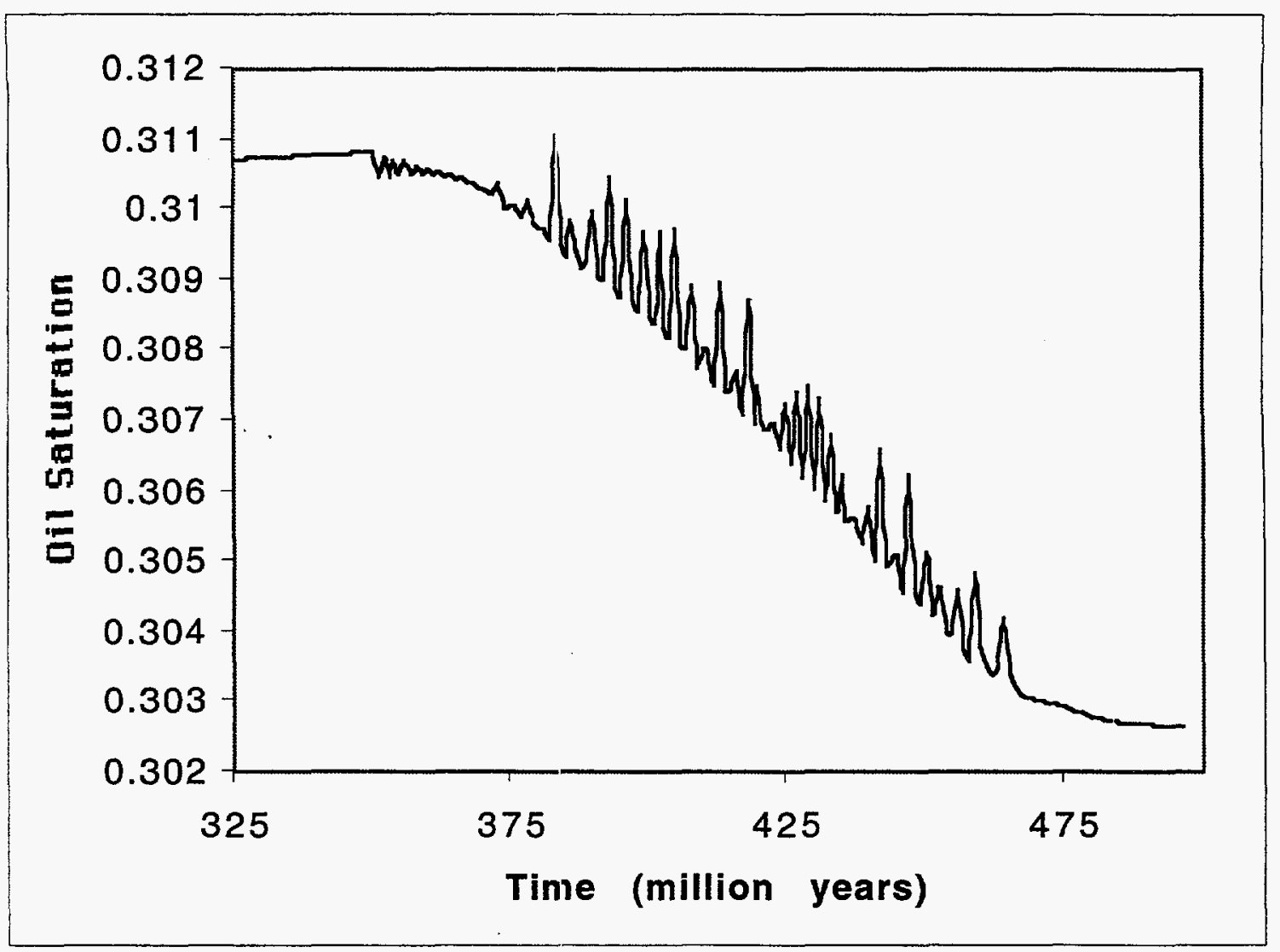

Fig. V-4e History of oil saturation in the Ellenburger formation. The oil saturation is essentially constant until fractures in the seal zone close. During the steady period, the rate of petroleum generation is balanced by the rate of loss through the seal. 

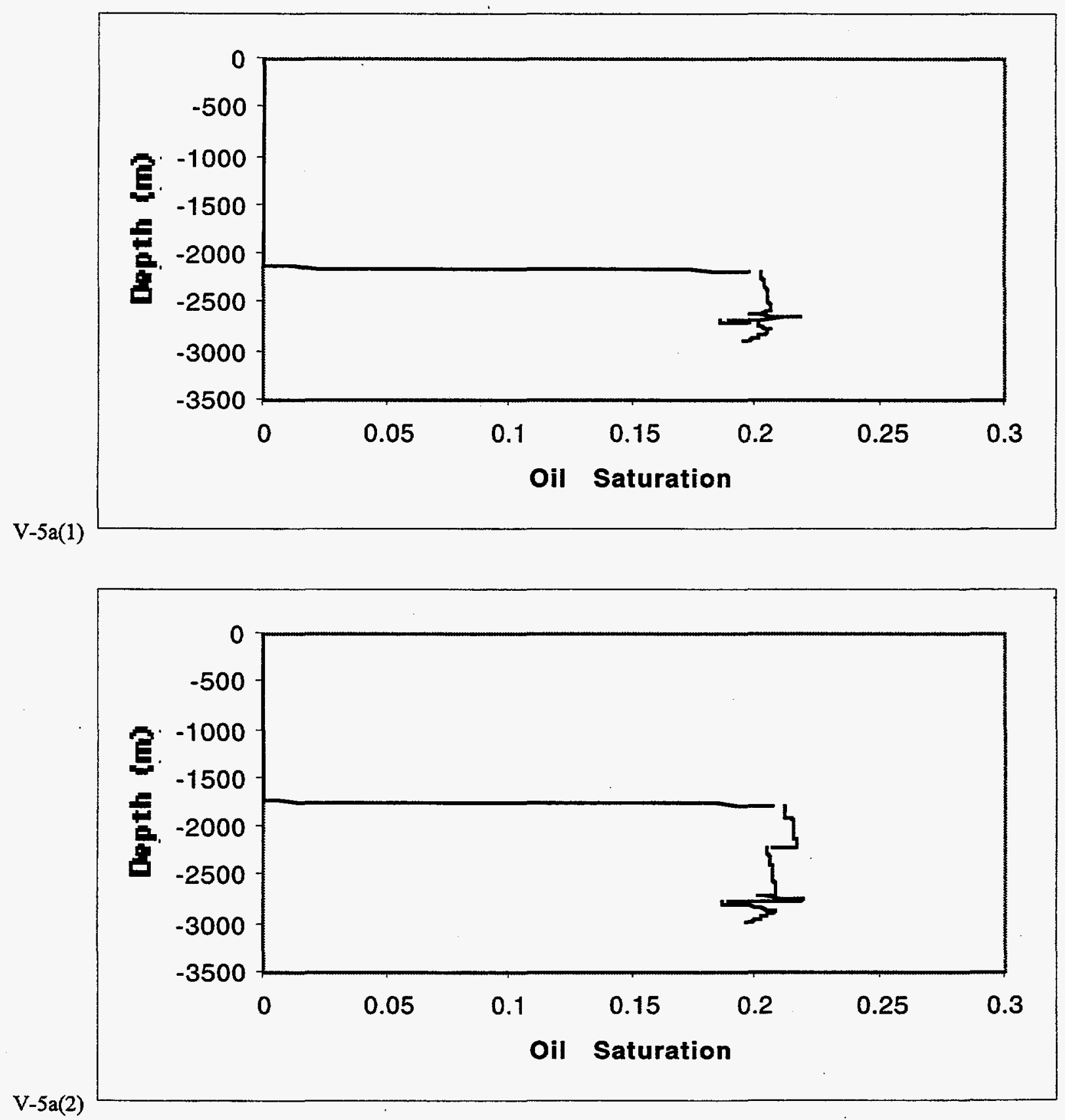

Fig. V-5a Simulated oil saturation profiles at 350, 400, 450 and 500 million years (present-day). 1-D simulation at Site $b$ with all parameters as used for the simulation of Fig. V-4 except that the grain size of dolomites in the Ellenburger and Simpson formations was increased from $0.01 \mathrm{~mm}$ to $0.1 \mathrm{~mm}$. As a result, the sealing role of the lower Simpson formation in retaining Ellenburger oil was compromised due to increased matrix permeability and increased shear/bulk viscosity ratio. 

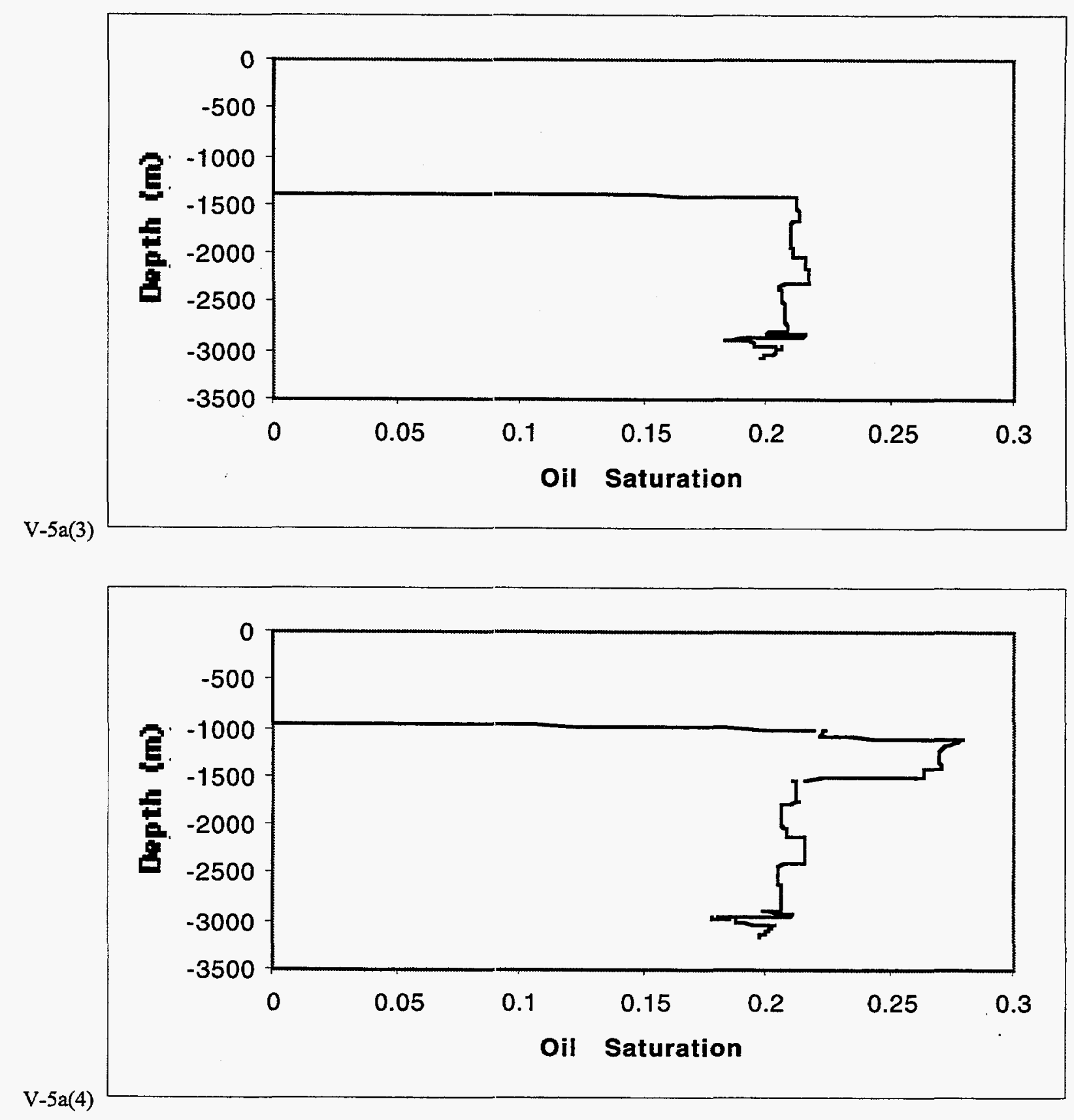


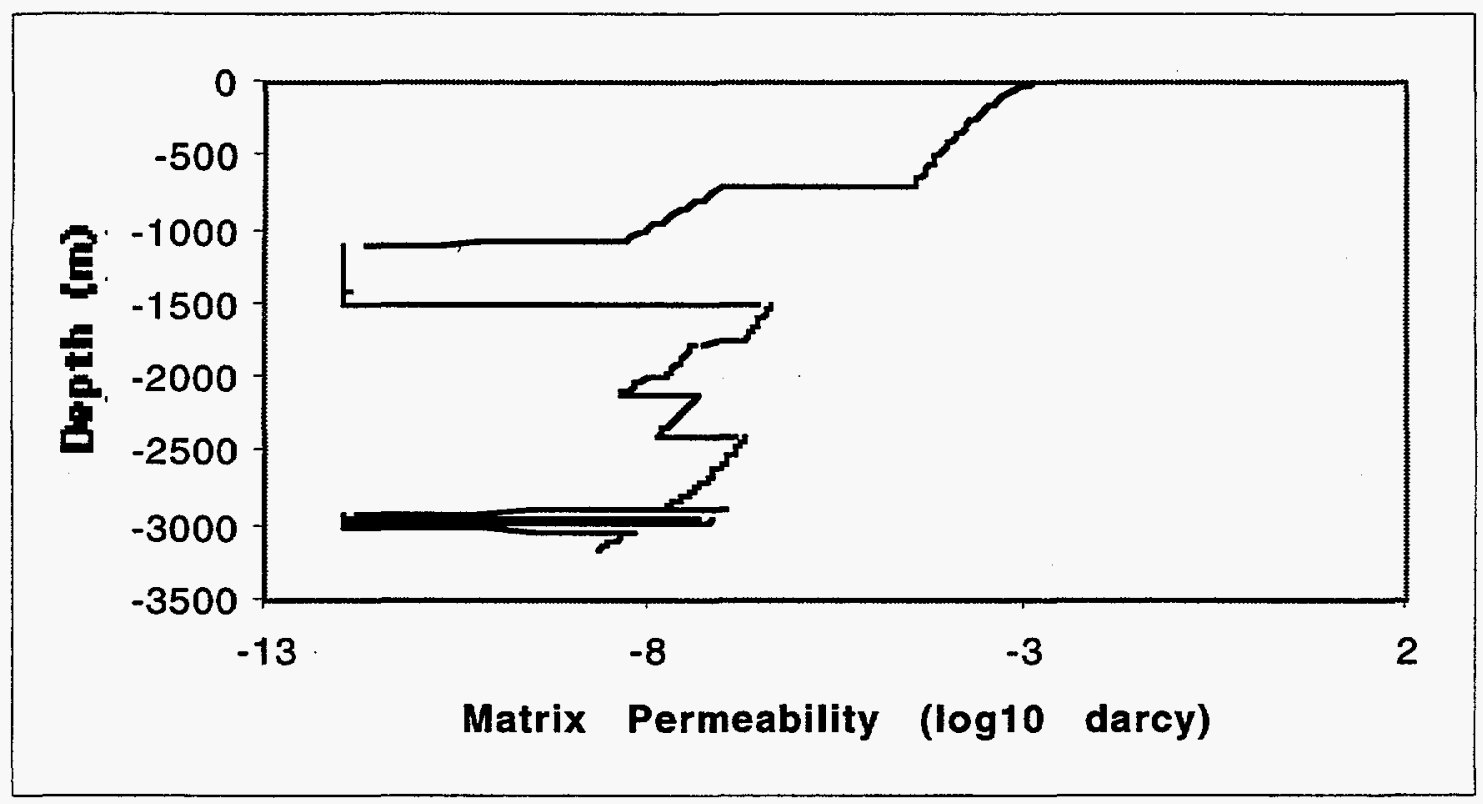

Fig. V-5b Simulated present day matrix permeability profile. This graph is strongly controlled by lithology. For example, the upper minimum permeability zone between 1,100 and $1,400 \mathrm{~m}$ is an anhydrite layer.

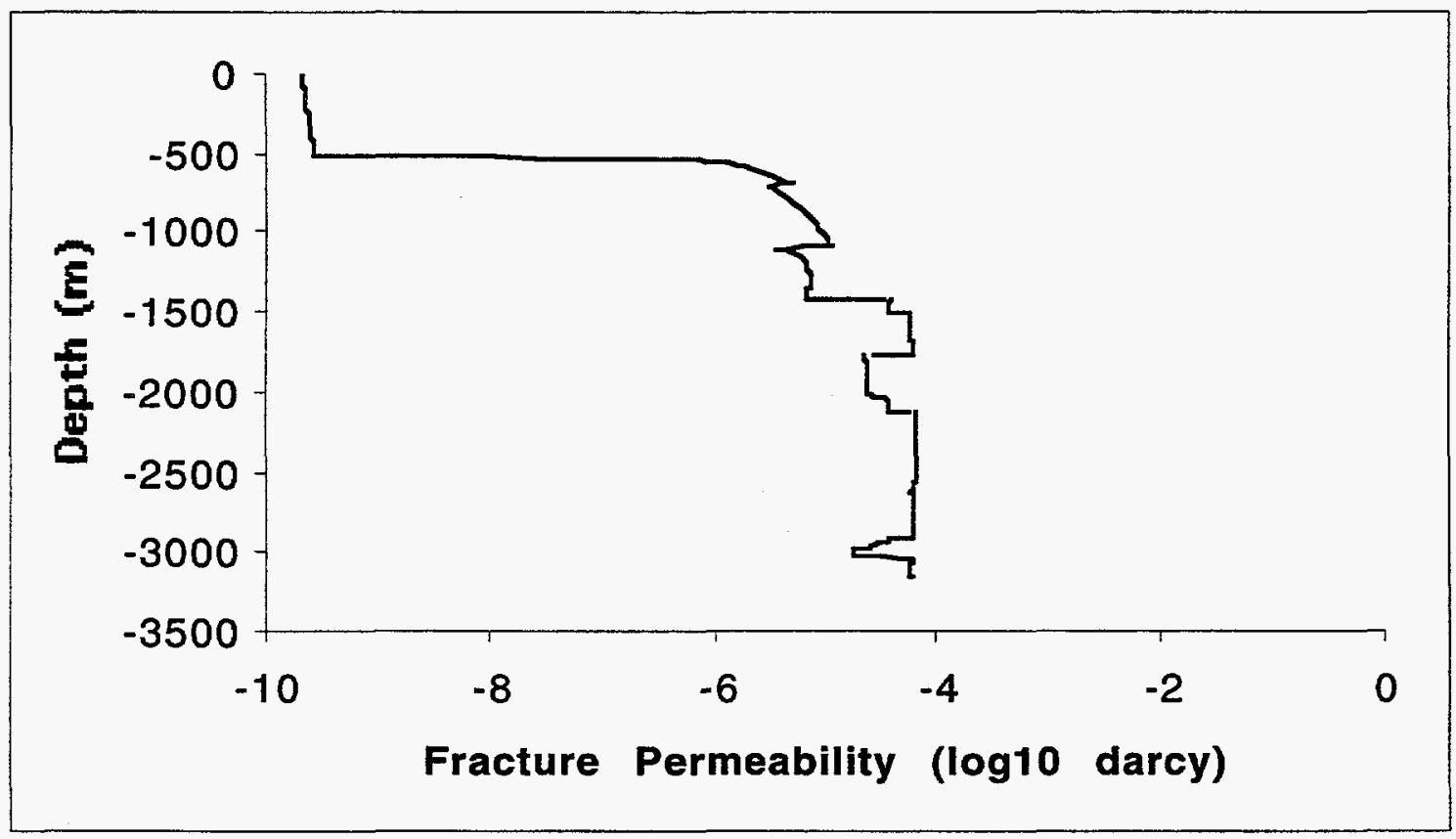

Fig. V-5c Simulated present day fracture permeability profile. 


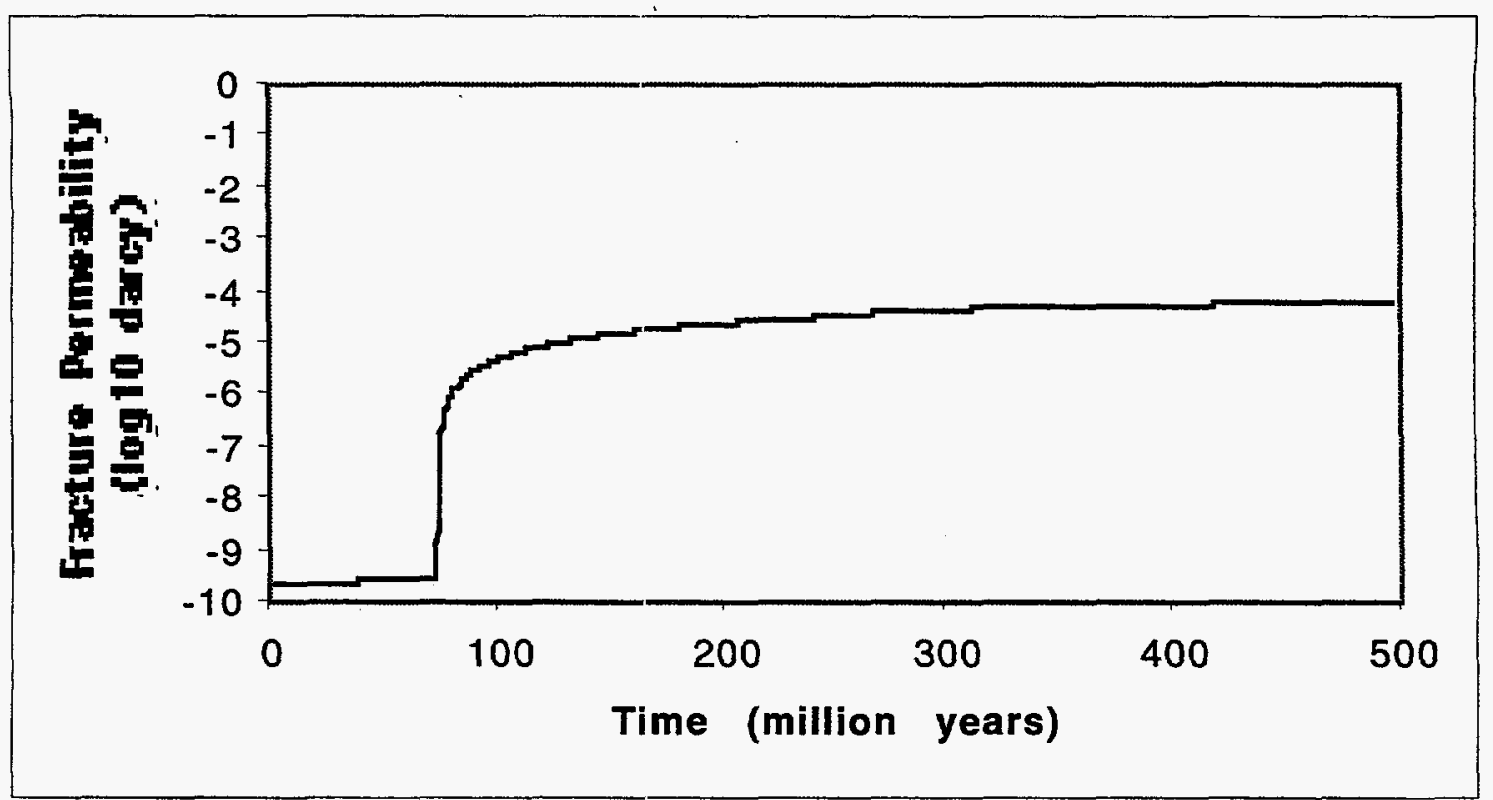

Fig. V-5d Evolution of fracture permeability in the Illenburger formation. In contrast to the case of Fig. V-4b, there is no fracture/expulsion cyclicity.

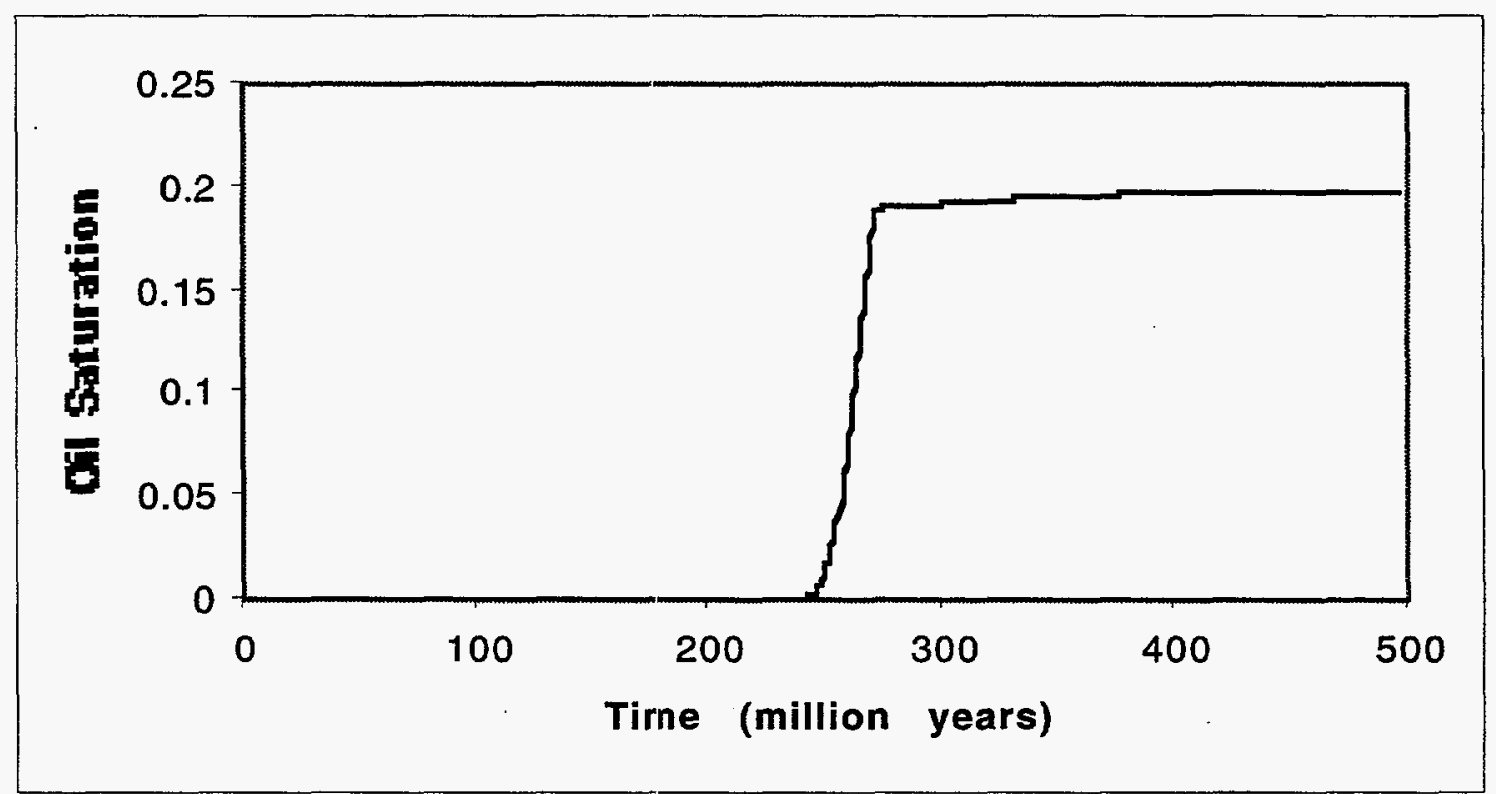

Fig. V-5e Evolution of oil saturation in the Ellenburger formation. 


\section{3-D SIMULATIONS}

\section{A. Overview}

The location and status of reservoirs is a fundamentally 3-D phenomenon. The evolving flexure locally creates extensional fractures that overlay those of the flexure-free system (as simulated in the previous section). Furthermore, petroleum can migrate laterally into or out of what are present day reservoirs. Furthermore, the dip of beds and their internal distribution of transport and mechanical properties is continuously changing over the basin's history.

Thus, a complete assessment of the preproduction state of Andector reservoirs was simulated in three dimensions. The simulated area was as described in Section III (see Fig. V-1 for the study area). It was assumed that all petroleum was generated from source rock within the Andector area. Lateral migration in or out of the side walls of the study area was neglected as was the influx of fluids from below the Ellenburger. Effects of lateral compression or extension were neglected for simplicity.

\section{B. Single-Phase Simulation}

As a baseline for the full problem, a single (aqueous) phase case was run. Thus, the effects of increased fluid volume by oil generation (with consequent overpressuring) and capillary pressure inhibition of flow into finer-grained horizons was not accounted for.

In three dimensions, fractures may have preferred orientation. Thus, we have used our new fracture network statistics model (Tuncay and Ortoleva 1998b). For simplicity, we have assumed that fractures are vertical but can take the six orientations as defined in Fig. VI-1. More complete simulations will be done in the future that allow for more orientations and deviation from the vertical orientation. The limited case considered here is sufficient for illustrating the directionality imposed on the system properties by the preferred fracture orientation that tectonics (notably flexure and directions of overall extension) imposes.

The single-phase simulation is shown in Figs. VI-2 to 8. Several variables and graphical techniques were used to attempt to understand the complex 3-D data.

E\&P planning can be greatly facilitated by having maps of key parameters in any target formation at any time in the basin's history. Figs. VI-8(a)-(c) show fracture properties predicted to have existed 290 million years ago in the Ellenburger Formation. Contours indicate depth to the top of the Ellenburger from sea level at that time. The depression in the topography in the northeast corner is associated with the fault there (represented in the data set as a gradational feature). While there were fractures across the formation at this time, they were enhanced by flexure associated with the fault.

The zone of greatest fracturing lies between the contours of 1228 and $1330 \mathrm{~m}$. As seen from Fig. VI-8(b) dominant fractures there are essentially in orientation group 2, i.e., in the northeast direction along the direction of principal curvature. As preferred fracture direction implies a preferred flow direction, this graphic suggests that the dominant fractures did not help in potential migration of petroleum from the northeast corner of the Andector study area to the remainder of the area. Rather, any such putative buoyancy-driven ("uphill") oil migration was 


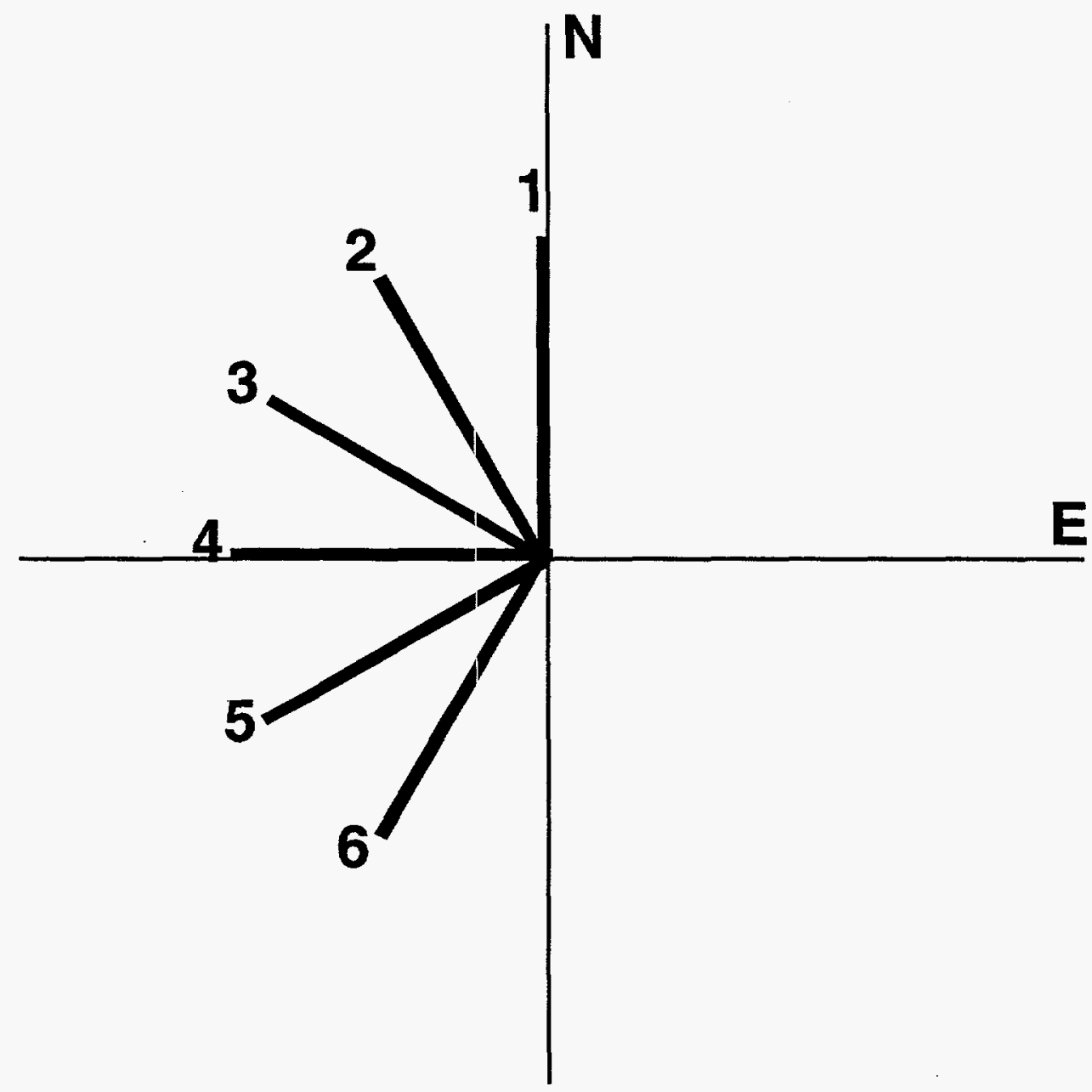

Fig. VI-1 Numbering system used to specify fracture orientations according to the fracture network dynamics model of Tuncay and Ortoleva (1998b):

born by the matrix and non-dominant fractures. Exploration analysis is facilitated by our modeling which gives the timing of fracture enhanced, directed migration or pathways relative to that of petroleum generation and expulsion. 


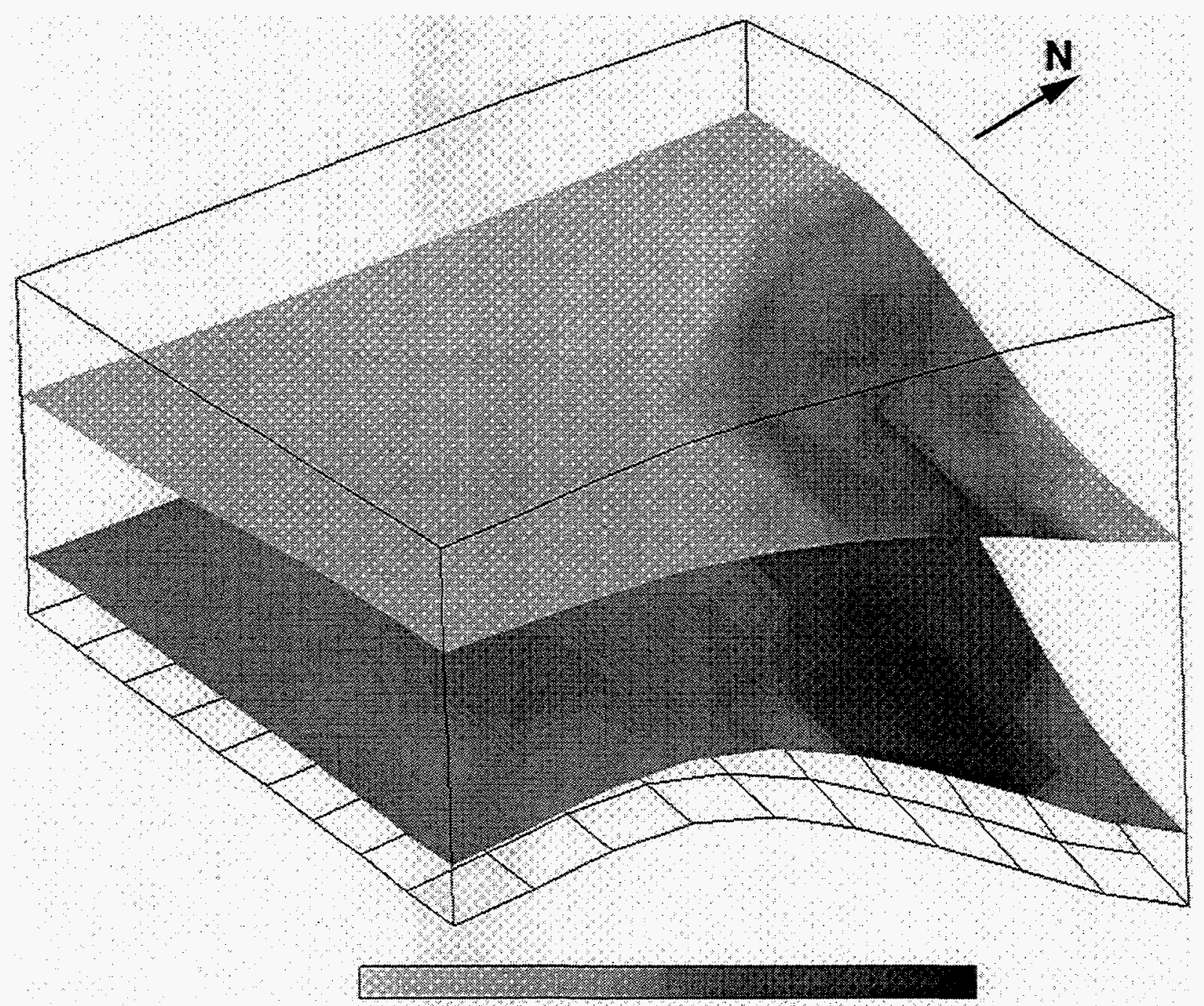

\section{$\begin{array}{llll}0.1 & 62.3 & 124.5 & 186.7\end{array}$}

Fig. VI-2 3-D view of predicted fracture length $(\mathrm{cm})$ depicted on two subhorizontal slices as the system would have appeared 290 million years ago. The slices follow grid layers that themselves follow bedding. As the northeast corner of the simulation domain sinks, it results in flexural strains. The fractures in the upper slice (Fusselman) are mainly flexure related. Fractures in the lower slice (Ellenburger) are longer because both rock stiffness and flexure are greater. The fractures in the shallower horizons do not appear in the 1-D simulations as they are caused by flexure whereas the deeper ones persist but are shorter in the 1-D simulations. 


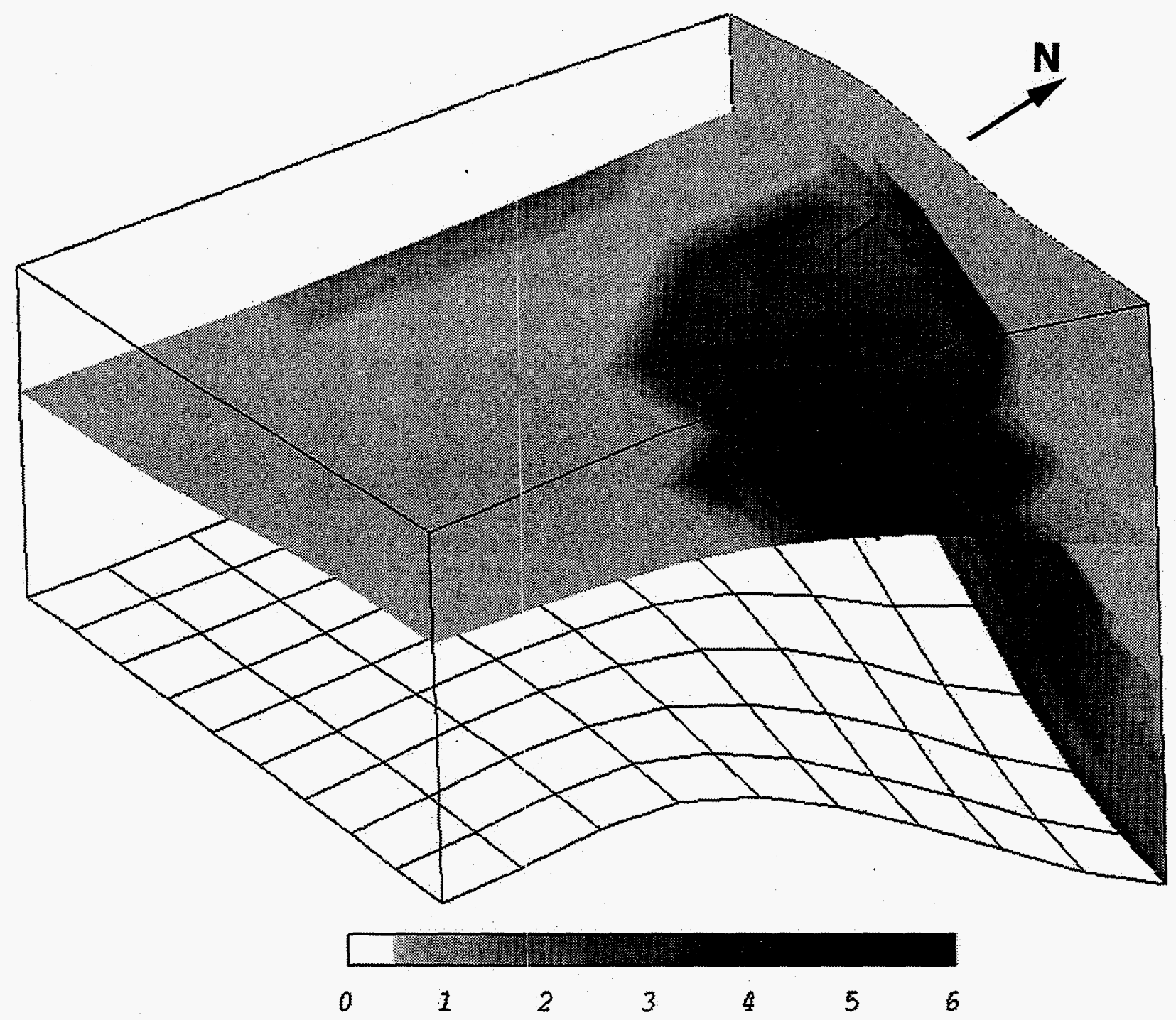

Fig. VI-3a 3-D view of dominant fracture orientation as explained in Fig. VI-1. Note that the fracture orientation follows the curvature caused by differential subsidence of the basin. The line segments suggest fracture orientation. The upper surface shown is the Fusselman Formation. 


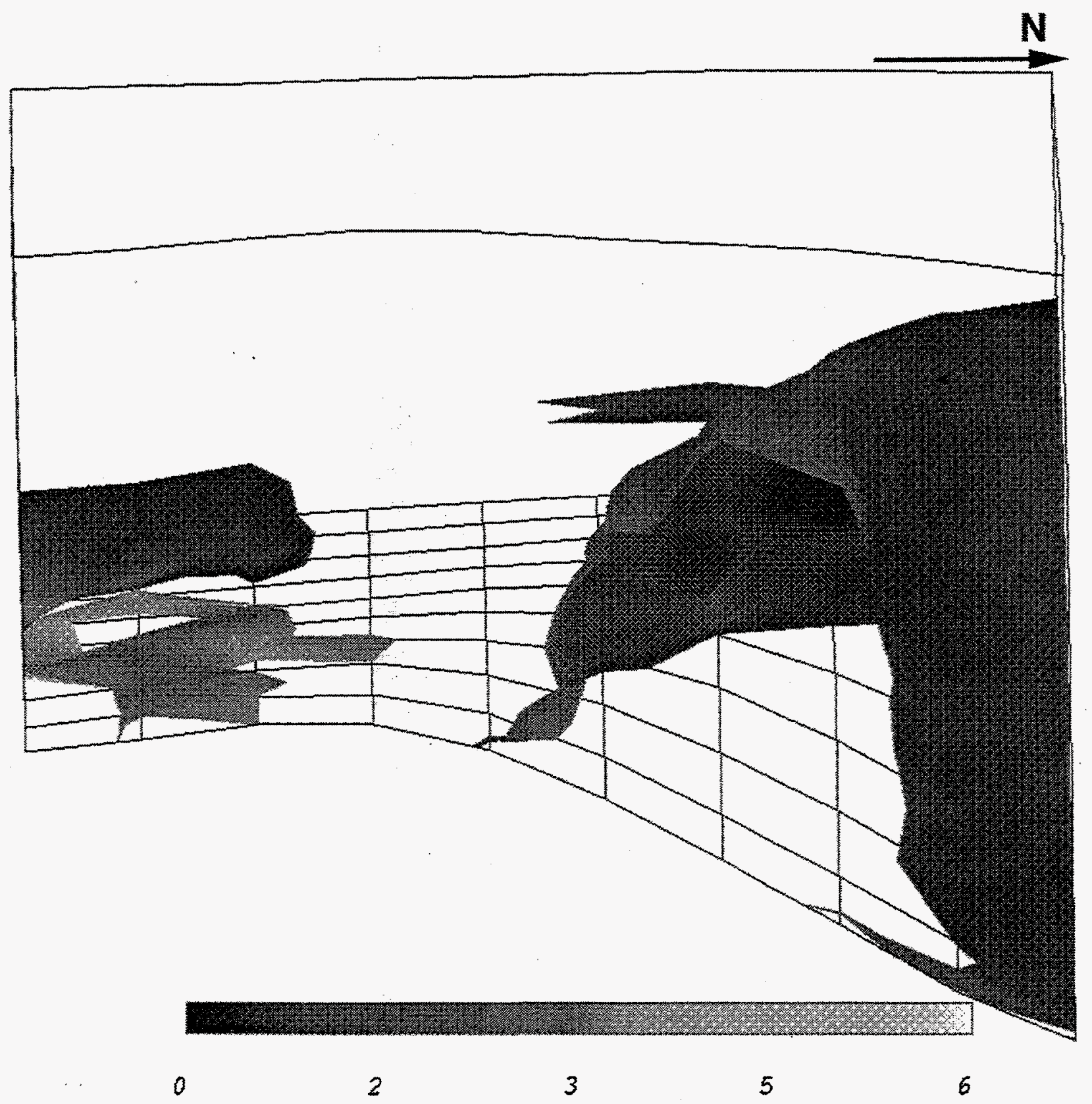

Fig. VI-3b As in Fig. VI-3a except depicted as surface within which the fracture length is greater than $90 \mathrm{~cm}$. Shading is for dominant fracture orientation. 


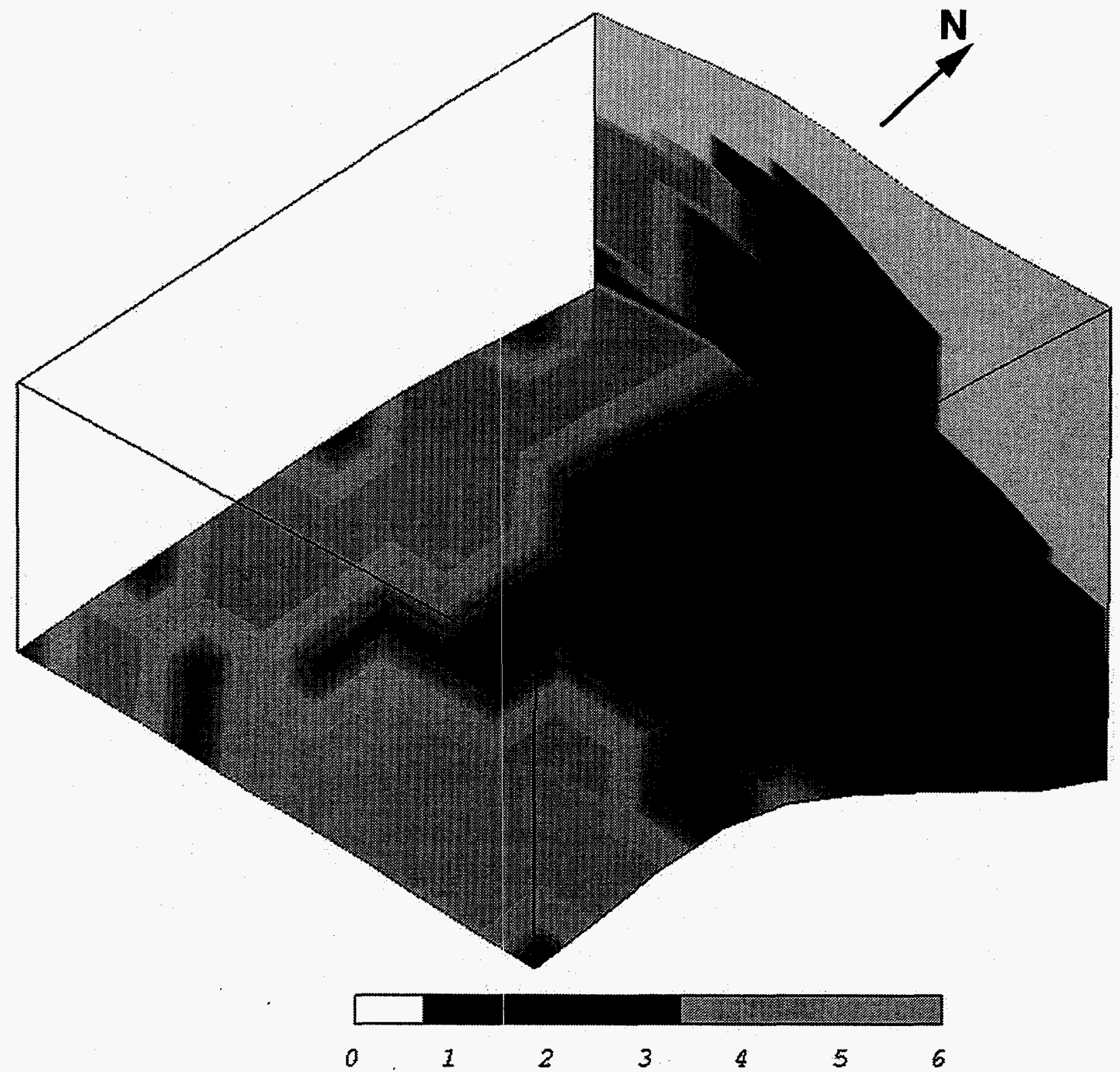

Fig. VI-4 3-D view of dominant fracture orientations in the Ellenburger formation $290 \mathrm{My}$. To simplify the depiction of fracture orientation, the orientations $1,2,3$ and 4,5,6 are lumped appearing dark gray and light gray, respectively. 

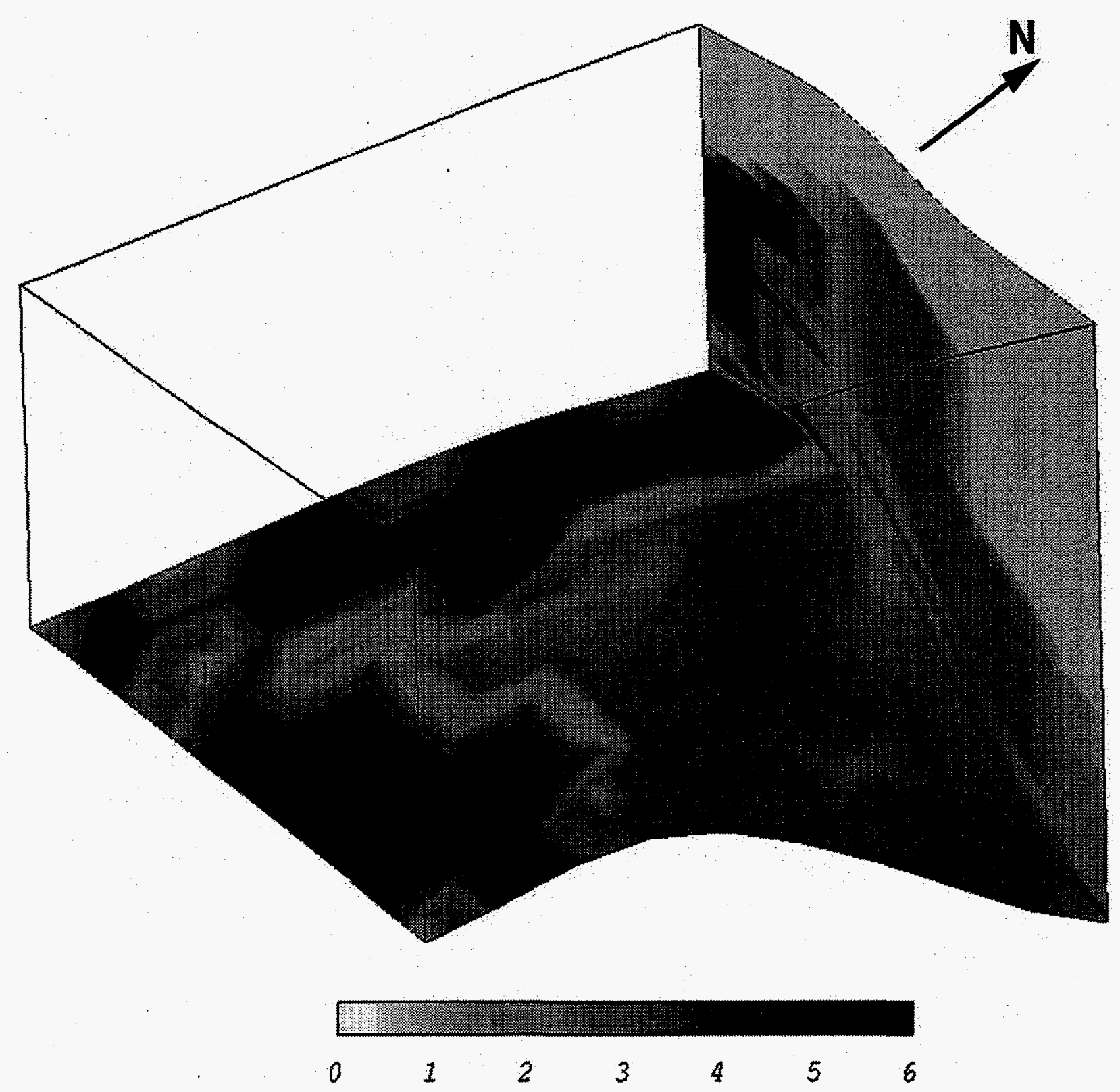

Fig. VI-5 3-D view of dominant fracture orientation in the Ellenburger formation $290 \mathrm{My}$. The complicated fracture network shown, results in anisotropic fracture permeability. Therefore a reliable prediction of petroleum migration path requires the modeling of anisotropy caused by fracturing. 


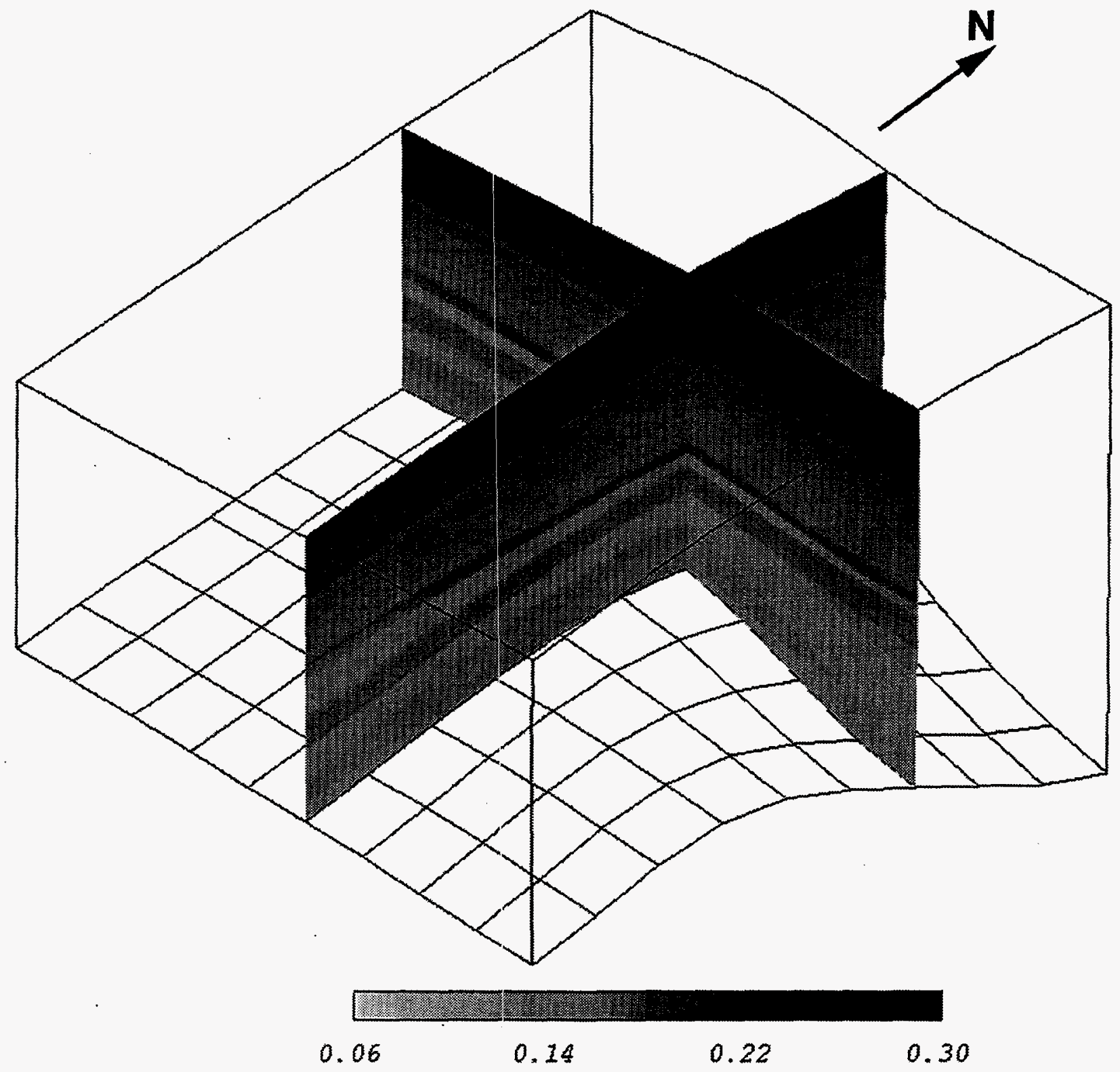

Fig. VI-6 3-D view of porosity distribution $290 \mathrm{My}$. The layered nature of porosity suggests that it is strongly controlled by stratigraphy. 


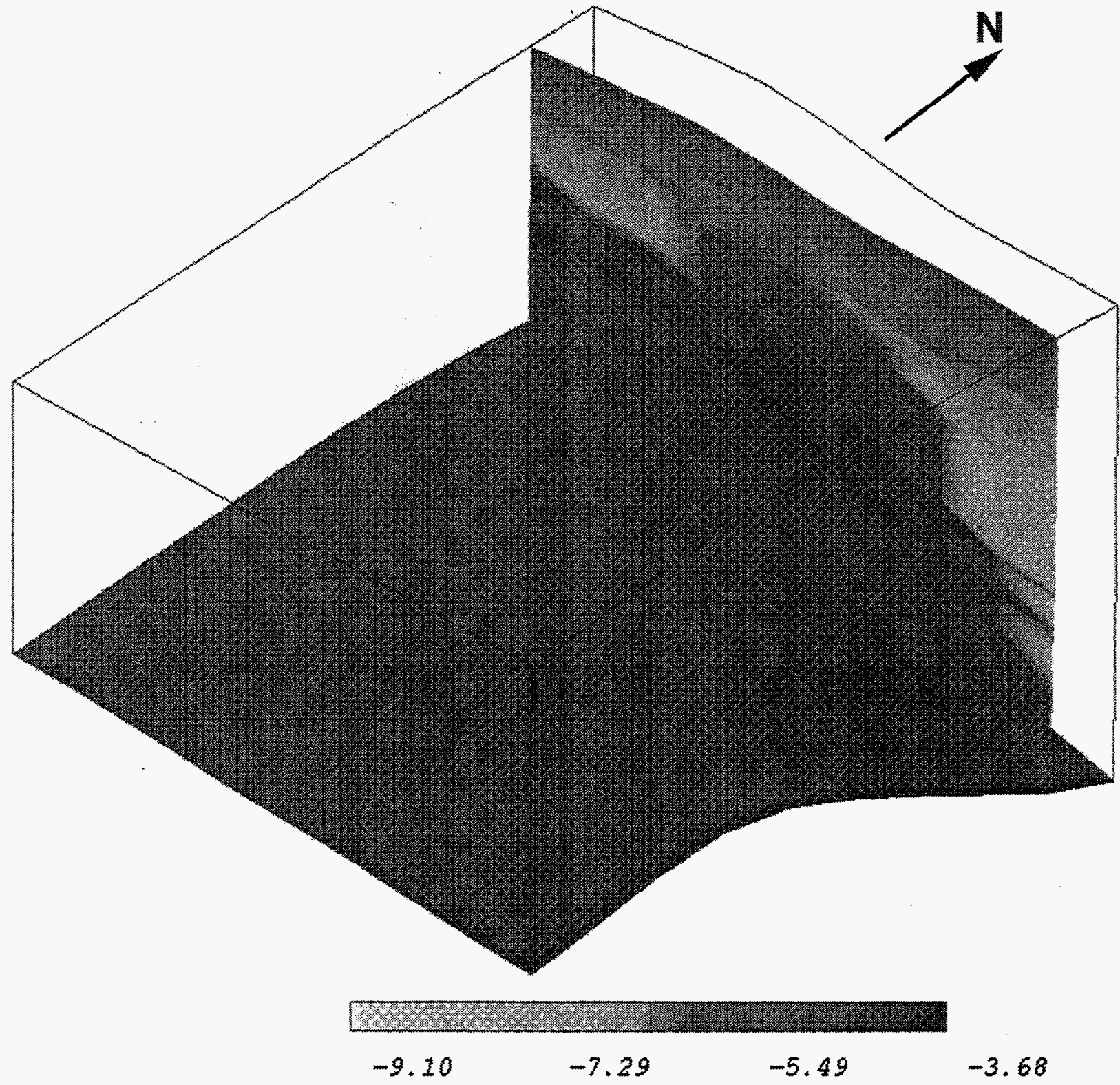

Fig. VI-7a 3-D view of fracture permeability $290 \mathrm{My}$. While porosity (see previous figure) closely follows the stratigraphy, the distribution of fracture permeability is more complex due to the interplay of stratigraphy and flexure. 


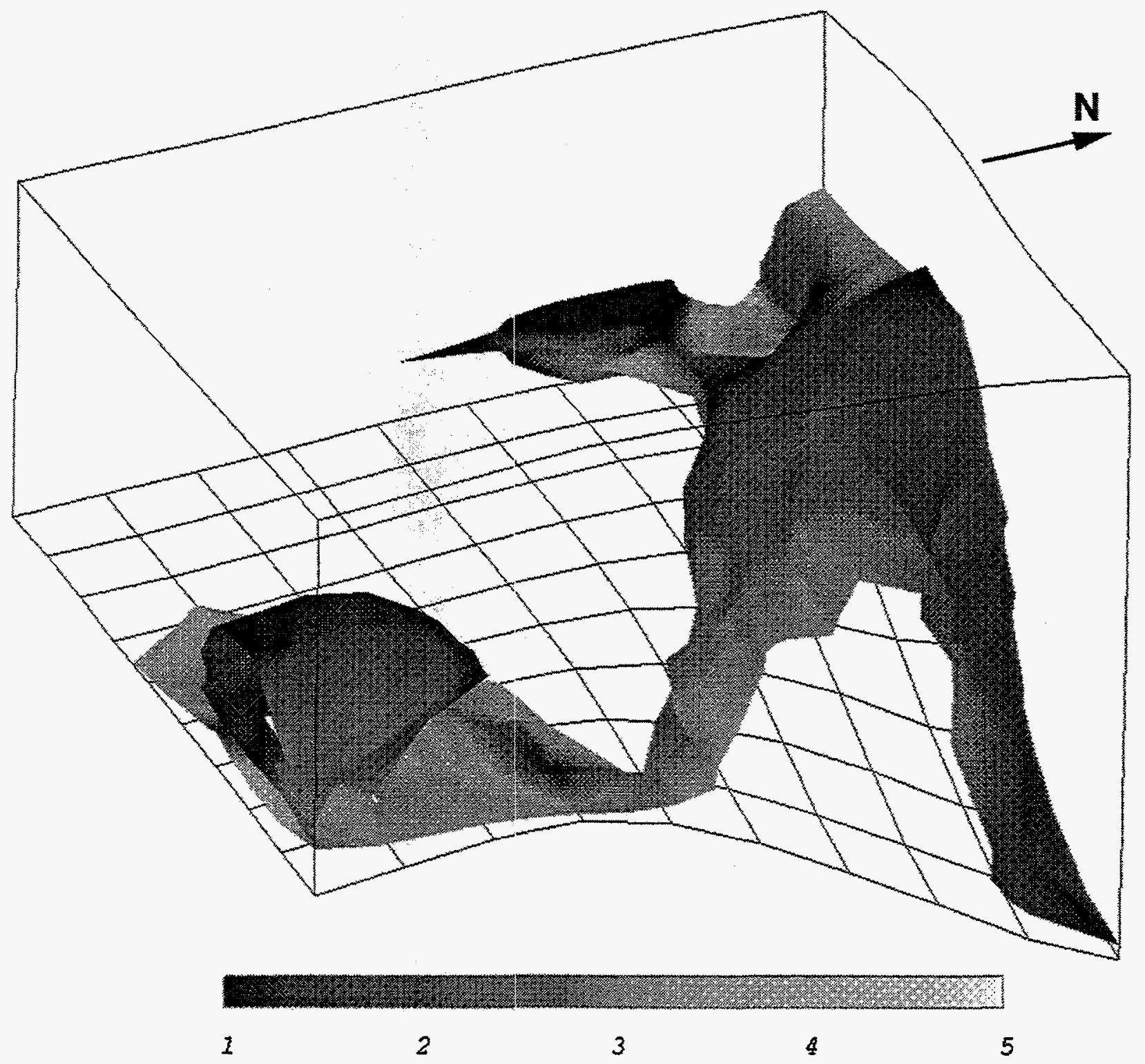

Fig. VI-7b As in Fig. VI-7a except depicted as surface within which the fracture permeability is greater than 5.5 $\log _{10}$ Darcy. Shading is for dominant fracture orientation. 


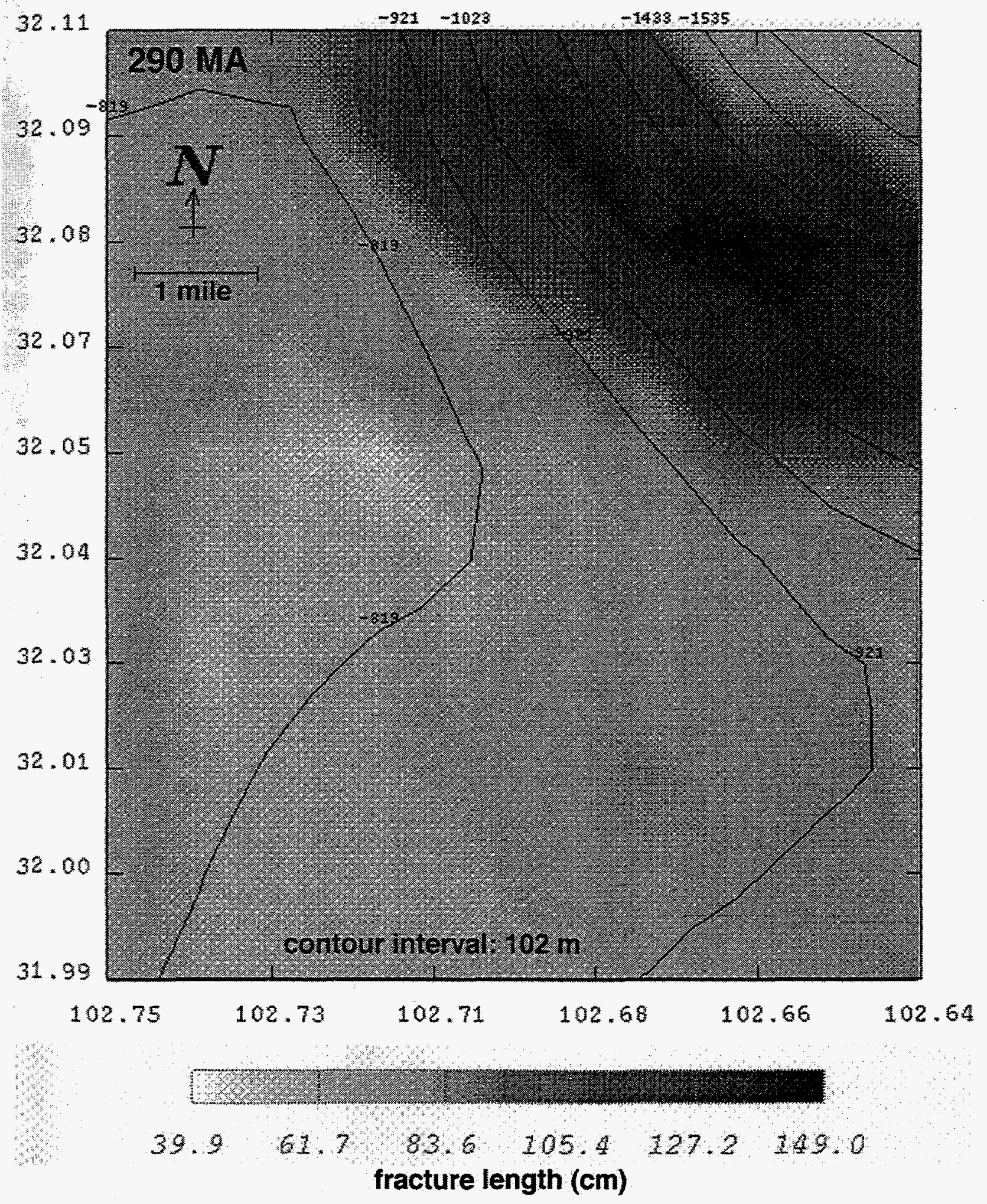

Fig. VI-8a Predicted map view of the Ellenburger Formation seen as it was 290 million years ago. Contours indicate depth in meters. Shown is fracture permeability shown as gray shading. 

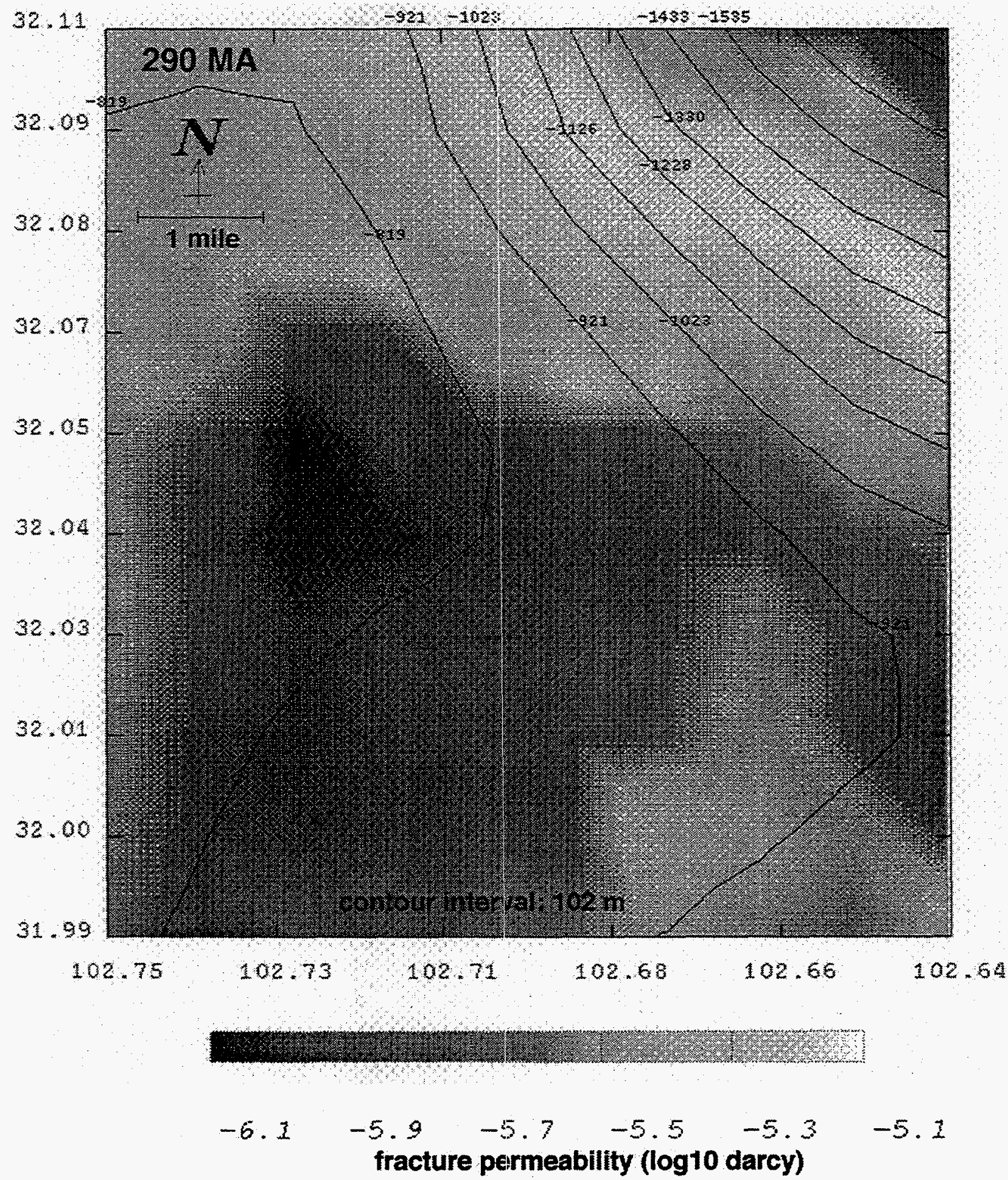

Fig. VI-8b Predicted map view of the Ellenburger Formation seen as it was 290 million years ago. Contours indicate depth in meters. Shown is dominant fracture orientation, shown as gray shading. 


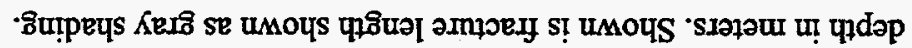

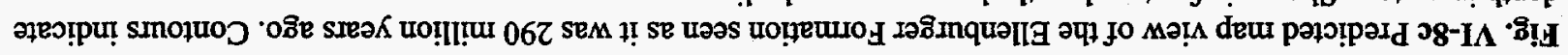

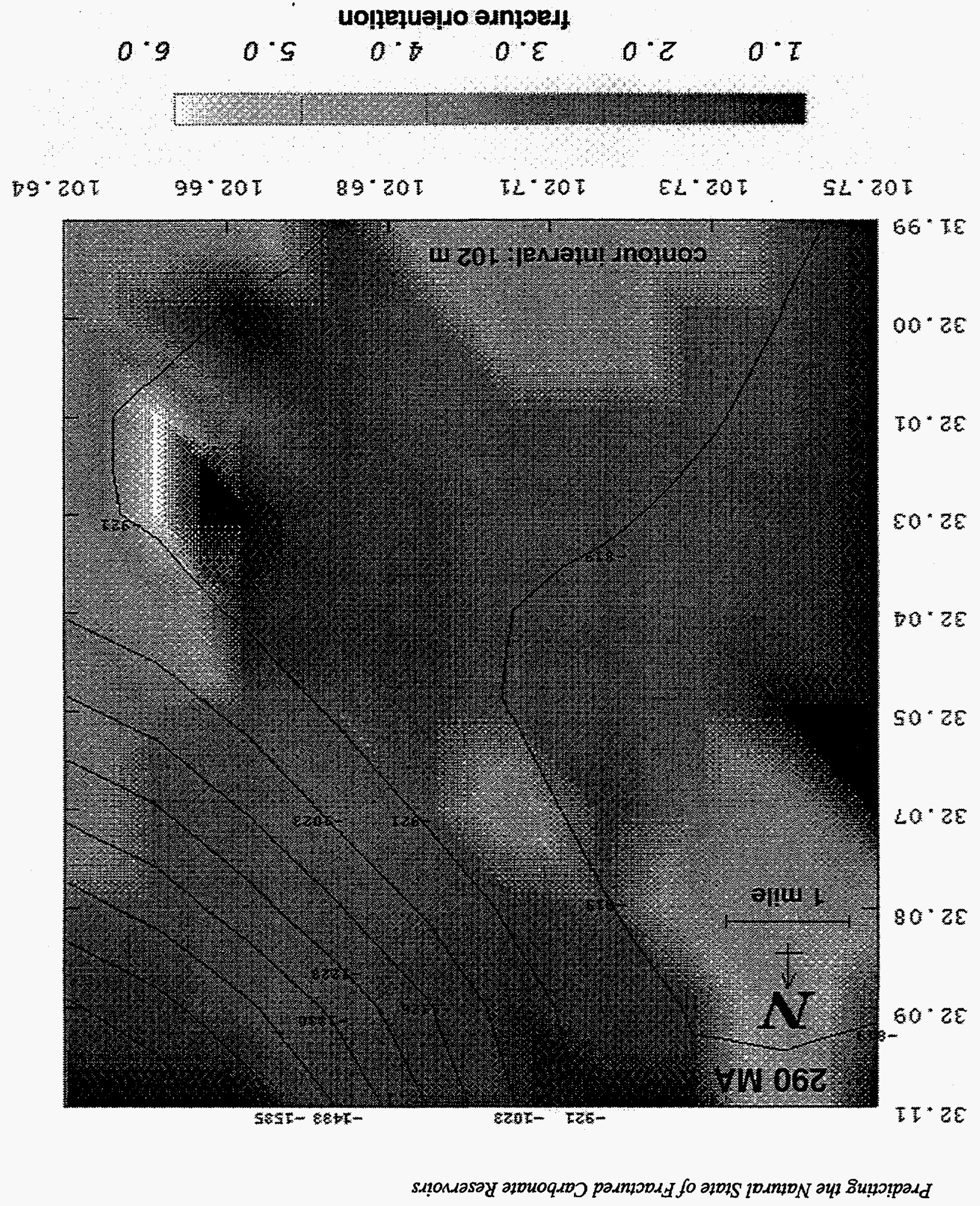





\section{CONCLUSIONS}

The coupled dynamics of continuous rock deformation, fracturing and petroleum generation, expulsion and migration were modeled to test the viability of forward RTM basin modeling for predicting the location and characteristics of naturally fractured, carbonate reservoirs. To test our approach, basin data usually gathered in basin and field analysis were integrated through our RTM model to predict the preproduction state of Andector Field. In a real sense, the essence of our approach is to use the laws of physics and chemistry to extrapolate from the surface or borehole to the prospective reservoir.

The results of our Andector RTM test were the following:

- fractures can occur in brittle zones (i.e., zones capable of sustaining low ratios of least to maximal compressive stress ratios) even in the absence of flexure;

- flexure rate during deformation is more important than flexure itself (i.e., present day flexure is not always a reliable indicator of fracturing);

- the timing and location of fractures in the geological past is at least as important as present day fractures in determining present day reservoir location and characteristics;

- due to the importance of time-dependent processes (visco-plasticity, pressure solution and gouge) as well as organic reaction-derived overpressuring and changing rheology due to diagenesis, static analysis (flexure or poroelastic) models cannot predict fracturing (either past or present-day); and

- the preproduction state of fracture intensity and orientation as well as petroleum emplacement could be reliably predicted by our model; some improvements in our model and its interface will make it an important new tool for integrated basin and field E\&P analysis.

In light of the above, we believe our modeling approach is an important new tool for naturally fractured reservoir prediction/analysis. Additional comments are in order as follows.

The present model has sufficient richness to predict fracture intensity and rose diagrams. These are key parameters commonly made in quantitative fracture characterization. Thus, well and outcrop fracture data can be used via our model to extrapolate away from wells and down to the subsurface. Such quantitative predictions also allow for improved calibration of our model.

The fracture-mediated expulsion of petroleum from source rock can be oscillatory. Each pulse of petroleum ejection can have its own migration history depending on the relative timing of fracturing and other parameters along putative petroleum migration pathways. Thus, the location, amount and quality of various petroleum pools depend on the history of fracturing, diagenesis, temperature and other factors. As these are all strongly coupled, they must be accounted for via fully coupled, forward models.

Better methods for estimating the compression/extension and basement heat flux histories would facilitate more accurate and cost-effective basin/reservoir modeling. These factors are needed as input data for our forward modeling approach and directly affect fracturing and diagenesis/petroleum generation, respectively. Our 3-D RTM model is potentially an excellent basis for constructing these histories. Quite generally, the present-day status of the basin is a functional of these histories. As the calibration of the physical and chemical laws improves, one can then optimize the model predictions by varying parameters determining these histories until predicted present-day formation shapes, textures, fluid and thermal well control and other 
observed parameters are accurately captured. This type of optimization approach to fixing poorly constrained geological data is an important application of our model.

Improvements of the model that would increase its predictive power include the following:

- more complete organic kinetics (for kerogen and fluid petroleum);

- upgrading the flow law to allow for three phases (oil, water and gas) and the exchange of components between them; and

- implement a dual porosity/permeability flow law calibrated in terms of the fracture network generated by our model.

These improvements can be carried out in a three year project.

The computational requirements of our 3-D simulator put our simulations at the forefront of modern computational grand challenges. The comprehensive aspect of our model requires that we simulate over 100 variables (stress tensor, fracture network characteristics, fluid phase saturations and composition, etc.). For minimally acceptable spatial resolution, at least 100,000 finite elements $\left(10^{6}\right.$ being a more acceptable minimum) are required. This level of computation requires enormous quantities of $\mathrm{CPU}$ time.

Typical CPU requirements are as follows:

- 1-D simulations- 6 to 48 hours

- 3-D minimal resolution-1-3 months

These numbers are for an 8-processor Silicon Graphic Origin 2000. The range of times depends on both the completeness of the sedimentary history (i.e., the number of formations resolved) and the time period of the basin history (i.e., $500 \mathrm{My}$ for the Permian Basin, West Texas and 75 My for the Piceance Basin, Colorado). CPU time also is affected by the number of fluid phases and chemical species (in the fluids and kerogen) accounted for.

The success of this project can best be evaluated in terms of the degree to which the 3-D RTM modeling approach has been shown to be viable for E\&P analysis and that it has greater or equal accuracy relative to that of other approaches. Our simulations show that classical (static) flexure analysis cannot account for all pathways to fracturing nor is it a reliable fracture indicator in cases where flexure does not lead to fractures (i.e., for slow flexure rate). On the contrary, our RTM process can account for all the factors leading to or repressing or healing fractures.

Computational demands of our approach are not a reasonable indicator of the lack of success of this project. The CPU requirements must be balanced by the potential benefits. Thus, a simpler approach, omitting several processes, would be fraught with greater uncertainty. In addition, computational power will certainly be improved in the coming few years. Computer speed has steadily doubled every eighteen months for the last two decades. Gigahertz computer chips have already been announced by several manufacturers.

A natural and cost effective extension of this project could make its benefits available to the industry. A speedup of a factor of two in our overall code will be obtained in six months and much greater efficiency would come with planned improved algorithms and parallelism. The later type of hardware is expected to become much more affordable in the next few years. Thus, million finite element, comprehensive simulations should be obtainable in a few CPU days in a follow-on project on affordable parallel platforms.

Improvements of our overall approach will also come with the aforementioned project as follows:

- methods to more reliably and efficiently gather and format the geological input data;

- improved calibration of the flow, rock mechanical, organic kinetic and other laws; 
- improved user interface;

- better output features for easier comparison of predictions and observed surface and well fracture and other data; and

- optimization shell for determining the best values of less well-constrained geological data (such as compression/extension and heat flux histories).

These improvements will make our RTM modeling available to the industry as a practical E\&P tool.

In summary, we believe that we have shown our approach to be viable for predicting the preproduction state of naturally fractured carbonate reservoirs. Our approach can improve on E\&P strategies based on static flexure or correlation approaches and to be affordable in the next two years considering the expected improvements in computer technology. 



\section{REFERENCES}

Andector Ellenburger Technical Committee. 1972. Proposed Andector Ellenburger Unit, Technical Committee Feasibility Report and Parameter Study, Andector Ellenburger Field, Ector County, Texas, 1-18.

Bostick, N. H. 1971. Time as a factor in thermal metamorphism of phytoclasts (coaly particles). Septieme Congress International de Stratigraphie et de Geologie du Carbonifere, Krefeld 2328, August 1971, Compte Rendu Band III.

Dewers, T., and P. Ortoleva. 1994. Nonlinear dynamical aspects of deep basin hydrology: Fluid compartment formation and episodic fluid release. American Journal of Science 294:713755.

Frenzel, H. N., Bloomer, R. R, Galley, J. E., Gibson, W. R, Hills, J. M., King, W. E., Seager, W. R., Kottlowski, F. E., Thompson, S., Luff, G. C., Pearson, B. T., and Slicon, D. C. 1988. The Permian Basin region, The Geology of North America, D2, Geological Society of America Publication, p. 261-307.

Galley, J. E.. 1958. Oil and Geology in the Permian Basin of Texas and New Mexico. In Habitat of Oil: A Symposium, edited by L. G. Weeks, 395-446. AAPG Special Publication.

Galloway, W. E., Ewing, T. E., Garret, C. M., Tyler, N., and Bebout, D. G. 1983. Atlas of Major Texas Oil Reservoirs, Bureau of Economic Geology, University of Texas at Austin.

Hanson, B. M., Powers, B. K., Garret, C. M., McGookey, D. E, McGlasson, E. H., Horak, R. L., Mazzullo, S. J., Reid, A. M., Calhoun, G. G., Clending, J. , and Claxton, B. 1991. The Geology of North America, Vol. P-2, Economic Geology, The Geological Society of America, 339-356.

Hardy, D. G. 1976. Bone Spring(s) Formation. In Lexicon of Permian Stratigraphic Names of West Texas and Southeastern New Mexico, West Texas Geological Society Publication 7666, 51-53.

Hills, J. M. 1984. Sedimentation, tectonism, and hydrocarbon generation in Delaware Basin, West Texas and southeastern New Mexico. AAPG Bulletin 54:1809-1827.

Hoak, T, Jenkins, R., Ortoleva, P., Ozkan, G., Shebl, M., Sibo, W., Sundberg, K., and Tuncay, K. 1998. Naturally Fractured Reservoirs: Optimized E\&P Strategies Using a ReactionTransport-Mechanical Simulator in an Integrated Approach, Annual Status Report DE9800493 to the U.S. Department of Energy, Contract number DE-AC22-94PC91008, p. 1167.

Hunt, J. M., Lewan, M. D., and Hennet, R. J-C. 1991. Modeling Oil Generation with TimeTemperature Index Graphs Based on the Arrhenius Equation. AAPG Bulletin 75:795-807.

Karweil, J. 1956. Die metamorphose der kohlen vom standpunkt der chemie, Duet Geol. Ges., $Z$. 107:132-139.

Katz, B. J, Robison, V. D., Dawson, W. C., and Elrod, L. W. 1994. Simpson-Ellenburger(.) Petroleum System of the Central Basin Platform, West Texas, U.S.A., The petroleum system-From source to trap: AAPG memoir 60, L. B. Magoon and W. G. Dow, eds., 453461.

Kerans, C. 1988. Karst-Controlled Reservoir Heterogeneity in Ellenburger Group Carbonates of West Texas. AAPG Bulletin 72:1160-1183.

Lane, E. W. 1947. Report of the Subcommittee on the Sedimentary Terminology, $A G U$ Transcripts 289:936-938. 
Nichols. 1947. Trans. Amer. Inst. Min. Met. Eng. 170:46.

Ortoleva, P. 1996. Self-organized Zoning in Crystal: Free boundaries, matched asymptotics and bifurcation. In Pattern Formation: Symmetry Methods and Applications, Fields Institute Communications Vol. 5, edited by John Chadam, Martin Golubitsky, William Langford, and Brian Wetton, 321-333. Providence, RI: American Mathematical Society.

Ozkan, G., and Ortoleva, P. 1998. Mechanical failure of cavities in poroelastic media. Submitted for publication.

Park, T. and Ortoleva, P. 1998. Random contact model of pressure solution. In preparation.

Payne, D. and Ortoleva, P. 1998. Lignin maturation: A chemical structural kinetics model. In preparation.

Pettijohn, F. J. 1975. Sedimentary Rocks, 3d ed. Harper and Row, Publishers, Inc.

Rice, J. R. 1975. Continuum mechanics and thermodynamics of plasticity in relation to microscale deformation mechanisms. In Constitutive Equations in Plasticity, A.S. Argon, ed., 23-79. Cambridge: MIT Press.

Roberts, R. W. 1974. University of Washington Department of Oceanography Special Report, No. 57.

Shumaker, R. C. 1992. Paleozoic structure of the Central Basin Uplift and adjacent Delaware Basin, West Texas. AAPG Bulletin 76:1804, 1824.

Stahl, W. J., and Carey, B. D. 1975. Source-Rock Identification by Isotope Analyses of Natural Gases from Fields in the Val Verde and Delaware Basins, West Texas. Chemical Geology 16:257-267.

Teichmuller, M., and Teichmuller, R. 1968. Geological aspects of coal metamorphism, Coal and Coal Bearing Strata, Inter-Univ., 135th Geol. Congr., Edinburgh, Oliver and Boyd, Pub.

Tuncay, K., and Ortoleva, P. 1998a. Basin deformation. In preparation.

Tuncay, K., and Ortoleva, P. 1998b. A new dynamic fracture statistics model. In preparation.

Tuncay, K., and Ortoleva, P. 1998c. An analytically soluble petroleum kinetic model. In preparation.

Tuncay, K., Zhan, X., and Ortoleva, P. 1998. Three-dimensional multi-phase dynamics in a sedimentary basin. In preparation.

Tyler, N., Bebout, D. G., Garret , Jr., C. M., Guevara, E. H., Hocott, C. R., Holtz, M. H., Hovorka, S. D., Kerans, C., Lucia, F. J., Major, P., Rupple, S. C., and Vander, G. W. 1991. Integrated Characterization of Permian Basin Reservoirs, University Lands, West Texas: Targeting the Remaining Resource for Advanced Oil Recovery. Bureau of Economic Geology, Report of Investigation No. 203. Austin: University of Texas.

Wilde, G. L. 1976. Wolfcamp series, Lexicon of Permian Stratigraphic Names of West Texas and southeastern New Mexico. West Texas Geological Society Publication 76-66, 327-331.

Williams, H., Turner, F. J., and Gilbert, C. 1982. Petrography: An Introduction to the Study of Rocks in Thin Sections, $2 \mathrm{~d}$ ed. W. H. Freeman and Company.

Yang, K., and Dorobek, S. L. 1995. The Permian Basin of West Texas and New Mexico: Tectonic History of a "Composite" Foreland Basin and Its Effects on Stratigraphic Development, Stratigraphic Evolution of Foreland Basins. SEPM Special Publication No. 52, p. 149-174.

Zienkiewicz, O. C., and Cormeau, I. C. 1974. Visco-plasticity and creep in elastic solids-A porous unified numerical solution approach. J. Numerical Methods Eng. 8:821-845. 